Florida International University

FIU Digital Commons

FIU Electronic Theses and Dissertations

University Graduate School

6-23-2015

\title{
Crisis Leadership: The Roles University Presidents and Crisis Managers Play in Higher Education - A Case Study of the State University System of Florida
}

Brenezza D. Garcia

Florida International University, daparre@fiu.edu

DOI: 10.25148 /etd.FIDC000120

Follow this and additional works at: https://digitalcommons.fiu.edu/etd

Part of the Higher Education Commons, and the Organizational Behavior and Theory Commons

\section{Recommended Citation}

Garcia, Brenezza D., "Crisis Leadership: The Roles University Presidents and Crisis Managers Play in Higher Education - A Case Study of the State University System of Florida" (2015). FIU Electronic Theses and Dissertations. 2180.

https://digitalcommons.fiu.edu/etd/2180 


\section{FLORIDA INTERNATIONAL UNIVERSITY}

Miami, Florida

CRISIS LEADERSHIP:

THE ROLES UNIVERSITY PRESIDENTS AND CRISIS MANAGERS PLAY IN HIGHER EDUCATION - A CASE STUDY OF THE STATE UNIVERSITY SYSTEM OF FLORIDA

A dissertation submitted in partial fulfillment of the requirements for the degree of

DOCTOR OF EDUCATION

in

HIGHER EDUCATION

by

Brenezza DaParre Garcia 
To: $\quad$ Dean Delia C. Garcia

College of Education

This dissertation, written by Brenezza DaParre Garcia, and entitled Crisis Leadership: The Roles University Presidents and Crisis Managers Play in Higher Education - A Case Study of the State University System of Florida, having been approved in respect to style and intellectual content, is referred to you for judgment.

We have read this dissertation and recommend that it be approved.

Valerie Patterson

Maria Lovett

Joy Blanchard

Benjamin Baez, Major Professor

Date of Defense: June 23, 2015

The dissertation of Brenezza DaParre Garcia is approved.

Dean Delia C. Garcia

College of Education

Dean Lakshmi N. Reddi

University Graduate School

Florida International University, 2015 
(C) Copyright 2015 by Brenezza DaParre Garcia

All rights reserved. 


\section{DEDICATION}

I dedicate this dissertation to my four siblings: MariaVictoria, Baron, Mia Bella and Dylan. The love I have for you is more than you will probably ever understand. In obtaining my doctorate, my hope is not that my academic accomplishments cast a shadow over your own hopes and dreams, but that it pushes you to hope more and dream bigger.

My wish, for you, is that this life becomes all that you want it to,

Your dreams stay big, your worries stay small,

You never need to carry more than you can hold,

And while you're out there getting where you're getting to,

I hope you know somebody loves you, and wants the same things too,

Yeah, this is my wish.

Tata / Titi loves you!

An additional dedication goes to all of my guiding angels in heaven -

- Madrina: God truly blessed me when you became my godmother. Your unconditional love and support throughout my childhood has never been lost on me. Thank you for always reminded me to embrace my inner nerd, and that my love for school would get me places.

- Janelle, Tony, and Chris: Losing friends like you at such a young age completely re-shape a person. While the trauma I experienced following your deaths, in part, led me to write this paper, your lives helped me become a better person. The laughs and memories we shared will always be carried in my heart. 
- Dr. Ellison: It is because of your help all those years ago that I ended up pursuing Higher Education as a degree. You were a true champion for your students, and I am extremely appreciative for all of your patience and care.

- Dr. Gallagher: You were my first "boss” at FIU. As a young, naïve, student assistant, I found you - this FIU legend - so intimidating. At work, I lovingly came to know you as PDG; and after your retirement, simply as Paul. Your passion for education was intoxicating, and you singlehandedly taught me how to love and fight for this place - FIU - that I now call home. I have no doubt that you will be on the graduation stage with me.

Your spirits never left me and have guided me through this process - and for that, I am forever grateful. 


\section{ACKNOWLEDGMENTS}

To my committee members: Oh what a fun-filled, scheduling rollercoaster ride it has been! Thank you for all of your feedback throughout this process and pushing me to reach this final stage.

To my participants: Thank you for being so open and honest with me. Your candor allowed this dissertation to come to life.

To the presidential schedulers: We share a special bond, and I wanted to offer a huge thanks for your help in getting your bosses to consider my request. Y'all are the best!

To my professors: Thank you for instilling in me the knowledge and confidence needed to get to this point. I will forever value your advice and encouragement.

To my husband, Charlie: Our marriage has not only survived my doctorate, but your law degree. Though the road has been tough, it has made it us stronger TOGETHER. I love you!

To my parents: Thank you for giving me the power of education and instilling in me a work ethic like no other. The sacrifices you both made for me growing up never went unnoticed. I share this degree with you.

To my family and friends: I have missed out on many memories with all of you these last few years because of my focus on school. Your inspirational texts, emails, calls, Facebook posts, and meal deliveries pulled me through to the finish line. I'm so lucky to have all of you in my life!

To J: Our bond has only grown stronger after each passing year. Beyond blessed to call you my best friend - Now and Always. 
To my OOP family (past and present): You have been with me on this journey since the beginning. Despite the added work for some of you due to my days off throughout this process, you have all supported my goals. There is no way that I could have made it this far without your love. \#OOPforLife

To Dr. Rosenberg: I started this journey with your blessing, and finished it only because of the never-ending support you offered me. You have been the greatest boss, mentor and cheerleader! Words cannot express how thankful I am for everything you have done for me - personally and professionally. From the bottom of my heart, and with the deepest love, THANK YOU!! 


\begin{abstract}
OF THE DISSERTATION
CRISIS LEADERSHIP:

THE ROLES UNIVERSITY PRESIDENTS AND CRISIS MANAGERS PLAY IN HIGHER EDUCATION - A CASE STUDY OF THE STATE UNIVERSITY SYSTEM OF FLORIDA
\end{abstract}

by

Brenezza DaParre Garcia

Florida International University, 2015

Miami, Florida

Professor Benjamin Baez, Major Professor

Universities have had a tumultuous history in terms of crises. Though crises have always existed, its definition and emphasis in the landscape of higher education has dramatically changed in the last 50 years. For this reason, the study and implementation of crisis management systems have become a growing phenomenon on campuses around the nation. However, as the types of crises institutions face diversifies, communities’ emphasis on leadership accountability has also become more magnified. The role of the president, thus, has become increasingly relevant and critical to the conversation concerning campus security and safety.

The purpose of this study was to better understand the phenomenon of crisis leadership in higher education. A case study of the State University System of Florida was chosen, interviewing all available university presidents and crisis managers. Its diversity in population, infrastructure and mission is the reason it was selected as an appropriate case. This study sought insight on how SUS presidents and crisis managers 
understood the concepts of crisis, crisis leadership and crisis management; what they perceived their roles and responsibilities to be throughout the crisis management cycle; and how these definitions and roles created and sustained a culture of safety, security and preparedness.

The 16 study participants (6 presidents and 10 crisis managers) offered a great deal of insight on how they defined crisis leadership and its respective roles pre-, during and post-crises. Participants believed that the differing definitions of crisis; the university's culture towards crisis management; the roles played by the university, presidents and crisis managers; resources (established and lacking); as well as the inevitable variability of crises, all played a critical role in leadership.

The study's findings supported Muffet-Willett's position that crisis leadership is fundamentally connected to the relationship between presidents and crisis managers. Both must offer support, tangibly and intangibly, to one another so that others across the university see the importance being placed on crisis management. Findings of this study supported the assumption made in the literature by student affairs authors that presidents are critical to crisis management. In addition, I concluded that crisis managers are also critical to crisis leadership. 


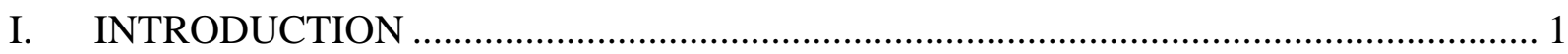

Statement of the Problem.............................................................................................. 1

Purpose of the Study ………………………………............................................. 3

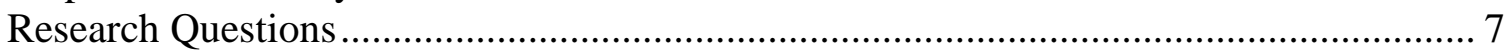

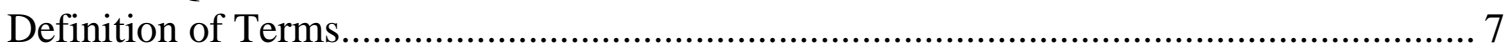

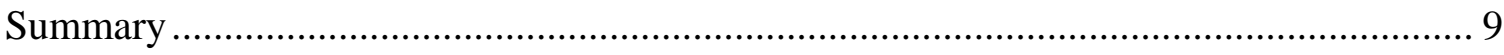

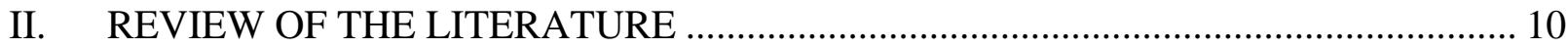

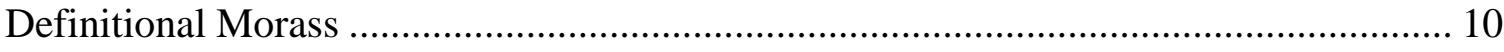

Corporate Definitions and Typologies.................................................................... 11

Governmental Definitions and Typologies ................................................................ 20

Academic Definitions and Typologies................................................................... 26

Historical Significance of Crisis Management in Higher Education................................. 29

University of Texas-Austin .................................................................................... 30

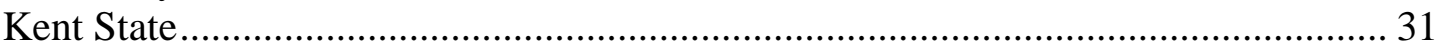

Lehigh University ……………………………………………………………... 31

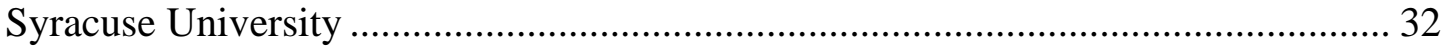

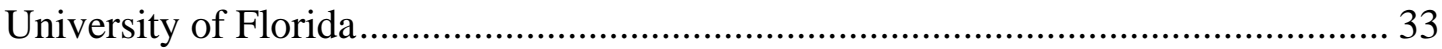

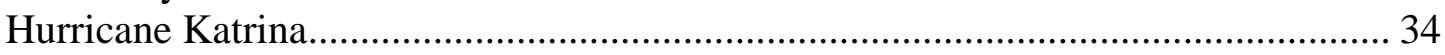

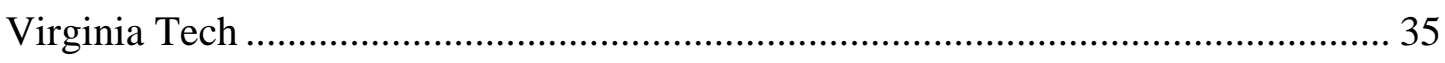

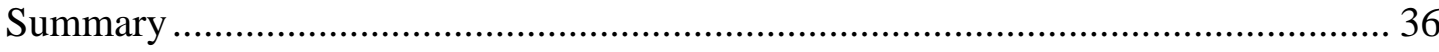

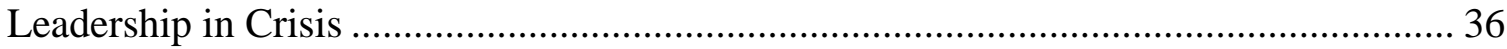

Leadership Skills Defined................................................................................... 37

Importance of Top Management................................................................................. 41

Crisis Leadership in Higher Education ........................................................................... 45

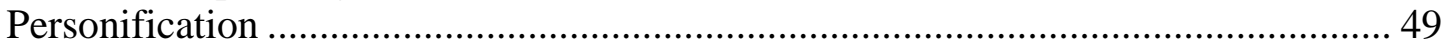

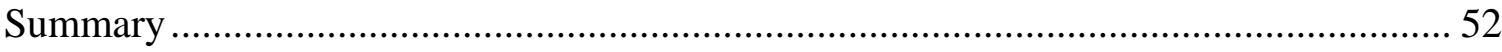

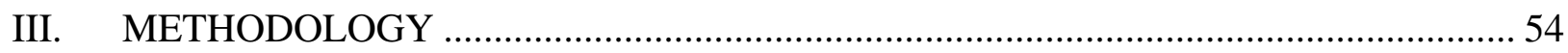

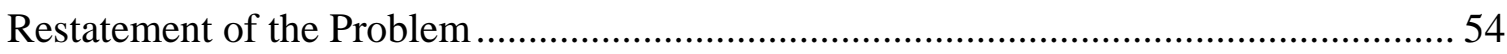

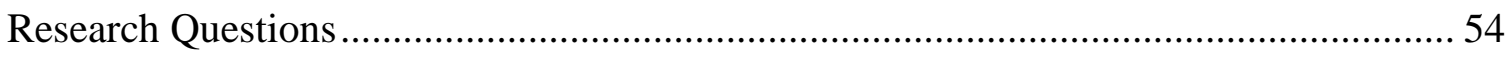

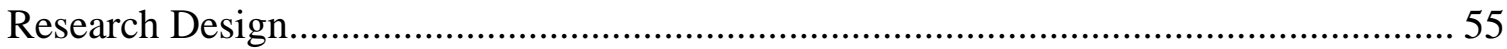

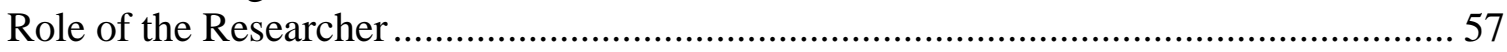

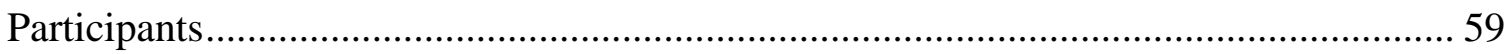

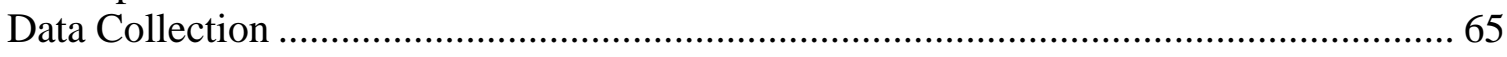

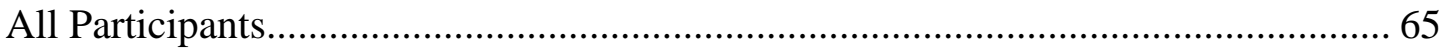

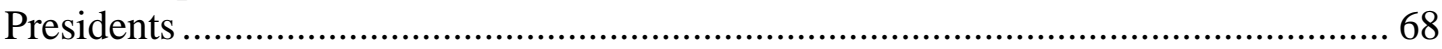

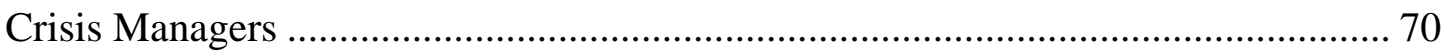

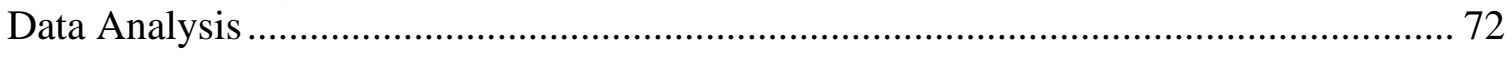

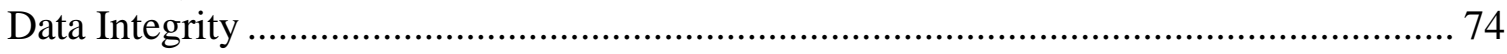

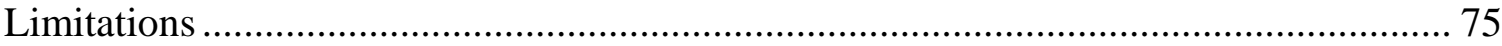




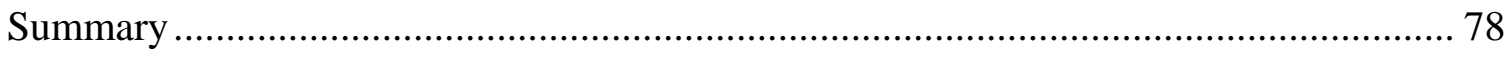

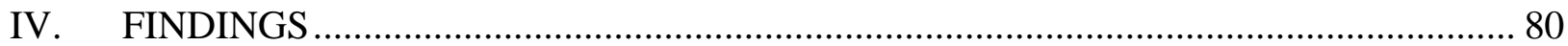

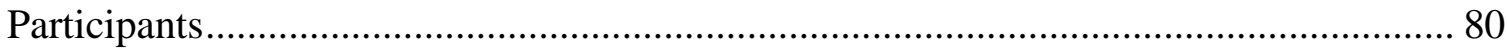

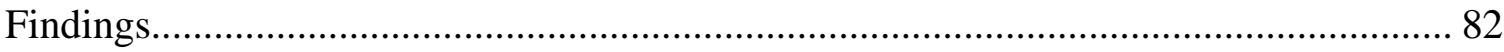

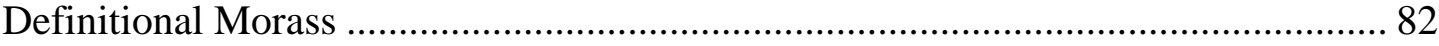

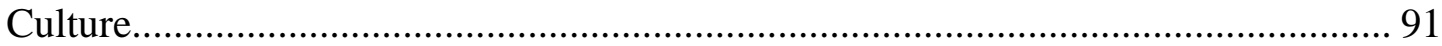

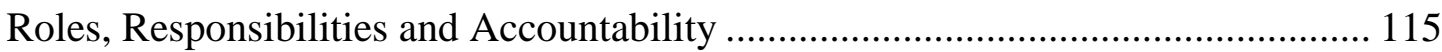

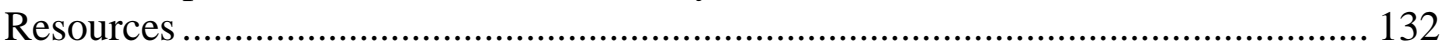

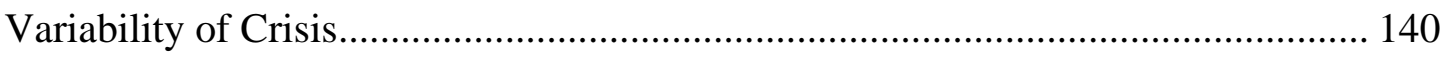

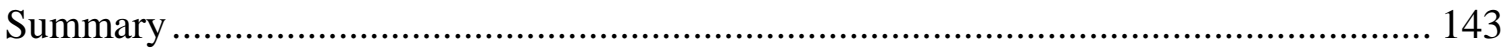

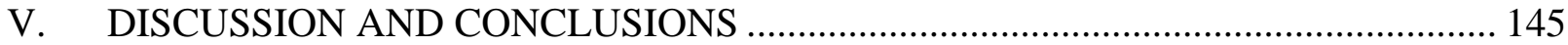

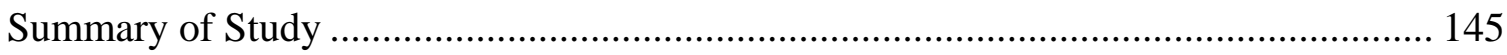

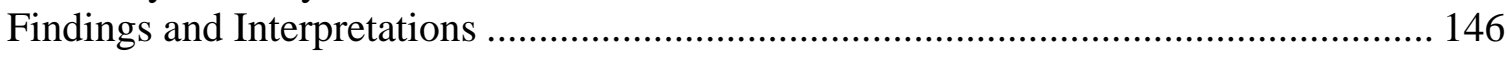

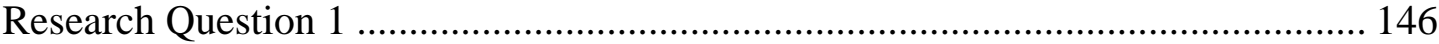

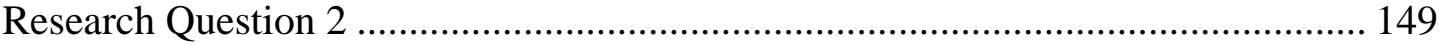

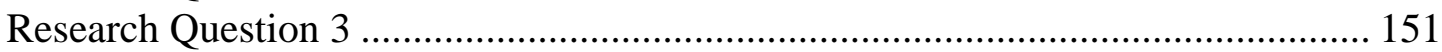

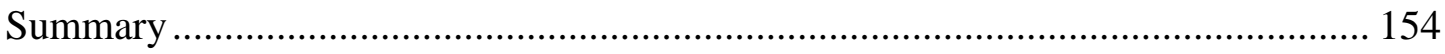

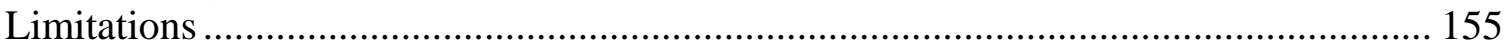

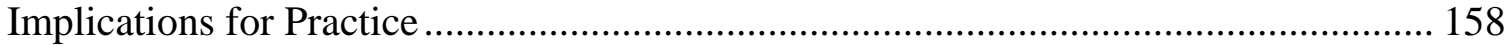

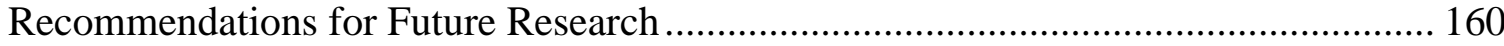

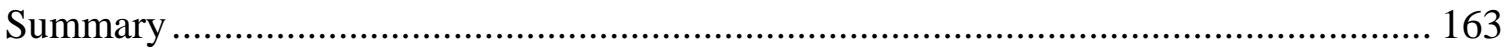

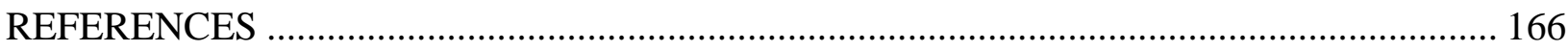

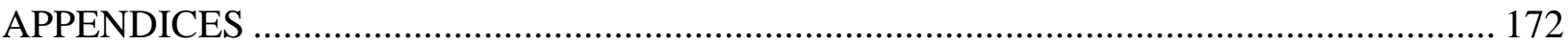

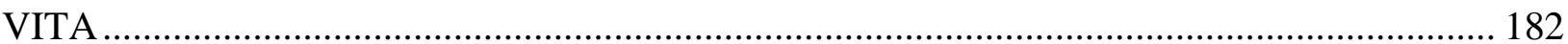




\section{LIST OF FIGURES}

FIGURE

PAGE

1. Pauchant and Mitroff's definition of terms in crisis management...............................14

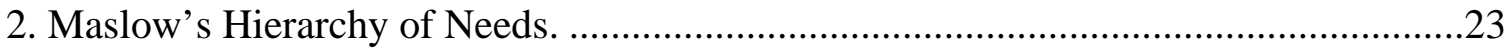

3. Tagiuri’s Model of Organizational Climate............................................................25

4. Zdziarski, Rollo and Dunkel's Crisis Matrix...........................................................28

5. Crisis Management Cycle..............................................................................28

6. Muffet-Willett and Kruse’s Crisis Leadership Continuum.......................................39

7. Muffet-Willet's Higher Education Crisis Leadership Practical Process Model...........43

8. Map of the State University System of Florida. ......................................................60

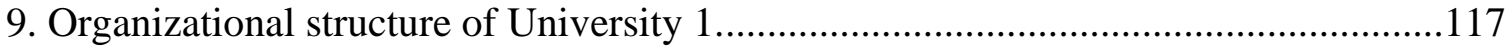

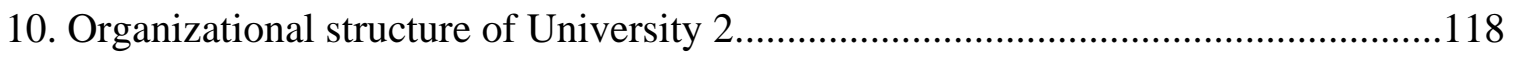

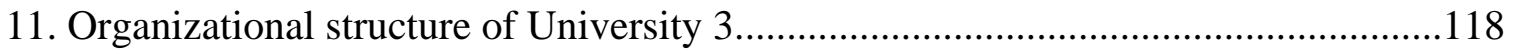

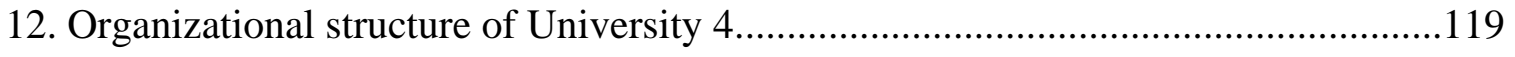

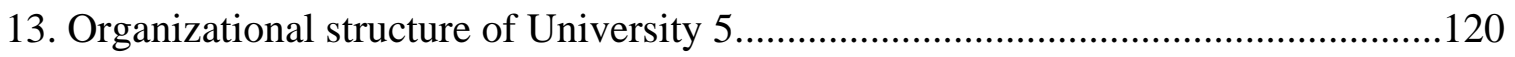

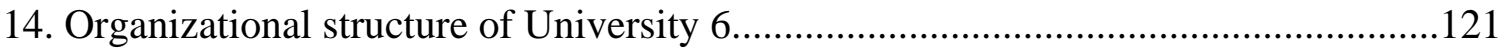




\section{LIST OF ACRONYMS}

Assistant or Associate Vice President

AVP

Board of Governors

BOG

Chief Executive Officer

CEO

Chief Financial Officer

CFO

Crisis Manager

$\mathrm{CM}$

Environmental Health and Safety

EHS

Emergency Management

EM

Emergency Operations Center

EOC

Emergency Operations Plans

EOP

Executive Policy Group

EPG

Federal Bureau of Investigation

FBI

Fiscal Year

FY

Florida Agricultural and Mechanical University

FAMU

Florida Atlantic University

FAU

Federal Emergency Management Agency

FEMA

Florida Gulf Coast University

FGCU

Florida International University

FIU

Florida Polytechnic University

FPU

Florida State University

FSU

Incident Command System

ICS

Institutional Review Board

IRB

National Association of Student Personnel Administrators

NASPA 
National Incident Management System

NIMS

New College

NC

Public Education Capital Outlay

PECO

State University System

SUS

University of Central Florida

UCF

University of Florida

UF

University of North Florida

UNF

University of South Florida

USF

University of West Florida

UWF

University of Texas at Austin

UT

Vice President

VP

Vice President of Student Affairs

VPSA 


\section{CHAPTER I}

\section{INTRODUCTION}

Universities have had a tumultuous history in terms of crises. Though crises have always existed, its definition and emphasis in the landscape of higher education has dramatically changed in the last 50 years. For this reason, the study and implementation of crisis management systems have become a growing phenomenon on campuses around the nation. However, as the types of crises institutions face diversifies, the university communities' search for accountability measures also becomes more magnified. The role of the president, thus, has become increasingly relevant and critical to the conversation of campus security and safety. This study was undertaken to contribute to the growing literature on crisis leadership in higher education, specifically by addressing how university presidents and crisis managers defined crisis and their roles in times of crisis; and, therefore, how they affected crisis management systems on their campuses as well as their institutions’ culture of safety and preparedness.

\section{Statement of the Problem}

Since the establishment of modern crisis management in the 1980s, the field has garnered more attention (Mitroff \& Anagnos, 2001). This is especially true for higher education in the last decade with tragic incidents like the 9-11 attacks, Hurricane Katrina, the Virginia Tech shootings, and the Sandusky scandal. Mitroff (2005) offered a 7-point argument on this issue, which illustrated that with the rapidly increasing number of major incidents, we have become a "crisis-prone society” (p. 3). "Crises are no longer an aberrant, rare, random, or peripheral feature of today's society. They are built into the very fabric of modern societies” (Mitroff \& Anagnos, 2001, p. 5). Thus, crisis 
management has become a phenomenon impacting how all academic administrators view the safety and security of their campuses.

The study of crisis has been a growing field since the 1960s, specifically with the work done by Hermann $(1963,1972)$ who is considered to be the founding researcher in crisis management. His seminal book titled International Crises has become the foundation for many subsequent authors in the field. However, he noted that the problem with crisis research at that time was the lack of relevance. In his second book, Hermann (1972) offered three limits to the study of crises: analysis has been restricted to single case studies; the common belief that each crisis is unique and therefore must be researched as such; and, the blurred meanings of the word crisis. "These inhibitions in the study of crises must be overcome if we are to develop any knowledge about crises as a class of events” (p. 4).

Sadly, with all of the horrific incidents affecting campuses across the nation, Hermann’s original problem in crisis research - lack of relevance - is no longer an issue. His other limits to the research, though, still stand true today. In the field of higher education, major incidents are often studied as stand-alone, distinctive events with lessons pulled for specific purposes. "Most of the student affairs and higher education literature on crisis management are anecdotal in nature, and relates the author's experience in dealing with a particular crisis” (Zdziarski, 2001, 6). Though nonetheless important and relevant to the field, the available literature contains more subjective incident reports rather than empirical research on the topic (i.e., anecdotal lessons learned versus rigorous analyses). 
Zdziarski (2001, 2006); Harper, Paterson, and Zdziarski (2006); Zdziarski, Dunkel, and Rollo (2007); and Hemphill and LaBanc (2010) have all produced significant work for student affairs professionals seeking insight into crisis management. Their research offered a unique perspective on how universities can better plan for, respond to and recover from major campus incidents. They also all alluded to the importance of the university president and how integral his/her support is for crisis management plans and teams. However, none of them analyzed the relationship dynamics of the crisis leader and crisis manager on their respective campuses. Similarly, none discussed how those role perceptions and interactions transcended into the campus' overall endorsement (i.e., institutional buy-in) to inculcate a culture of safety, or explained why their involvement was in fact significant.

Though research is vast in this field, it is all highly observational, idiosyncratic and situational. There are no research-oriented, specifically related to higher education, that helps answer why leaders (i.e., university presidents) are so critical to the study of crisis. This study sought to answer that question by better defining what a crisis leader is, and what roles these leaders play (both individually and with crisis managers) in crises.

\section{Purpose of the Study}

In Zdziarski’s (2001) influential dissertation on crisis management, he stated that one of the possible directions for further research of his study "should be approached from other perspectives within the institution (i.e., academic affairs, administration, finance, etc.)” (p. 114). Since his work was published, numerous incidents dealing with poor decision-making and slow response/action (e.g., Virginia Tech shooting) have supported the need to have additional research done within the field of crisis 
management. Zdziarski's recommendations, tied to the new trend of increased leader accountability, brought me to study crisis leadership.

For the purpose of this study, Zdziarski et al.'s (2007) definition of crisis was used as the basis to formulate the research questions. As will be described in more detail in the literature review, their well-summarized description took the commonalities of corporate and government typologies, while bringing the uniqueness of higher education into the fold. The study sought to validate whether Zdziarski et al.’s position could be expounded past student affairs professionals into the realm of university presidents and crisis managers. Along these lines were the differing definitions and roles of crisis management and crisis leadership.

Mitroff (2004) defined the differences between crisis management and crisis leadership as the former being "reactive” and the latter "proactive” (p. 10). In other words, crisis management can be called "crash management - what to do when everything falls apart” (Pauchant, 1992, p.10), while crisis leadership takes a more holistic, strategic approach. Given the different meanings of crisis by different authors and management cultures, many can agree that a crisis leader is also not necessarily a crisis manager (Daniels \& Daniels, 2007). If a leader offers direction, vision, and inspiration, "a manager, then, is a technician who helps people, processes, and systems function together efficiently” (p. 35).

It is through this perspective that I separated a crisis manager from a crisis leader throughout the rest of this study. In this study, a crisis manager is defined as a middlemanagement incident coordinator, while a crisis leader represents the interests of the institution as a whole and all the constituents involved in the crisis (specifically for this 
study, a university president). Though many commonalities exist between crisis managers and crisis leaders, there are fundamental differences that one must understand, which will be discussed in more detail later in the literature review.

Since Zdziarski's (2001) dissertation, which was the foundation of this study, three other academic works have been published that discuss crisis leadership in higher education, similar to the way it is defined in this study: a dissertation by Stacy M. Burrell (2009), a dissertation by Stacy L. Muffet-Willett (2010), and a recently published book by former Tulane University president, Scott Cowan (2014).

Burrell grounded her research of crisis management systems on Christian-based institutions. This perspective carried with it various ethical and religious variables not normally found in secular universities across the nation. It is a very specific viewpoint that could be difficult to consider and properly analyze in my data, especially since this was a case study of public universities. Muffet-Willett (2010), on the other hand, did focus on crisis leadership as defined in this study. Her dissertation helped me gather strong comparing and contrasting crisis management and crisis leadership literature, which allowed me to hone in on my research questions. Muffet-Willett took one of Zdziarski's research direction proposals and focused her research on crisis management from the administration perspective, which is similar to my impetus. However, she interviewed two leaders from private universities (of which I did not), and she did not interview a single university president (which is the focus of my research) or crisis manager (as was defined in this study).

Cowan’s (2014) new book, The Inevitable City: The Resurgence of New Orleans and the Future of Urban America, discussed the challenges faced by and opportunities 
presented to Tulane University in the aftermath of Hurricane Katrina. Throughout the book, he illustrated principles of crisis leadership through a recounting of his experiences; some of which are discussed in the forthcoming literature review to help support this study's findings. However, the book is just that - an autobiography of life lessons taken from what is notably one of the greatest examples of higher education leadership in the face of adversity.

As noted earlier, Zdziarski (2001, 2006); Harper et al. (2006); Zdziarski et al. (2007); and Hemphill and LaBanc (2010) have all mentioned the importance of the university president and how integral his/her support is for crisis management plans and teams. However, each of these sources only had one or two sentences on the matter. None of these publications detailed why or how presidents played such a vital role.

As such, I have yet to find any comprehensive, empirically-based work on higher education crisis leadership that also focuses on the university president. This is what makes this study unique. Similarly, with the ever-growing responsibility placed on university administrators to keep their institutions safe at all costs and also the increased liability for the actions of their employees (recent examples being Florida A\&M, Penn State and Rutgers), this dissertation is of timely relevance for universities looking at implementing crisis management systems or reviewing their current practices.

The purpose of this dissertation, therefore, was to better understand the phenomenon of crisis leadership in higher education. Specifically, I chose to conduct a case study of the State University System (SUS) of Florida, interviewing all available university presidents and crisis managers. Through the study, I found commonalities and analyzed key differences amongst the presidents and crisis managers related to their 
definitions of and roles in crisis leadership, and how those definitions and perspectives enhanced, supported and/or hindered institutional crisis management systems. The findings have hopefully contributed to higher education literature by both strengthening and opposing former hypotheses on the importance of leadership in crises.

\section{Research Questions}

Due to the definitional morass related to the terms crisis and crisis leadership, three research questions formed the basis of this study:

1. In the State University System of Florida, how does each president and crisis manager define "crisis”, “crisis management” and "crisis leadership” on their campuses?

2. Per those definitions, (a) What roles do crisis managers and crisis leaders see themselves playing in crisis management and crisis leadership, respectively?, (b) What roles do the crisis managers see the presidents playing in crisis management, if any?, and (c) What roles do the presidents see crisis managers playing in crisis leadership, if any?

3. How do those definitions and perceptions create a culture of preparedness towards and support of crisis management systems at their universities?

\section{Definition of Terms}

The following are terms used throughout the paper that may be unfamiliar or have multiple meanings to the reader:

- Crisis: An intentional, unintentional, expected, unexpected, environmental, facility and/or human event that causes disruption to the operations of the 
university. This definition was adapted from Zdziarski et al.’s (2007) Crisis Matrix. Other definitions of crisis are described within the literature review.

- Crisis Leader: A proactive, high-ranking official who has ultimate decisionmaking authority, and serves as the face of a major campus crisis. Specifically for this study, a university president.

- Crisis Manager: A reactive, middle-management official who manages all tasks related to a campus crisis. This individual also serves as the lead official for more minor incidents at their university.

- Founded: The year each institution was established. In this study, this referred to when the legislature approved the university's creation, not the year each opened its doors or joined the SUS.

- President: The top-ranking leader of a college or university. Called by different names depending on the institution (e.g., president, chancellor, CEO, etc.), "president" is the commonly used term within the sample studied, and hence used throughout the paper for consistency.

- SUS: State University System. In this case, it is being used to refer to the 12institution public university system in the State of Florida.

- Tabletop: An exercise to simulate crises scenarios with a goal to teach participants the proper way of responding and also to learn what, if any, gaps in the university exist (in terms of communication, resources, etc.).

- University: An institution of higher learning offering advanced degrees. Though the U.S. has multiple higher education institutions (i.e., universities, colleges, community colleges, technical institutes, etc.), "university” is the commonly used 
term within the sample studied. Specifically, New College is the only institution that does not have the word "university" in their name. Therefore, university was used throughout the paper for consistency to refer to all of the institutions in the sample.

\section{Summary}

Crisis management is a field that has been studied since the 1960s, and more indepth starting in the 1980s. Crisis leadership, on the other hand, is an area of study that has been highly subjective in nature. Part of this is due to the innumerable definitions of the term and how it affected the management of crises on university campuses. University presidents play a critical role in helping explain both their definition of and role in crises. Thus far, subjective anecdotes of crisis leadership have filled the majority of the literature (such as former Tulane president, Scott Cowen, who wrote heavily on his accounts from Hurricane Katrina). Though exceptions exist, there was a lack of empirical research in this field. Hence, there was a need to interview presidents, along with crisis managers, in order to gain a first-hand, candid perspective on the definitions of and roles in crisis leadership, as well as the relationship between them. The forthcoming literature review offered a foundational and historical basis that helped answer the study's research questions. 


\section{CHAPTER II}

\section{REVIEW OF THE LITERATURE}

\section{Definitional Morass}

Etymologically, crisis comes from the Greek word krisis, meaning turning point in a disease, and from krinein, meaning to judge or decide (etymonline.com; Seeger, Sellnow, \& Ulmer, 2003). Today, crisis is an overused term in our everyday vernacular to describe a serious problem (Fearn-Banks, 2011). I felt no quote better described the difficulty in defining what a crisis was than the one John Gerring (2004) used to describe a case study: “the many academic attempts to clarify what 'case study’ means has resulted in a definitional morass, and each time someone attempts to clear up the mess of definitions, it just gets worse” (p. 342, as cited in Flyvbjerg, 2011, p. 302).

Similarly, crisis management is now a term used by "a variety of disciplines, including business, education, public administration, communications, political science, and psychology” (Zdziarski, 2006, p. 4). How one defines these terms is highly dependent on which field he/she comes from. Simply put, "there is no single, universally accepted, definition of a crisis” (Mitroff, Pearson, \& Harrington, 1996, p. 7). This is supported by the third of Hermann's (1972) limits to the study of crises, which relates to the blurred meanings of the word crisis.

The multiple definitions cause what Coombs (1999) described as a fragmentation of the literature. In my review of the available literature on crisis management and crisis leadership, three key areas appeared: (a) how crisis is defined in the corporate world, which is from where the study of crisis management originated, (b) how governmental agencies define crisis, specifically related to disaster management, and (c) academia’s 
definition of crisis and crisis management, which is the capstone of crisis leadership in higher education as defined in this study.

Due to this definitional morass, three research questions formed the root of this study. The first asked how each president and crisis manager defined "crisis”, "crisis management” and "crisis leadership” on their campuses. Per those definitions, the second question sought to answer how crisis managers and crisis leaders saw themselves involved in crisis management and crisis leadership, respectively; how crisis managers saw presidents playing a role in crisis management, if any; and how presidents saw crisis managers playing a role in crisis leadership, if any. Furthermore, it sought to understand how those definitions and role perceptions contributed to the chosen, or missing, crisis management systems at their respective universities. It is through this muddled lens and perspective that the study first illustrated the several definitions of crisis and crisis management in order to create a contextual foundation for the creation of my first research question, and then showcase how these definitions influenced and supported the second and third research questions.

\section{Corporate Definitions and Typologies}

The field of modern crisis management is credited to have begun with the Tylenol poisonings of 1982 (Mitroff \& Anagnos, 2001). After seven people were killed in the Chicago area, close to 31 million bottles with a retail value of over $\$ 100$ million were pulled from the shelves by Johnson \& Johnson after it was learned that only three batches were poisoned with cyanide (Rehak, 2002; Mitroff \& Anagnos, 2001). When Johnson \& Johnson took responsibility for the incident, though no direct fault was tied to them, it changed the dynamics of how organizations handled crises. 
Though Mitroff and Anagnos (2001) considered themselves the founders of this field, there is a great amount of literature that can be divided into innumerable sub-topics (e.g., disaster management, risk management, issues management, etc.). For the purpose of this literature review, I have focused on the top authors credited with contributing to the way universities understand crisis management today. These authors were chosen according to Coombs (1999) rationale: "by the number of people citing the approach as an influence in the development of their crisis models” (p. 10).

The study of crisis has been a growing field since the 1960s, specifically with the work done by Hermann $(1963,1972)$ who is considered to be the founding researcher in crisis management. His pivotal book, International Crises, has become the foundation for many subsequent authors in the field. However, he noted that the problem with crisis research at that time was the lack of relevance. In his second book in 1972, Hermann offered three limits to the study of crisis management: analysis has been restricted to single case studies, the common belief that each crisis is unique and therefore must be researched as such, and the blurred meanings of the word crisis. "These inhibitions in the study of crises must be overcome if we are to develop any knowledge about crises as a class of events” (p. 4). Though the lack of relevance is no longer a factor, Hermann's stance did lead to an expanded field of literature.

A crisis, defined by Webster as a turning point, does not need to have a negative connotation. "It is merely characterized by a certain degree of risk and uncertainty" (Fink, 1986, p. 15). Along those lines, crisis management should be described as "the art of removing the risk and uncertainty to allow you to achieve more control over your own 
destiny” (p. 15). In other words, any pre-planning for those potential turning points can be considered crisis management (e.g., tabletop exercises).

Fink's typology for crisis consisted of up to four phases. The prodromal crisis stage is considered the early warning, or pre-crisis stage (pp. 21-22). In this stage, crisis managers are aware of impending dangers and risks and take necessary steps to prepare. The acute crisis stage is "the point of no return" (p. 22). Some damage has already occurred, and it is the leadership's responsibility to take control of the situation before the incident escalates. The third stage, chronic crisis, is a time of "recovery," "self-analysis," and "healing" (pp. 23-24). Last is the crisis resolution stage where the incident has been resolved. The goal of any crisis manager should be to get to the last stage immediately after the first stage, but, as we know from history, that is not always possible.

Fearn-Banks (2011) slightly disagreed with Fink’s stance on the negative undertones of crisis. She described a crisis as "a major occurrence with a potentially negative outcome affecting the organization, company, or industry, as well as its public, products, services, or good name” (p. 2). Similar to other authors discussed in this review, Fearn-Banks noted that there are different types and stages of crisis. For her, it was more about the scale, or degree, of crisis. There are minor crises (incidents limited to a specific area and/or can quickly be controlled) and major crises (incidents involving significant injury or loss of life/property and an extended disruption to operations) (p. 321). The stages include detection, prevention/preparation, containment, recovery and learning (pp. 4-5). As such, she described crisis management as "a strategic planning process, one that the organization can prepare for, with a high emphasis on communications” (p. 2). 
Similarly, in an earliest publication, Pauchant and Mitroff (1992) differentiated the meanings between an incident, accident, conflict and a crisis (p. 12). For them, a "crisis" can be defined as such with only two conditions. The first is that the entire organization is being affected, and the second is that members of the organizations are forced to take corrective and/or defensive action. Their model (Figure 1) delineated these distinctions in a matrix.

\begin{tabular}{|lll|}
\hline System level & & System area \\
\hline & Subsystem & Whole system \\
Physical & Incident & Accident \\
Symbolic & Conflict & Crisis \\
\hline
\end{tabular}

Figure 1. Pauchant and Mitroff's definition of terms in crisis management.

The first column contains the Systems Levels, which breaks down into physical and symbolic aspects. The next column, Systems Areas, divides into the subsystem and whole system. An "incident" falls at the physical level, but only affects a subsystem. For example, the student-athlete gym is closed because of a water pipe bursting. An "accident”, on the other hand, is also at the physical level, but affects the entire system. A hurricane affecting campus operations could be an example of this. At the symbolic level, you have "conflict", which affects just a subsystem, and then "crisis" which affects the whole system. The previous alludes to incidents like tension between a student group and the administration, while the latter refers to something like an on-campus shooting. After writing the aforementioned book with Pauchant, Mitroff continued his research with other collaborators. Mitroff and Pearson (1993) posited that in order to 
create an effective crisis management program, a "systematic framework" of the most critical variables of crisis must be analyzed: types, phases, systems and stakeholders of crises (p. 14). These variables take into account the scope, time progression, response modes, causes, resources, and people. This integrated system would help any crisis manager better assess the organization's risks and opportunities.

Building on their previous work, Mitroff and Anagnos (2001) jointly offered a "guiding definition" of crisis: "an event that affects or has the potential to affect the whole organization” (p. 34). To them, crisis management (CM) differed from emergency and risk management. They believed that CM dealt with "man-made or human-caused crises" and are "not inevitable" (p. 6). They noted that "for the first time, human-caused crises now rival natural disasters in scope and magnitude” (p. 23) and should hence be given more weight. For these reasons, companies must think beyond public relations and understand that new skills are needed in today's world in order to better manage crises (Mitroff \& Anagnos, 2001).

By the time of their 2001 publication, not only had accountability measures become a recommended standard operating procedure in their writings, but an unlearned lesson came to fruition: “the failure of success” (Mitroff \& Anagnos, p. 20). Management consultant, Peter Drucker, has noted that companies run into problems more often because they have grown accustomed to their success and become complacent, and less so because of frequent problems that arise. It is similar to the "if it ain’t broke, don't fix it” mentality. The companies therefore repeat their actions, simply because that is the way they have always been done, until the day that is no longer good enough and crisis ensues. 
Society first understood crises in terms of natural disasters, things out of our control. Currently, we see crises as unplanned, critical incidents. Mitroff (2005) differentiated between these "normal" and "abnormal" events (pp. 9-10) as follows: "Normal accidents represent the unintentional breakdown of complex technical and organizational systems” (e.g., fires, floods, manufacturing mistakes, etc.). "In contrast, abnormal accidents represent the intentional breakup of complex technical, organization, and social systems” (e.g., bombings, cyberattacks, shootings, etc.) (p. 10). As noted earlier, Mitroff and Anagnos (2001) strongly believed that these incidents are made and caused by humans. In other words, there are in fact events that are unavoidable for organizations.

Coombs (1999) partially agreed with Mitroff and defined crisis as "unpredictable but not unexpected” (p. 2). He posited that crisis managers can most effectively respond to crisis by classifying it into the following categories: natural disasters, malevolence, technical breakdowns, human breakdowns, challenges, megadamage, organizational misdeeds, workplace violence, and rumors. Once categorized, they can be properly managed in order "to ward off or reduce the threats by providing guidelines for properly handling crisis" (p. 3). Coombs also suggested that "issues management, risk assessment, and stakeholder relations all serve to scan information that could be relevant to crisis management” (p. 18). Lerbinger (2012) later took these types of crises and classified them into three groupings: "crises of the physical world, crises of the human climate, and crises of the management failure” (p. 18).

Lerbinger (2012), though, offered a slightly different definition of crisis, suggesting that an organization's reputation must also be at risk: "a crisis is an event that 
brings, or has the potential for bringing, an organization into disrepute and imperils its future profitability, growth, and possibly, its very survival” (p. 9). Though the definition differs from the aforementioned authors, Lerbinger's characteristics of a crisis (suddenness, uncertainty, and time compression) are in line with those described in other literature.

Seymour and Moore (2000) conjectured that crisis “'happens’ in two ways: first, by actually catching a company unprepared; second, by exploiting surprise and weaknesses in the company's culture to dig itself in” (p. 10). They advised that companies are vulnerable to crisis if they: (a) "get too comfortable about risks," (b) "start with the wrong perspective," (c) "fail to respect the emotions of our audiences," (d) "try to 'lose' the problem," (e) "individuals or teams try going it alone," and (f) "ignore the warning signs” (pp. 17-23). How companies respond to and recover from these crises, therefore, are the crux of their success.

Corporate literature is very careful, though, to separate crisis management from risk communication and issues management. Seymour and Moore (2000) defined risks as "personal fears" and issues as "social concerns" (pp. 161-162). Individual fears can spread and cause national concern, hence risks can easily turn into issues, and issues into crises. For example, a small community's fear of sanitation issues can quickly turn into a state-wide or nation-wide concern. Companies, then, must foresee the fine transition when a problem will soon become public enough that they have to move from issues management into crisis management (Seymour \& Moore).

Skinner and Mersham (2002) took crisis management and offered a multidimensional approach, breaking it down into issues, disasters, and crises. They defined 
an "issue" differently than Seymour and Moore; they saw it as an "unresolved or ambiguous social or policy matter of public concern” (p. 12). They saw a "disaster" as a "rapid disruption of routine operations causing serious damage to property and/or injury to people, and a 'crisis' as an unstable or crucial time or state of affairs whose outcome will make a decisive difference...for an organization” (p. 12). Ultimately, Skinner and Mersham (2002) believed it is disasters, or unresolved issues, that lead to and cause crises.

In sum, Skinner and Mersham (2002) defined crises as "unplanned events that directly or potentially threaten a company's reputation; the environment; the health, safety or welfare of employees; and the health, safety or welfare of citizens in communities...” (p. 23). They saw crisis management as a process with five stages: detection, prevention, containment, recovery and learning (p. 24) - similar to the Crisis Management Cycle - and described the overlap of issues and crisis management through the work of Bland (1998):

A crisis is an issue in a hurry. You could also say that an issue is an infant crisis. Both present some kind of threat - to your reputation, your bottom line, your license to operate and so on - but usually over a different period of time. Crisis management therefore requires more in terms of advance planning, team building, training, simulations and prepared plans. You have to be able to 'press a button' and preplanned operations rapidly fall into place. (p. 172, as cited in Skinner and Mersham, p. 18)

Therefore, issues management is considered "an 'early warning' process" that allows the organization's top leadership to better plan and communicate and is important in the success of crisis management.

Seeger et al. (2003) researched organizational crisis and defined it as "a specific, unexpected and non-routine organizationally based event or series of events which 
creates high levels of uncertainty and threat or perceived threat to an organization's high priority goals” (p. 7, cited from Seeger et al., 1998, p. 233). They used Hermann’s (1963) model, which is considered the first and most widely used model of crisis, to come to that definition. Hermann posited that a crisis is based on three conditions: "(1) threatens high priority values of the organization goals, (2) presents a restricted amount of time in which a decision can be made, and (3) is unexpected or unanticipated by the organization” (p. 64). Seeger et al. (2003) felt that though not all of these conditions have to be present for a crisis to exist, "the perception of a serious and credible threat is a requisite feature of all crisis events” (p. 8).

Similar to Seymour and Moore (2000) and Skinner and Mersham (2002), Seeger et al. (2003) also believed that there is a noted difference between risk communication and issue management. Per their research, this is supported by Crable and Vibert's (1985) work: "issues are unresolved questions or perceived problems that arise in the public domain with the potential to affect an organization" (p. 11). Therefore, "issues management is the strategic process of 'issues identification, monitoring, and analysis' seeking to influence their resolution in a manner mutually beneficial to the organization and its stakeholders” (Heath, 1997, as cited in Seeger et al., 2003, p. 11).

Overall, corporate definitions and typologies of crisis are no doubt affected by definitional morass. Their views on crisis, risk and issues management all differ while coinciding at the same time. Regardless of stage, level, or type, all of the aforementioned authors would agree, though, that crisis entails a certain "suddenness" to it. No matter how much you prepare, there comes a point where there is minimal control and the incident becomes more about mitigating and recovering. This common definition is 
something that I looked for from the study participants. It was important to understand if and why their definitions were in line with or rejected this shared notion.

\section{Governmental Definitions and Typologies}

From the numerous lessons learned from private organizations, federal, state and local governments have also had their fair share of management issues to address.

Though all agencies have dealt with their own types of crises, the governmental organization most relevant to this paper's definition of crisis is the Federal Emergency Management Agency (FEMA). They were tasked with supporting the nation not just in recovery from, but also in preparation for natural disasters. Though natural disasters are only one part of the definition of crisis as used in this study, FEMA's implementation strategies are nonetheless important to the subsequent discussion of crisis management and crisis leadership within higher education.

FEMA can trace its history back to the Congressional Act of 1803 after government assistance was provided to a fire-ravaged city in New Hampshire (Dunkel \& Stump, 2007). They came to define an incident as "an occurrence or event, natural or human caused, that requires a response to protect life or property” (FEMA IS-700.A). The agency, though, was officially established in 1979 under President Jimmy Carter. In 2003, when George Bush signed the Homeland Security Presidential Directive (HSPD)5, Management of Domestic Incidents as a response to the 9-11 attacks, he directed the Department of Homeland Security to develop and administer a new system (LaBanc, Krepel, Johnson, \& Herrmann, 2006). This directive required all federal agencies to adopt and use the National Incident Management System (NIMS) "as their individual domestic 
incident management and emergency prevention, preparedness, response, recovery and mitigation programs and activities” (FEMA IS-700.A).

The system provides a consistent, nationwide approach for multiple agencies or jurisdictions to work together to build, sustain and deliver the core capabilities needed to achieve a secure and resilient nation (FEMA IS-700.A). The Incident Command System (ICS), a component of NIMS, is a flexible, collaborative system that "consists of a standard management hierarchy and procedures for managing temporary incident(s) of any size” (FEMA IS-100.HE). Together, they "answer how to manage emergencies from preparedness to recovery regardless of their cause, size, location or complexity” (FEMA IS-700.A).

The concept of the Incident Command System was developed more than 40 years ago in the aftermath of a devastating wildfire in California. During 13 days in 1970, 16 lives were lost, 700 structures were destroyed, and over 0.5 million acres burned. The overall cost and loss associated with these fires totaled \$18 million per day (FEMA IS100.HE). Although all of the responding agencies cooperated to the best of their ability, numerous problems with communication and coordination hampered their effectiveness. As a result, Congress mandated that the U.S. Forest Service design a system that would "make a quantum jump in the capabilities of Southern California wildland fire protection agencies to effectively coordinate interagency action and to allocate suppression resources in dynamic, multiple-fire situations” (FEMA IS-100.HE).

The Forest Service's system gradually became a national model for best practices, until Homeland Security produced the official NIMS manual in 2004 (FEMA IS100.HE). This manual made ICS a key component. In part, it created essential features 
that all universities (especially those that generally require mutual aid from other agencies) must properly implement. Without suitable application, universities across the nation are left without the appropriate resources to seek assistance during times of need.

Generally, FEMA is associated with disaster management for states and cities. However, institutions of higher education are not immune from environmental, human, or facility incidents, emergencies or disasters (Coombs, 1999; Zdziarski et al., 2007). An example of such a crisis, and discussed in more detail later in this review, was Hurricane Katrina in 2005. Students and faculty were forced to leave New Orleans and attend other universities across the nation (some permanently), crippling city's higher educational system.

Universities in New Orleans were forced to deal with several agencies (including FEMA) who were overwhelmed in handling city-wide issues. This caused a lot of confusion and miscommunication, leaving the door wide open for mishaps to occur. "Whenever outside assistance is summoned to deal with a campus incident, questions can arise over 'who’s in charge’” (Dunkel \& Stump, 2007, p. 122). For example, institutions with NIMS-compliant plans have what are referred to as emergency operations plans (EOPs).

A university EOP, if NIMS compliant, will provide a command structure and assignments of responsibility and authority; a concept of operations focused on mitigation, preparedness, response, and recovery; and a series of annexes or appendixes that address specific emergency response functions such as communication and warning, fire and rescue, public information, evacuation, and the emergency operations center (EOC). (LaBanc et al., 2006, p. 55)

Had these New Orleans institutions had a comprehensive plan in place prior to the hurricane they may have had a more efficient and effective recovery period. 
Protecting lives, preventing injury, and minimizing property damage are among the primary goals of NIMS/ICS. These goals are important and relevant because they address our basic need for physical safety, as detailed in Maslow’s (1943) hierarchy of needs (Figure 2). However, the need for safety extends beyond the physical. It transcends into the social-emotional, the organizational, and the cultural (as cited in Cole, Henry, Tyson, Fitzgerald, \& Hopkins, 2009). One framework that recognizes and integrates all four of these aspects is the Tagiuri model, which has been identified by Cole et al. (2009) as an appropriate framework for examining school climate and the related aspects of safety. Based on this model, one should see that learning not only requires a secure physical setting, but also a caring, welcoming, and predictable environment.

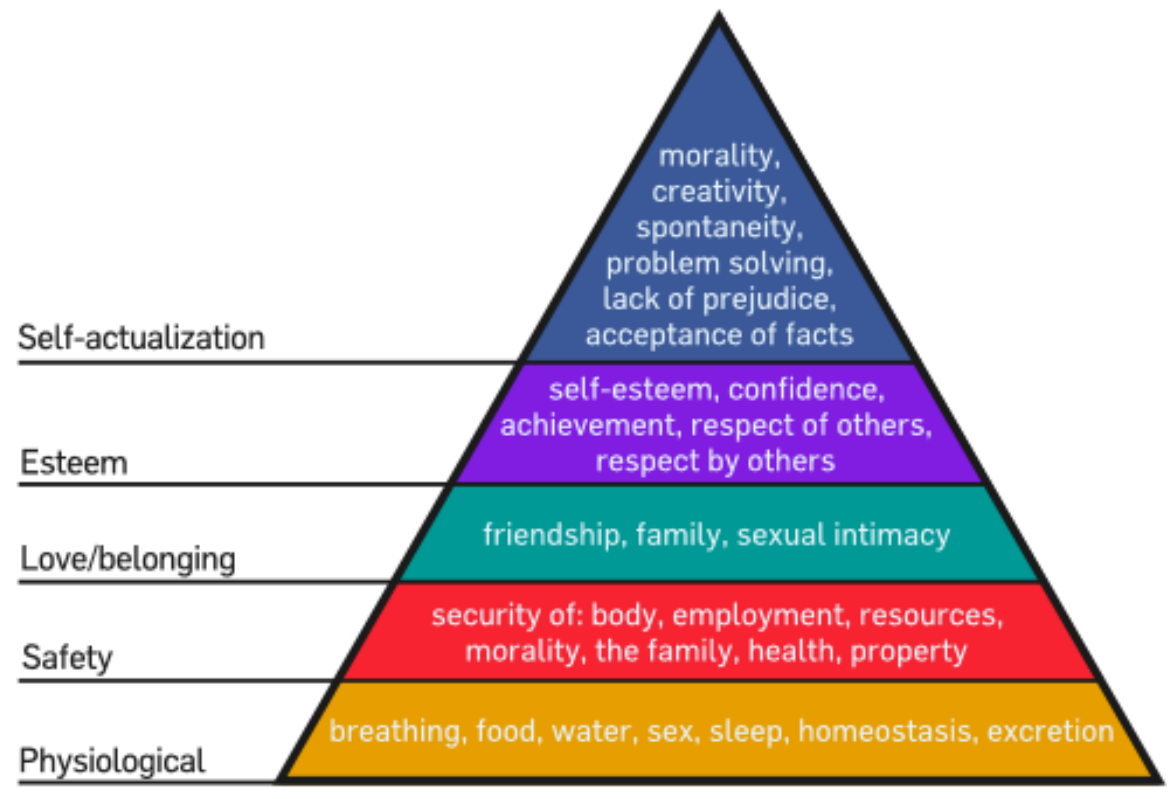

Figure 2. Maslow’s Hierarchy of Needs. 
Tagiuri (1968) presented four intersecting components of organizational climate: culture, ecology, milieu, and organization or structure (Figure 3). According to Tagiuri, as articulated by Lindahl (2006), organizational culture includes:

Assumptions, values, norms, beliefs, ways of thinking, behavior patterns, and artifacts; this definition seems to parallel closely many of the prominent authorities in the field. However, his construct of organizational climate tends to be more encompassing than that of many of his peers. Within ecology, he included buildings and facilities, technology, and pedagogical interventions. Within milieu, Tagiuri subsumed the race, ethnicity, socio-economic levels, and gender of organizational members and participants, their motivation and skills, and the organization's leadership. His organization or structure construct includes communication and decision-making patterns within the organization, the organizational hierarchy and formal structures, and the level of bureaucratization. Although this definition is so comprehensive as to resemble French and Bell's (1998) organizational systems model and can somewhat blur the core definition of organizational climate, it serves as a good reminder of the interrelatedness of all these factors with organizational climate and culture. It also illustrates the broad range of organizational issues that must be taken into consideration when planning for large-scale organizational improvement. (p. 4)

This theory can be used by any organization and is easily adaptable into the ICS model, especially for educational organizations. Institutions with a school crisis team, or a similar group, but unfamiliar with ICS, should be comforted in knowing that many similarities exist with their organization's standard culture of safety and security. Both follow a hierarchical system and acknowledge that multiple levels of response may occur. The only key difference is that the more comprehensive structure and function of ICS will allow for a coordinated response should other agencies need to be involved in the crisis (Nickerson, Brock \& Reeves, 2006). 


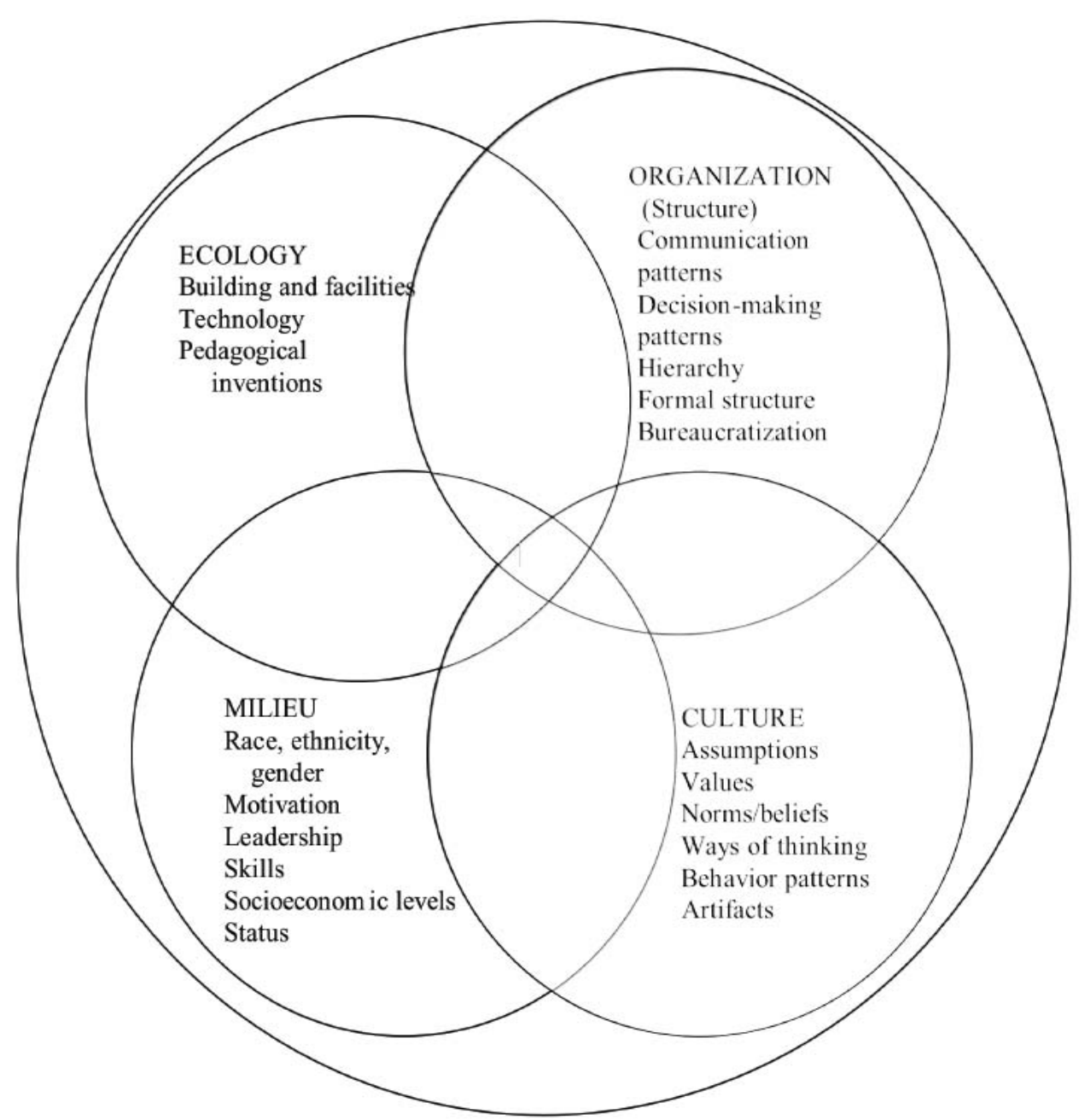

Figure 3. Tagiuri’s Model of Organizational Climate.

Given today's increased number of threats and the national trend of dwindling institutional budgets, colleges and universities must be ready to partner with local, state, and federal agencies to respond to and recover from an emergency.

ICS allows campus personnel and community responders to adopt an integrated organizational structure that matches the complexities and demands of the incidents without being hindered by jurisdictional boundaries. With institutes of higher education blending into the larger community response system, ICS allows all involved to know their roles and work together, without jeopardizing anyone's voice or authority. (FEMA IS-100.HE) 
By using the Incident Command System, institutions can help ensure the safety of its first responders, students, employees and visitors. It can also help achieve response objectives and the efficient use of resources.

Using ICS during crises only succeeds, though, when everyone assumes personal accountability. Emergency plans require an all-hands, all-lenses methodology, that will offer a multifaceted approach to safety. Institutions must dramatically increase their ability to develop, practice, and effectively implement functional incident response plans. In a world where resources must be shared more frequently due to budget crunches, organizations must have the infrastructure capable of supporting external aid and multiagency coordination. In a true crisis, leadership must understand that this pre-planning could be the difference between $\$ 100,000$ in damages or $\$ 1$ million - and in some extreme cases, between life and death.

\section{Academic Definitions and Typologies}

Definitional morass of crisis has also affected academic institutions. As our society combats economic issues, “crises” in higher education can include that of decreasing budgets, faculty hiring, student rights, academic freedom, etc., and are often "of their own making" (Dressel, 1981, p. 178). Consolidating many of the corporate and governmental definitions and typologies, Zdziarski (2001) initially believed that all crises, especially in higher education, could be categorized into four categories: natural, facility, criminal and human. For the purpose of this study, Zdziarski’s later adapted definition of crisis (2006) will be the metric used for his well-rounded explanation that hits the main arguments made by aforementioned authors in terms of disaster, issues and risk management. 
He classified "a campus crisis [as] an event, often sudden or unexpected, that disrupts the normal operations of the institution or its education mission and threatens the well-being of personnel, property, financial resources, and/or reputations of the institution” (Zdziarski, 2006, p. 5). Like Skinner and Mersham (2002), Zdziarski (2006) posited that there are three levels of crisis: (a) "a disaster is an unexpected event that disrupts normal operations of not only the institution but the surrounding community as well,” (b) “a crisis is an unexpected event that disrupts the entire institution,” and (c) "a critical incident is an event that causes a disruption to part of the campus community” (p. $5)$.

In a later publication, Zdziarski et al. (2007) created the Crisis Matrix (Figure 4) and reduced Zdziarski’s (2001) original four categories of crises down to three: environmental, facility and human (the "natural” group being renamed to "environmental”, and the "criminal” group being enveloped into "human”). All of these crises are part of the larger Crisis Management Cycle (Figure 5), or Crisis Management Process - Planning, Prevention, Response, Recovery and Learning. It is these models that make up the core of higher education crisis management systems. 


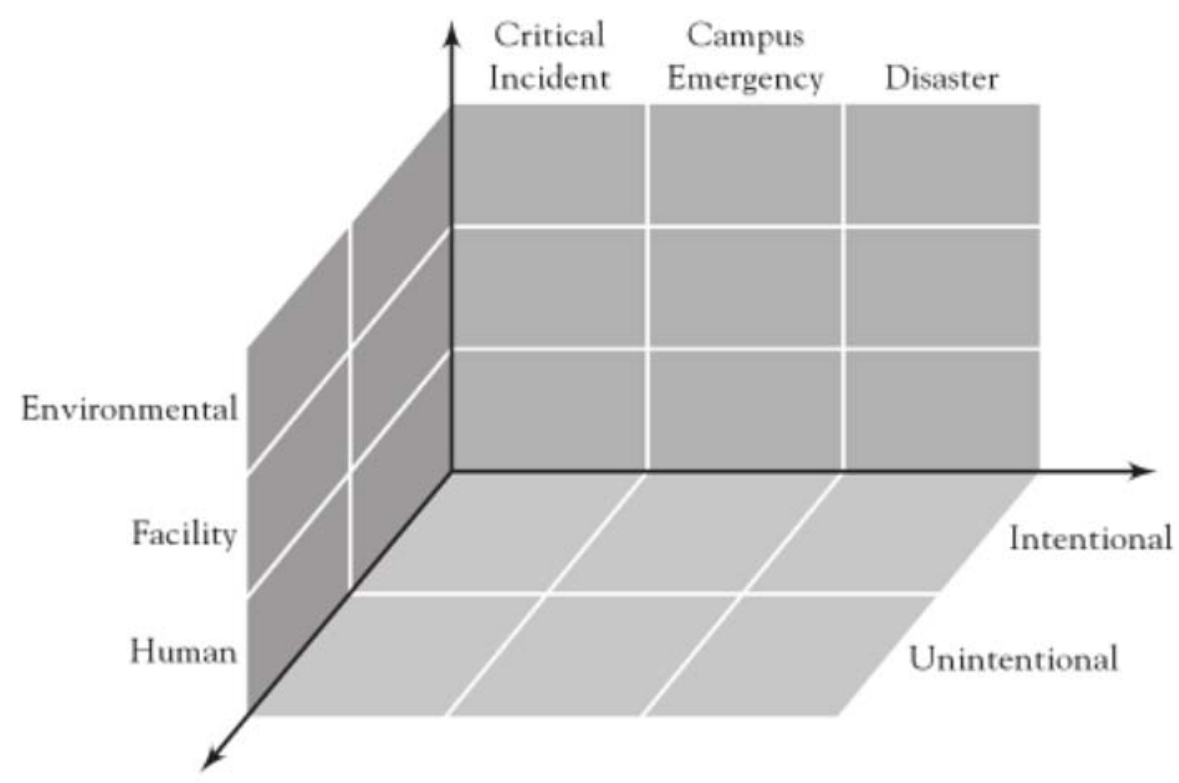

Figure 4. Zdziarski, Rollo and Dunkel’s Crisis Matrix.

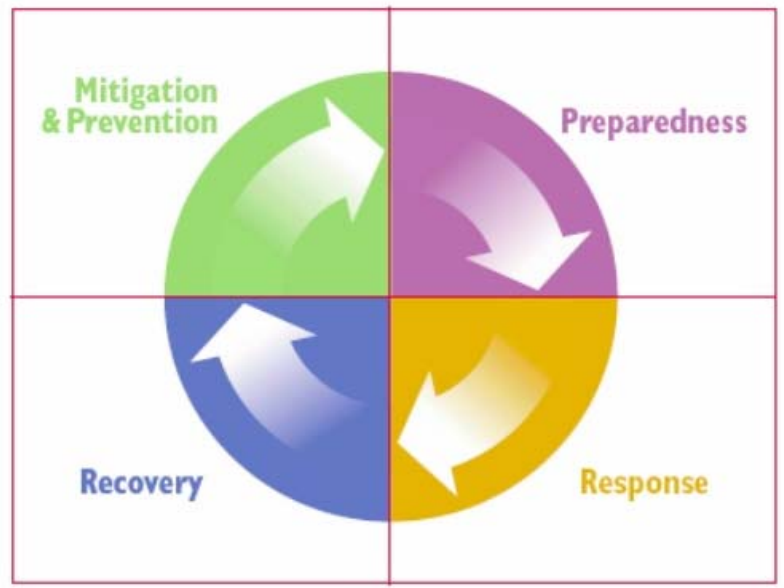

Figure 5. Crisis Management Cycle.

As noted earlier, Zdziarski’s (2006) definition of crisis has been the best summarized description for academic institutions. It takes the commonalities of corporate and government typologies, while bringing the uniqueness of higher education into the 
fold. It is distinctive because of the specific challenges and opportunities that only universities experience during times of crisis, much like the studies is this next section.

\section{Historical Significance of Crisis Management in Higher Education}

Though crisis is not a term that can be traced back to a specific date or incident, there are several tragedies that have occurred throughout America that have inextricably changed the fabric of our culture. Specifically for higher education, universities have been seen as organizations "of social harmony built on charitable foundations that [work] to enhance the intellectual abilities and professional capabilities of all members of a collaborative academic community” (Ferraro \& McHugh, 2010, p. 1). As such, each institution, "for better or for worse, is expected to be - and needs to be - an institution especially committed to life and safety” (Ferraro \& McHugh, 2010, p. 2).

This expectation is once again supported through Maslow's (1943) hierarchy of needs. He posited that once the basic physiological needs are met, all humans have a

desire to feel safe. This tenet was something parents felt, into the early $20^{\text {th }}$ century, campuses should offer their children (Ferraro \& McHugh, 2010; Muffet-Willett, 2010). However, as history has shown us, this has not always been the case. Over the last five decades, some unfortunate incidents created a national movement in higher education for institutions to better learn from, react to, and prepare for crises.

As discussed in the first chapter and supported by others like Zdziarski (2001), there is no empirical research on this topic. The following incidents simply offered practical examples of the aforementioned literature, as well as needed historical significance, by illustrating a few key moments in our history that have led to the formation of university crisis management systems as we know it today. 


\section{University of Texas-Austin}

The long-standing view of universities as safe havens changed on August 1, 1966. The Texas Bell Tower at the University of Texas-Austin was the tallest building in the entire city at the time, with a height of 307 feet. All citizens were free to climb to the top observation deck for a 360-degree panorama of the city. It was this vantage point that attracted Charles Whitman, a former U.S. Marine Corps sharpshooter, to campus. At around 3:00 AM that day, Whitman killed his mother and his wife, leaving a note stating he did not want them to suffer for the actions he would commit later in the day. Close to noon, Whitman opened fire on the UT-Austin campus for 96 minutes. He killed 14 people, and injured dozens more. (Ferraro, \& McHugh, 2010).

Though this was not the first crisis to ever happen on a college campus, nor the last, "this incident stands out for its undeniable impact on the community and the nation" (Zdziarski et al., 2007, p. 7). Given that the event occurred in a state’s capital, media outlets were more readily available to capture the gruesome details. The nation was glued to their television and radio sets as the events unfolded. The incident marked the first time a university crisis was at the center of news coverage.

UT's police officers at that time did not carry weapons and could not appropriately take charge of the incident, hence Whitman's lengthy stand-off. Because of this inability to respond, "police agencies across the nation began developing a new type of response” (Zdziarski et al., 2007, p. 8). Snow (1996) credited the UT incident for the creation of the first Special Weapons and Tactics teams (SWAT), which of course has had a long-standing impact on crisis incidents across the nation. 


\section{Kent State}

During the 60s and 70s, there was a large amount of protests related to civil rights and anti-war campaigns. On April 30, 1970, U.S. President Nixon announced that the country would be invading Cambodia and, hence, widening the Vietnam War. The next day, an anti-war rally was held within the Commons of Kent State University. After peaceful demonstrations turned into violence within the city, Kent Mayor, Leroy Satrom, declared a state of emergency. He sought Ohio Governor, James Rhodes, to dispatch the Ohio National Guard to the university.

On Monday, May 4, another rally was held on campus. Just before noon, the National Guard asked the protestors to disperse. When they refused, General Canterbury of the National Guard ordered his men to prepare their weapons. After the crowd once again refused to stop the protest, gunshots and tear gas was released into the crowd, air, and/or ground. "Altogether between 61 and 67 shots were fired in a 13 second period” (Lewis \& Hensley). In total, there were four students killed and nine injured.

The event triggered a nationwide student strike that forced hundreds of colleges and universities to close. H. R. Haldeman, a top aide to President Richard Nixon, suggested the shootings had a direct impact on national politics. Political researchers have posited that the Kent State shootings eventually destroyed the Nixon administration and "[came] to symbolize the deep political and social divisions that so sharply divided the country during the Vietnam War era” (Lewis \& Hensley).

\section{Lehigh University}

One of the seminal cases on how institutions across the nation changed their way of approaching on-campus incidents was the murder of Lehigh University freshman, 
Jeanne Clery. In April 1986, Josoph M. Henry entered a women’s residence hall where Clery resided, and proceeded to rape, beat and murder her. In an interview by People Magazine (1990), the parents of Jeanne Clery recounted how "they assumed Lehigh was as safe as it looked.” At the time of Clery's murder, Lehigh only had 12 security guards for its 5,400 student population, and had 38 violent offenses in a 3-year period; for context, Penn State, with six times as many students, had just 24 incidents (Gross \& Fine, 1990). However, no parent or student had any way of knowing this unless they contacted the FBI for the university's crimes report.

With the loss of their child as a motivation, the Clery family used the money gained from a law suit settlement with the university to form a foundation and lobby the Pennsylvania legislature to require colleges and universities to create an easily accessible report of on-campus crimes. They soon gained national momentum, and in 1990 the federal government passed the Crime Awareness and Campus Security Act (later renamed the Clery Act). The Act required all institutions that obtained federal funding (including financial aid for its students) to keep and disclose information about crime on and near their respective campuses (securityoncampus.org). This federal mandate "has changed the nature of the discussion on college campuses at orientation programs, putting front and center the expectations of today's parents regarding the responsibility of institutions to protect and warn their children about potential harms” (Rollo \& Zdziarski, 2007, p. 10).

\section{Syracuse University}

For the first time in the history of higher education in the U.S., international terrorism had affected our opinion of student safety outside of campus. On December 21, 
1988, the transatlantic Pan Am Flight 103 from London Heathrow International Airport to New York’s JFK Airport exploded in mid-air and crashed down around Lockerbie, Scotland. Attacked by two Libyan nationals, the bombing accounted for the deaths of 259 passengers and crew members. Among the flight manifest were several students returning

to the U.S. from study abroad, but Syracuse University claimed the most with 35 students aboard the plane (archives.syr.edu/panam/).

Like with the UT-Austin murders, this incident brought national coverage and shocked the nation, forcing Americans to realize how vulnerable we really were. Through this incident, the U.S. had officially re-entered an era of international threat. "Once again, the scale of this tragedy and its impact on our campuses changed the way we view our off-campus experiences but also affected our sense of safety from forces in the world that until this incident seemed far away” (Rollo \& Zdziarski, 2007, p. 11). We were later reminded the impact an incident of this nature could have on the landscape of higher education during the 9-11 terror attacks.

\section{University of Florida}

On the first day of classes at UF in August 1990, two female student bodies were found inside their apartment complex. Within the next five days, three additional bodies were found, all but one were female, and all were murdered by Danny Rolling. Once news broke of the tragedies, the university was overwhelmed by concerned parents and inquisitive media outlets. The switchboards were jammed and news trucks lined the campus (Collison, 1990). "The age of the twenty-four-hour news channel and satellite television trucks that allowed any story of local significance to immediately become a national story dawned,” (Rollo \& Zdziarski, 2007, p. 12). 
Unlike with the University of Texas-Austin incident, where it took days to set up a press conference, the University of Florida did not have the luxury of time. The nation was watching and waiting for a response. The university, and all institutions moving forward, had to put plans in place that allowed administrators and spokespersons to respond quickly and accurately in a time of such tragedy (Rollo \& Zdziarski, 2007). The community demanded to know that the university was safe. However, John V. Lombardi, university president at the time, made a poignant statement that resonates until this day: "Unfortunately, there are no 100\% safe environments in America or at any university. To tell you there is no risk is simply not to be realistic" (Collison, 1990).

\section{Hurricane Katrina}

Hurricane Andrew devastated the South Florida region in 1991, and after the effects it had on the University of Miami and Florida International University, institutions across the nation realized the impact a storm could have on their operations and the lives of their constituents (Rollo \& Zdziarski, 2007). However, no one could ever have planned for what occurred to New Orleans, Louisiana, in 2005 after Hurricane Katrina wiped out the entire city. Though numerous institutions across the region and other states were affected (Georgia, Florida, Alabama and Mississippi), none were greater than Tulane University, Xavier University, Loyola University, Dillard University, Southern University and University of New Orleans - all in the heart of the city - with almost \$2 billion in damages (Rollo \& Zdziarski, 2007). As noted earliest in the literature review, institutions were left to fund themselves as FEMA focused its efforts on city-wide issues.

Led by the now revered Tulane University president, Scott Cowen, universities in the area sought mutual aid from colleges and universities across the nation to allow their 
students to enroll and continue their studies in schools outside of New Orleans until the institutions could re-institute their basic infrastructures. Through this tragedy, we learned that “even resources can be shared, among institutions that before Katrina seemed divided by an uncrossable chasm formed through history, traditions, and culture” (Rollo \& Zdziarski, 2007, p. 22). Faced with this unthinkable task, Cowen stated in a press conference: "This is the most significant reinvention of a university in the United States in over a century,” (Pinto, 2005). Cowen's numerous articles on the challenges faced by institutions in New Orleans have become a key resource to university presidents and crisis management teams. His recent book will be discussed in further detail later in this chapter.

\section{Virginia Tech}

Described as "the bloodiest and most pitiless assault in the history of American higher education,” April 16, 2007 marked a day few in higher education will ever forget (Ferraro \& McHugh, 2010, p. 16). The mass shooting, done by Seung Hui Cho, occurred on two parts of campus, leaving 33 dead. The first shooting, leaving two dead, made officials believe it was “domestic” in nature and that it was an isolated incident (Hauser \& O’Connor, 2007). Though institutional protocols were followed for the first incident, the university was not locked down, allowing Cho to go on a 9-minute shooting rampage later in the day inside Norris Hall. The decision to not shut down operations after the first incident sparked criticism against the administration on whether they communicated the potential dangers to the campus community in an appropriate and a timely manner.

Prior to this incident, the UT-Austin shooting was the deadliest event to occur at any university. Also more worrisome was the killer's ties to the university. Once the 
investigation into the murders and the assailant began, it was discovered that Cho had seen psychologists on campus. This fueled a national conversation on the responsibility the university had to disclose Cho's erratic behaviors and thoughts for the greater safety of the community, and how accountable or liable the institution was to the families of the deceased students. This debate continues today as campus incidents tied to mental health issues, like the Florida State shooting (which occurred while this study was underway), become more rampant.

\section{Summary}

Though these cases were just a few of the unfortunate incidents to have happened on university campuses over the last five decades, they were nonetheless significant to the study. In each of these examples, attention was given, lessons were learned, actions were corrected, and crises were defined. It was through these incidents that universities have learned to manage and lead in crisis. Crisis managers and crisis leaders alike have evolved into their roles today, in part, because of it.

\section{Leadership in Crisis}

The previous sections provided a contextual foundation for this study and an overview of crisis and crisis management, as well as the historical significance of those two within higher education. We now turn to the focus of the study, crisis leadership. But before one discusses leadership in crisis, it is important to first understand the definition of leadership.

Despite the variable meanings by different authors and organizational cultures, most can agree that a leader is not necessarily a manager (Daniels \& Daniels, 2007). If a leader offers direction, vision, and inspiration, "a manager, then, is a technician who 
helps people, processes, and systems function together efficiently” (p. 35). Though many commonalities exist, there are fundamental differences that one must understand. Leaders deal with change and effectiveness, and also have a focus on creating, the external, and the future (pp. 40-44). Managers, on the other hand, deal with stability and efficiency; they focus on delivering reinforcers, the internal, and the near-term (Daniels \& Daniels, 2007, pp. 40-44). It is through this perspective, that I separated a crisis manager from a crisis leader throughout the rest of this study.

\section{Leadership Skills Defined}

Leadership, as defined by Seeger at al. (2003), "frequently frames the larger meaning of the crisis, which may be necessary for followers to begin the initial sensemaking process that ultimately leads to coordinated, harm-reducing actions” (p. 239). They posited that crisis leadership has four factors. Traits refer to a leader's personal qualities; style refers to specific actions and behaviors taken by the leader; contingency focuses on matching the leader's style with the specific task at hand; and symbolic to the "qualitative and symbolic dimensions of the leader's activities" (pp. 243247). Likewise, the functions of crisis leadership are divided into what leaders can actually do pre-crisis, during crisis, and post-crisis.

Expanding on a leader's traits, Inc released a short article in 2014 titled "5 Things Successful Leaders Do in a Crisis.” Though focused on business leaders, the article still touched upon characteristics that all leaders, regardless of their field, can implement during times of crises. The first two lessons were that leaders “don't let their emotions get in the way” and "are brave.” In other words, leaders should always remain calm. Becoming overwhelmed can lead to fear, which can transcend into the team becoming 
worried that the situation is direr than it actually is and/or they will not be able to overcome the situation. Leaders being "accountable for their victories and their losses" and that they "don't take failure personally" were the next two traits. Successful leaders not only own up to their mistakes and accept the responsibilities placed on them to act and respond, but they also do not take offense if their decisions don't go as planned. Lastly, "successful leaders possess positive attitudes from start to finish.” During and after crises, teams and communities can be frustrated and/or exhausted. It is important for a leader to always offer encouragement, support and appreciation for their team's hard work - despite any setbacks.

Leadership, of course, also entails perceived and actual power, authority and influence. Dressel (1981) defined each of these by their respective relationship to one another. Power, he viewed, was "the ability, by any means, to control or determine the formulation, interpretation, or application of policy” (p. 75). Authority was the "recognized power" that was granted to specific leaders by their office and/or supervisor (p. 75). Influence, on the other hand, was "informal power" used in consultation, persuasion or suggestion (p. 75). It is important to understand these dynamics within any organization, so that decisions can be made by the right person, for the right reason, and at the right time.

The skills of insight, decision-making, communication, and focus are not unique to crisis management, but they do "[make] a difference during the management of a crisis” (Silva \& McGann, 1995, p. 125). Leaders must develop insight to constantly question rules, policies, and practices in order to see the incident in its truest form (Silva 
\& McGann, 1995). They must avoid "addressing symptoms rather than the cause of a crisis” (p. 129).

Management books advise that one of the keys to a successful leader is good decision-making. However, the important variable in crisis "involves isolating pivotal pieces of data that prompt rapid decision making and swift action” (Silva \& McGann, 1995, p. 132). Similarly, and according to Muffet-Willett and Kruse (2008), "the ability of a leader to adapt to a changing and complex environment is a key foundation of crisis leadership” (p. 255). They created a Crisis Leadership Continuum (Figure 6) that showcased the differing types of situations crisis leaders could be faced with. The point they were making was that decision-making in crises conditions is difficult enough for a seasoned leader, let alone an ill-prepared one. They posited that experience and training can go a long way to better prepare leaders to act.

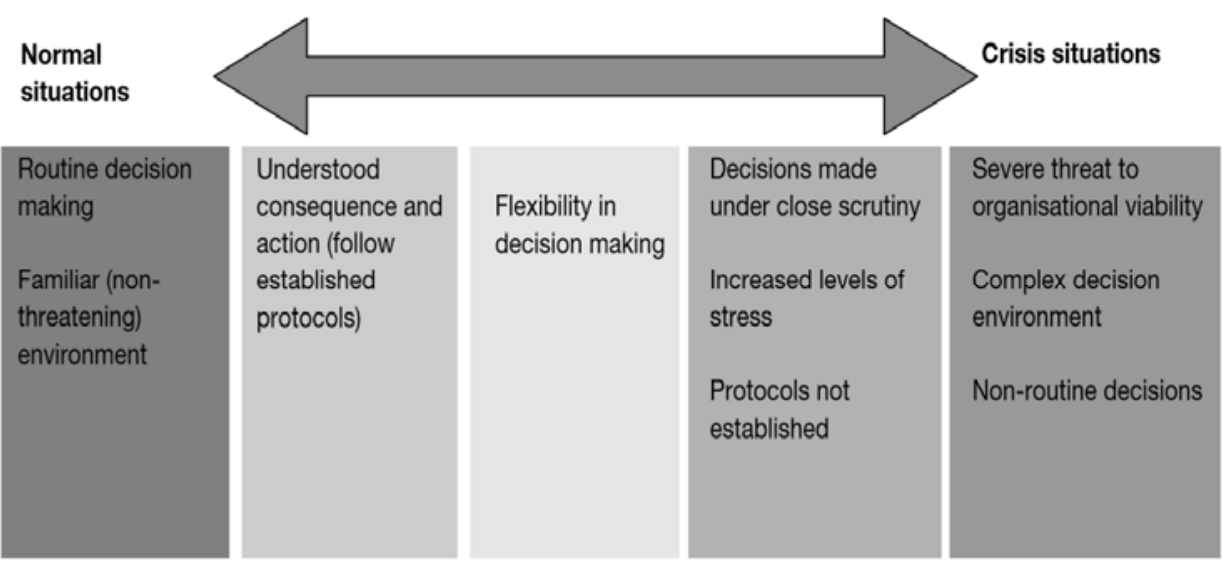

Figure 6. Muffet-Willett and Kruse's Crisis Leadership Continuum.

Crisis communication, though not a topic detailed thoroughly in this literature review, is also and nonetheless critically important. According to Silva and McGann (1995), “the key to developing effective crisis communication lies in stopping bull----!” 
(p. 136). Honesty, especially to your employees, will build trust in the leader's actions and in the management system. The last of the four skills discussed by Silva and McGann is focus, which is described in terms of "concepts" instead of "activities” (p. 136). Here, leaders must center their decisions on the overarching goal for that specific incident, instead of handling each question or issue separately.

As previously mentioned, decision-making is at the root of crisis leadership. Dressel (1982) offered seven dimensions for decision-making that still stand true today: (a) "the awareness or consciousness that a decision is expected and is being made,” (b) "the importance or interest attached to an issue and a decision regarding it," (c) "the process by which the decision is to be made," (d) "the identification of exactly what is involved in making the decision," (e) "the amount of flexibility or rigidity that exists both in directing the nature of the decision and in the decision itself, “ (f) "the identification of whether the decision deals with structural, procedural, or substantive matters,” and (g) “implementation and evaluation” (pp. 62-64). Leadership, then, must understand that practices are not necessarily rules. Turning a practice into a regulation is itself a "double decision” (p. 69). So it is with crisis management.

Of course, the skills desired by crisis leaders and crisis managers alike can vary from organization to organization. Lerbinger (2012) described the two most common forms of crisis decision-making: maintenance learning and shock learning. Maintenance learning describes a system where employees "uphold an existing system” (p. 307). In other words, they do the same things the same way just because that is the way they have always been done. Shock learning, on the other hand, is when an event occurs that shakes up the organizations protocols. 
However, Lerbinger (2012) proposed that crisis leaders and managers should follow Warren Bennis’s decision-making method of “innovative learning” (p. 307). Bennis posited that the core characteristics of this learning style are "anticipation and participation” (as cited in Lerbinger, 2012, p. 307).

Unless executives incorporate the additional modes of crisis management problem solving in their lexicon of competencies both they and their organizations will falter. But if executives adopt new perspectives and acquire new skills in dealing with expanded external environments, they will become leaders and their organizations will excel. (Lerbinger, 2012, p. 311)

Therefore, it is critical for leaders to also be open to learning new techniques and gaining knowledge through all methods, even if through their own failures as noted earlier by Mitroff \& Anagnos (2001).

Unless there is a firm decision made by top management that crisis management is an important aspect of the organization's values and policies, there will never be a way to enforce it when the time comes to implement the plans. Though this stance was alluded to in Dressel's work, it was something that was specifically addressed in the study's findings. During the participant interviews, decision-making in crisis was be raised as a sub-theme to Culture. The data analysis of those responses confirmed Dressel's position.

\section{Importance of Top Management}

Early warning signs to any crisis are important to the successful response of and recovery from the incident. Therefore, constituents, especially employees, need to be empowered to speak up when they know of potential risks and threats (Mitroff \& Anagnos, 2001). For crisis management programs specifically, "experience demonstrates repeatedly that without a champion nothing significant will occur with regard to any 
major program in an organization” (p. 149). These champions can come from all parts of the organization, but one must obtain buy-in from the whole leadership and management teams on the reasons why CM is so important. "In other words, one must sell simultaneously up and down the entire chain of command” (p. 151).

Zdziarski (2001, 2006); Harper et al. (2006); Zdziarski et al. (2007); and Hemphill and LaBanc (2010) have all alluded to the importance of the university president and how integral his/her support is for crisis management plans and teams. However, none of them discussed how that support transcends into the campus' desire to inculcate a culture of safety, or explained why their involvement is in fact significant. Muffet-Willett's (2010) dissertation on crisis leadership took one of Zdziarski’s (2001) proposed research directions and focused on university crises from the administration's perspective. The biggest takeaway from her work was the Higher Education Crisis Leadership Practical Process Model (Figure 6).

This model consisted of five actions that she believed contribute to effective crisis leadership in universities. The first action, which related most directly to this study, is “top administrative support and involvement” (Muffet-Willett, 2010, p. 149). The deed not only provides a symbolic investment in the process, but also contributes to accountability and effective management of the entire system. For those organizations that have crisis management teams, "without the involvement of upper administration, the collaborative structure ... can become loosely held together, leading to power struggles, egos, and turf war issues among the group members” (p. 135). Therefore, effective crisis leadership is intrinsically tied to the relationship with the crisis managers. The leader “must value the team's formation, support the team with a charge, and be 
ready to provide resources to assist the team's work" (Sherwood \& McKelfresh, 2007, p. $62)$.

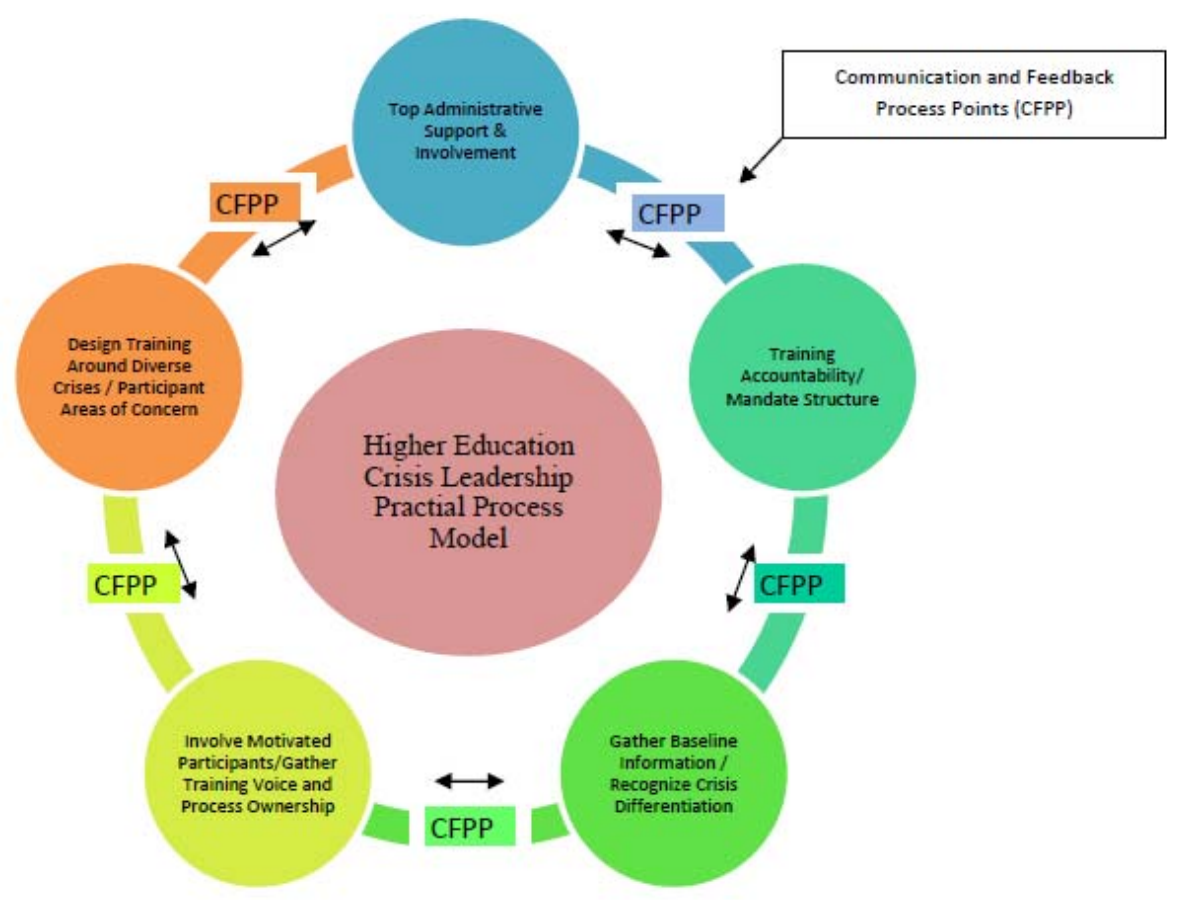

Figure 7. Muffet-Willet’s Higher Education Crisis Leadership Practical Process Model.

It is important to remember to always keep top management informed of all emergency incidents, and ignore the "until it’s really necessary" response (Skinner \& Mersham, 2002, p. 33). Providing "filtered" news to the top management only leads to poor decision-making because the CEO did not receive all of the facts (p. 48). The “don’t tell the boss mentality” can also be a detriment (p. 48). However, excluding them from the communication cycle altogether is just as bad. Recent cases have illustrated "that noninvolvement by the top ranking officer of the corporation can waste time, impair decision-making, and jeopardize the company’s credibility” (p. 60). 
For these reasons, organizational leaders must first look at the culture of trust, accountability and communication they have created and are continuing to build. Employees should always feel comfortable in approaching leaders with serious concerns and constructive feedback. That is why providing access to top management, cannot only open the lines of communication, but it can remove any speculation that the leadership has turned a blind eye to an incident or is involved in a cover-up. A relevant example of this was the Penn State scandal where lower ranking staff members were afraid to speak up about Jerry Sandusky's actions against children. The times the incidents were reported, the administrators who knew thought they did their due diligence by "reporting up" to the university president even though they did not verify that President Spanier took proper corrective action.

Sometimes incidents move into the public domain like stated by Seymour and Moore (2000), which cause, especially in recent years, the media to focus all their energy in uncovering the truth. In these instances, the president often has the most credibility, and is seen "as a true representative of the company, as a person who can make decisions, and speak for the company" (Fearn-Banks, 2011, p. 37). However, it is important to know when the CEO should speak and when the crisis is so specialized that an expert should be assigned to be the official spokesperson (Fearn-Banks, 2011). Here, crisis leaders (or presidents) and crisis managers create a symbiotic relationship; both depending on each other to succeed.

Though their roles are different in times of crisis, presidents and managers must nonetheless work together to mitigate the incident at hand. Crisis leadership becomes the 
tool to bridge communication gaps, solidify institutional values and work towards common goals.

\section{Crisis Leadership in Higher Education}

Mitroff (2004) defined the differences between crisis management and crisis leadership: the previous being "reactive” and the latter "proactive” (p. 10). In other words, crisis management can also be termed "crash management - what to do when everything falls apart” (Pauchant, 1992, p.10); whereas, crisis leadership takes a more high-level, pre-incident, strategic approach. Of the universities researched prior to the start of interviews, most had two or three employees assigned to lead the crisis management effort (as defined in this study). Usually they were an in administrative position who reported to one of the vice presidents and had operational oversight of oncampus incidents. The president, on the other hand, (for the most part) served as the principal leader during times of crisis. It was expected that in true crises (i.e., not small incidents), he/she set the tone for the response and was the spokesperson for the constituents involved. This differentiation between manager and leader is the mainstay of my research.

Crisis leadership is loosely defined as supporting a healthy infrastructure for crisis management, dedication to constant training and policy review, accepting that wrong actions can offer the organization a unique perspective on how to improve, and the ability to influence others to follow the leader’s ethical commitments (Seeger et al., 2003;

Klann, 2003). However, it is important to separate the "integrated design” of crisis leadership and the “centralized” structure of crisis management (Mitroff, 2004, p. 19). Whereas adding another committee or department can add to the growing bureaucracy of 
an institution, developing the infrastructure for crisis leadership to thrive is tantamount to the safety and well-being of the institution as a whole and not just on a case-by-case basis (Mitroff, 2004).

An example of this infrastructure is the organization-wide management team recommended by the ICS. It is suggested that colleges and universities perform table-top exercises throughout the year that allow for real-life simulations of potential crises. To do them properly, the crisis management team is not the only one involved. The university administration, including the president, forms what is called the Executive Policy Group (EPG). While the CM team handles the detailed oversight of the incident, the EPG handles all major decisions like closures, evacuations, etc. Their purpose is to offer a holistic approach to the issues at hand, while balancing the individual needs proposed to them by the team.

Keeping these models in mind, Klann (2003) argued that there are three components of effective crisis leadership: communication, clarity of vision and values, and caring relationships. As also discussed by Dressel (1981), Klann (2003) urged leaders to use their influence as an ability to persuade and motivate, but not in an authoritative way. "[This] difference lies not in the importance of influence as a leadership capacity but rather in the particular context of crisis itself” (pp. 11). Dressel (1981) also observed that "few administrators who have been at an institution over a period of time with no serious problems can adjust to a crisis situation” (p. 179). Only through preparation, lessons learned and experience can one truly be ready for crisis. This is another aspect of Muffet-Willett's (2010) model, which describes the need for collaborative training. 
As such, there is a key disparity between "a successful leader" and "an effective leader” (Klann, 2003, p. 20). Similar to Seeger et al. (2003), Klann (2003) posited that “an organization's senior leadership is needed before, during, and after a crisis, and its quality can determine the length, severity, and ultimate consequences of the crisis” (p. 21). The decisions, actions and behaviors that crisis leaders offer will inevitably affect the success of the institution's response.

Along these lines, Zdziarski (2001) conducted a survey of the National Association of Student Personnel Administrators (NASPA) member institutions about their perceptions of crisis management teams. One of his questions related to the internal stakeholders with the greatest involvement in crises, which resulted in an interesting fact - the university president was ranked 13 out of 23. Zdziarski (2006) noted that "the ranking [was] less important than the point it illustrates: although the president is informed and involved in most campus crises, he or she may not necessarily be directly involved on the crisis management team” (p. 15). Contrary to the ICS recommendation, this involvement will of course depend on the institution's campus culture, created by the significance placed by the president's leadership.

Melding into these factors and functions are the president's own values and ethics, the core guiding principles of any person's actions and words, which are brought out most visibly during crises (Seeger et al., 2003). These individual philosophies can affect an institution's attitudes towards crisis management, as noted by Fred P. Pestello, President of Saint Louis University, in a 2015 AGB Trusteeship article: "Like Polaris Guiding Ancient Mariners To Safe Shores, a College’s or University’s Deep-seated Values Are the Beacons That Its Executive and Board Members Should Rely Upon to 
Lead Them Through a Crisis”. He believed that sometimes crisis leaders are so focused on the short-term responses needed during crises, that they lose sight of the university's mission, vision and values. When this occurs, trust in the leader's capabilities can sometimes be undermined. For example, Florida International University's first institutional value is "freedom of thought and expression." If they were to have a large protest on campus and a hasty decision was made by the administration to shut it down, it would, in theory, go against one of the university's core values.

Every university is different. They each have different missions, student populations, research foci, and campus cultures. As such, the role of every president is different; each with their own goals for their tenure. The safety and well-being of campus is always a concern for presidents, but how deep-seated they make those values greatly depends on the importance placed on them. Sometimes the lack of attention can create a culture of apathy or non-reporting, causing room for errors to grow. This perspective is supported by the study's findings and are discussed in more detail in the following chapters.

Presidents are seen as leaders, academics, politicians, fundraisers, chief executives, but also most recently as "targets” (Trombley, 2007). The latter alludes to the recent scandals affecting campuses around the nation, namely "human crises” (Zdziarski, 2001) involving allegations of child molestation, embezzlement, hazing, murder and failed communications. Presidents have been named key conspirators, regardless of their direct involvement in an incident. Because they are the institutional leader, the public is holding them more accountable for the actions (or lack thereof) of their organizations. Key examples of this are: (a) the criticism of Virginia Tech President Charles W. Steger 
for supposedly not properly warning the university community of the threat related to the 2007 on-campus shootings, (b) the 2012 resignation of FAMU President James H.

Ammons after the hazing death of one of the university's band members, and (c) the 2012 charge of perjury against former Penn State President Graham Spanier during the Sandusky trial for claiming not to have known about the incidents.

Especially in today's universities, "when a president takes the lead in crisis preparedness of an institution, ultimately he/she takes ethical responsibility for its constituents and their well-being” (Burrell, 2009, p. 57). This accountability measure is yet another thing that differentiates a crisis manager from a crisis leader in my study. The study's findings both supported and opposed this opinion by defining the presidents' role in crisis and analyzing the relationship between managers and their leader.

\section{Personification}

As noted earlier, former Tulane University president, Scott Cowan, released a book on his experiences leading Tulane through the aftermath of Hurricane Katrina. Many in the field of higher education have called his speeches and articles a shining example of effective leadership in crisis. His book, The Inevitable City (2014), not only describes the journey he and his colleagues went through in New Orleans, but also broke down the leadership components he used throughout the recovery process.

In his introduction, Cowan shared what he believed leadership is and why it is important:

Leadership is about making a significant positive difference in the lives of organizations and people. It involves envisioning a future that does not currently exist and working with others to realize it. The journey from vision to outcome is a long one that requires giving of yourself, empowering and inspiring others, being willing to give and take, and finding the courage to act and the 
determination and will to succeed. To effect transformational change is often difficult and chaotic, but leaders always act to ambitiously optimize a situation, aiming for the best possible in a highly imperfect world. They recognize good ideas, understand and respect conflicting points of view, and actively engaged with others. Most important, they don't quit till they get it done. (pp. 6-7)

For Cowan, leadership came down to ethical and moral decision-making, individual life lessons including one's upbringing and personal beliefs. Using this as a foundation, Cowan shared his perspective on what happened during Katrina through 10 leadership principles, each described in its own chapter: (a) do the right thing, (b) seek common ground, (c) marshal facts, (d) understand reality, (e) aim high, (f) stand up for your beliefs, (g) make contact, (h) innovate, (i) embrace emotion, and (j) be true to core values.

Doing the right thing "is what separates true leaders from those who do not have the capacity or insight to search out what's required to resolve complex issues” (p. 13). As noted earlier, crisis leaders have to bear an added level of accountability. Their decisions to do what they believe is what "determines success versus failure” (p. 13). While the leader at the end must make a call, a decision should not be made without gaining input from experts and colleagues.

Effective leaders have the ability to find commonalities and bring people together because they are good listeners, can see all points of view, empathize with those who may oppose them, and find the connecting tissue of ideas that forms the basis of principled and fact-based decisions. (p. 29)

In other words, collaboration and teamwork is important in crisis decision-making. In this shared process, facts and reliable evidence direct the leader to make informed judgement calls. This information gathering leads to the fourth element of crisis leadership for Cowan, which is "the ability to understand the reality of situations" (p. 72). Although this 
data collection is key to decision-making, so is understanding the differing variables of the situation at hand. With school in session, President Cowan had to frame his decisions quite differently than if the hurricane had hit during a university break.

In crisis, leaders must set goals, both short-term and long-term, to help guide those involved on where to focus their energies. The main goal in crisis, as noted by Fink (1986), is to always move towards crisis resolution as efficiently and effectively as possible. However, in order to do so, crisis leaders must establish order and vision, as also discussed by Klann (2003). These goals, though, must always be set with integrity.

People will follow those who stand for something they respect, who adhere to a code of ethics, and who are consistent in their thoughts and actions. A leader who lacks a moral compass, compassion, and a willingness to fight for his or her beliefs is not worth following. (Cowan, 2014, p. 119)

Leaders in crises should be dependable, and their decisions should always be consistent with their words, actions and beliefs. And when they are not, a proper justification should be shared in order to keep transparency.

Tied to collaboration, which was mentioned earlier, relationship-building is also critical to successful crisis leadership, a point also raised by Klann (2003). These partnerships offer open and shared communication as well as cooperative engagement, which can lead to innovation and creativity. President Cowan spoke about the types of institutional cultures that "are laboratories for progress, yielding novel approaches that have the potential to alter the landscape of the future” (p. 164). Just as important as the university's culture, it was equally important to understand and accept the community's beliefs, values and histories. This emotional component also has a great effect on crisis decision-making, especially when dealing with systematic change. These cultural 
elements all contribute to a leader's own culture. His/her own values and beliefs can be changed by their environment. However, for Cowan, a leader's core values will forever remain unchanged. "Leaders remain true to core values of responsibility, persistence, integrity, and creative problem solving, with an eye to the ultimate good. By strengthening inner character, a leader develops the capacity for results, showing the way forward by example” (p. 207). In sum, Cowan believed that all leaders in crisis must make forward-thinking decisions with all available facts, through collaboration, with conviction and for the greater good.

\section{Summary}

Significant events in the last 50 years have contributed to these definitions of crises, while also shaping the landscape of campus safety and security. Crisis management teams offer an important contribution to that sense of protection, by being the day-to-day accountable officers to the campus community. However, without support from top management, crisis management teams would be limited in their successes. University presidents, based on the literature review, serve a critical role as crisis leaders in setting the institutional tone when responding to crisis and influencing their respective campuses to implement effective crisis management plans.

A study of this nature is important in order to start creating a concise view of crisis leadership within higher education. Crisis, crisis management and crisis leadership can mean different things to different organizations. Corporate, governmental and educational literature all have their own unique nuances. In the context of higher education, for example, crisis is best defined by Zdziarski et al. (2007) as an intentional or unintentional, human, environmental or facility incident, emergency or disaster. 
However, this definition was taken solely from a student affairs perspective. It is through this definitional morass that I found the basis of my research, and sought to find clarity amongst crisis managers and leaders alike. That is why interviewing both university presidents and their respective crisis managers aided in answering how both groups define crisis, crisis management and crisis leadership, while also understanding the roles they each believe they played as well as how those roles contributed to a culture of safety and preparedness. 


\section{CHAPTER III}

\section{METHODOLOGY}

\section{Restatement of the Problem}

As noted in Chapter 1, several authors have all produced significant work for student affairs professionals seeking insight into crisis management. Their research offered a unique perspective on how universities can better plan for, respond to and recover from major campus incidents. They all touched upon the importance of the university president and how integral his/her support was for university crisis management systems. However, none of them detailed how that support transferred into an institution-wide ethos of safety. The differences and relationships between crisis managers and crisis leaders are of integral importance. The purpose of this dissertation, therefore, was to better understand the phenomenon of crisis leadership in higher education through the lens of university presidents and their crisis managers.

\section{Research Questions}

In an effort to better define crisis leadership in higher education, three research questions formed the basis of this study:

1. In the State University System of Florida, how does each president and crisis manager define "crisis", “crisis management” and "crisis leadership” on their campuses?

2. Per those definitions, (a) What roles do crisis managers and crisis leaders see themselves playing in crisis management and crisis leadership, respectively?, (b) What roles do the crisis managers see the presidents playing in crisis 
management, if any?, and (c) What roles do the presidents see crisis managers playing in crisis leadership, if any?

3. How do those definitions and perceptions create a culture of preparedness towards and support of crisis management systems at their universities?

\section{Research Design}

A qualitative study was selected as the basis of research because of the goal to find meaning (Bogdan \& Biklen, 2007) in the phenomenon of crisis leadership from the perspective of institutional administrators. Literature in this field has discussed how important top management is for crisis management, but only one study that I have found (Muffet-Willett’s 2010 dissertation) and one book (Cowan, 2014) have investigated the university leaders' perspective on crises. Likewise, in the review of the literature, no work was located that discussed whether the assumptions made by the student affairs authors discussed in the literature review about the presidents' role in crises were in fact relevant to the study of crisis leadership.

Purposely, a case study was chosen because its definition matched the research parameters: “an intensive analysis of an individual unit (as a person or community) stressing developmental factors in relation to environment” (Merriam-Webster, 2015). The way the research questions were framed - use of the "how" and "why" questions and the study's focus on contemporary events are additional reasons why a case study served as the best research method for this dissertation (Yin, 2009). The study was bound within the context of crisis leadership through the perspectives of university presidents and crisis managers in the State University System of Florida. More specifically, this was 
an "instrumental case study" where the "case is examined mainly to provide insight into an issue or to redraw a generalization” (Stake, 2000, p. 445).

The study's theoretical framework was based on a basic interpretive approach, seeking how the participants made meaning of crisis leadership in higher education. Merriam (2002) stipulated that this type of research involves "phenomenology and symbolic interactionism” (p. 37). Drawing from these, this study facilitated a general understanding on how university presidents across the nation made meaning of crisis management and crisis leadership, especially in a time where more accountability is being placed on their shoulders.

Adding to the interactionism of the interpretive approach to case studies is the political theory called Miles’ Law. Rufus E. Miles, Jr. was an assistant secretary for three United States Presidents: Dwight D. Eisenhower, John F. Kennedy and Lyndon B. Johnson. His law stated that "where you stand depends on where you sit." Miles postulated: "We see things and form judgments of things from our own perspective. We need to discipline ourselves to see things from other's vantage point” (McKinney, 2008). Similarly, how crisis leaders and crisis managers form their own definitions and understand their own roles (and perceive that of the other group) could also establish the relationship dynamics (symbiotic, independent, or otherwise) between crisis managers and crisis leaders at universities.

The main method of analysis for the study was modified analytic induction. Because a goal of this study was to find commonalities between the presidents' thoughts on crisis leadership, while also keeping in mind that there could be vast differences, this procedure allowed for in-depth data collection and analysis. This also tied well with the 
decision to use purposeful sampling as it is the sampling method used in analytic induction (Bogdan \& Biklen, 2007).

\section{Role of the Researcher}

The impetus behind choosing crisis leadership as my dissertation topic was 3pronged. I must first start on a personal level. On November 14, 2004, two FIU students (one, a member of my sorority and the other, a member of a fraternity - but both friends

of mine) passed away from carbon monoxide poisoning while they were talking inside a car. As the incoming president of my sorority, I was charged with organizing remembrance vigils, forced to conduct media interviews, and thrown into caring for 100+ women who were now under my leadership. At 22, I was ill-equipped to handle so much responsibility. No doubt, it reframed my collegiate experience in a way few could understand.

A week after their passing, I began working for FIU's Office of the President. Throughout my 10 years in the office (from 2004 through the time this was published), I had seen my bosses (formerly President Maidique, and currently President Rosenberg) deal with a lot of different crises. As an observer of or participant in all of their decisions, I had definitely grown professionally. My unique vantage point gave me an exclusive perspective into the pitfalls and opportunities of crisis leadership in higher education.

Lastly came my academic experiences. Towards the end of my doctoral coursework, I took a class called Crisis Management in Higher Education. The course was taught by our Dean of Students, Cathy Akens, and it gave me an opportunity to explore the CM field in greater detail. Through a class assignment where I analyzed the Bonfire incident at Texas A\&M in 1999, I found that my interest in crisis management 
had increased. The next semester when I was tasked for another course to commence this study's literature review, I was able to delve deeper into the crisis management and higher education literature. During this time, I learned about the lack of empirical research in this arena. After consulting with my boss, President Rosenberg, about my dissertation research options, I decided that with my personal and professional experiences, my direct contact with university presidents, and the need for expanded research on crisis leadership in higher education, there was a niche in the literature to which I could contribute.

In further preparation for this study, I participated in four trainings that would contribute to researcher credibility. The first, required by the University Graduate School, was the Institutional Review Board (IRB) training in social and behavioral sciences research. This course offered me the foundation needed for the appropriate conduct of human subjects' research in my field. The other three were FEMA certification courses: Active Shooter (IS-907), National Incident Management System (NIMS) An Introduction (IS-700.a), and Introduction to the Incident Command System for Higher Education (IS100.HE). Though voluntary, these FEMA trainings provided me a strong bridge between the literature and the real-life processes that public universities go through. Specifically, since all SUS universities are required to follow NIMS protocols for emergency management, this procedural knowledge became useful during the participant interviews (especially when meeting with the crisis managers from emergency management departments).

Additionally, I also participated at my home institution’s quarterly tabletop exercises through the data collection and analysis period of this study. These gatherings 
are meant to simulate real-life scenarios, test how the administration would respond, and analyze if there are any gaps in communications, resources, and/or operations that the university should address. I attended tabletops on a hurricane, chemical spill, cybersecurity breach and protest. Like with the FEMA trainings, these helped provide me contextual familiarity with the terminology, personnel, and operations of a crisis management system.

\section{Participants}

Purposeful sampling is a key characteristic of case studies. The particular unit of analysis is selected out of the researcher's interest in the topic, but "depends upon what you want to learn and the significance that knowledge might have for extending theory or improving practice” (Merriam, 2002, p. 179). Because of the scarce empirical research available on crisis leadership in higher education, it was important to select university presidents and crisis managers as the participants for this study. However, because states and institutions differed so variably in their educational policies and procedures, it was best to narrow the pool of possible participants so that the data could more easily be accessed and analyzed.

The State University System of Florida (Figure 8), which was chosen as the sample for this study, boasted 12 universities. According to the Florida Board of Governors’ (BOG) 2013-2014 Accountability Report (the most recent version available at the time of this study's publication), the System served close to 338,000 students; 77\% being undergraduate students, 18\% graduate, and 5\% as unclassified (i.e., non-degree seeking, dual enrollment, etc.). Total degrees awarded for the 2013/2014 academic year totaled over 83,000, and the system employed over 62,000 full-time and part-time 
personnel. The SUS's diversity in population, infrastructure and mission were the reasons it was selected as an appropriate sample, so that it could be representative of current public university systems in the United States.

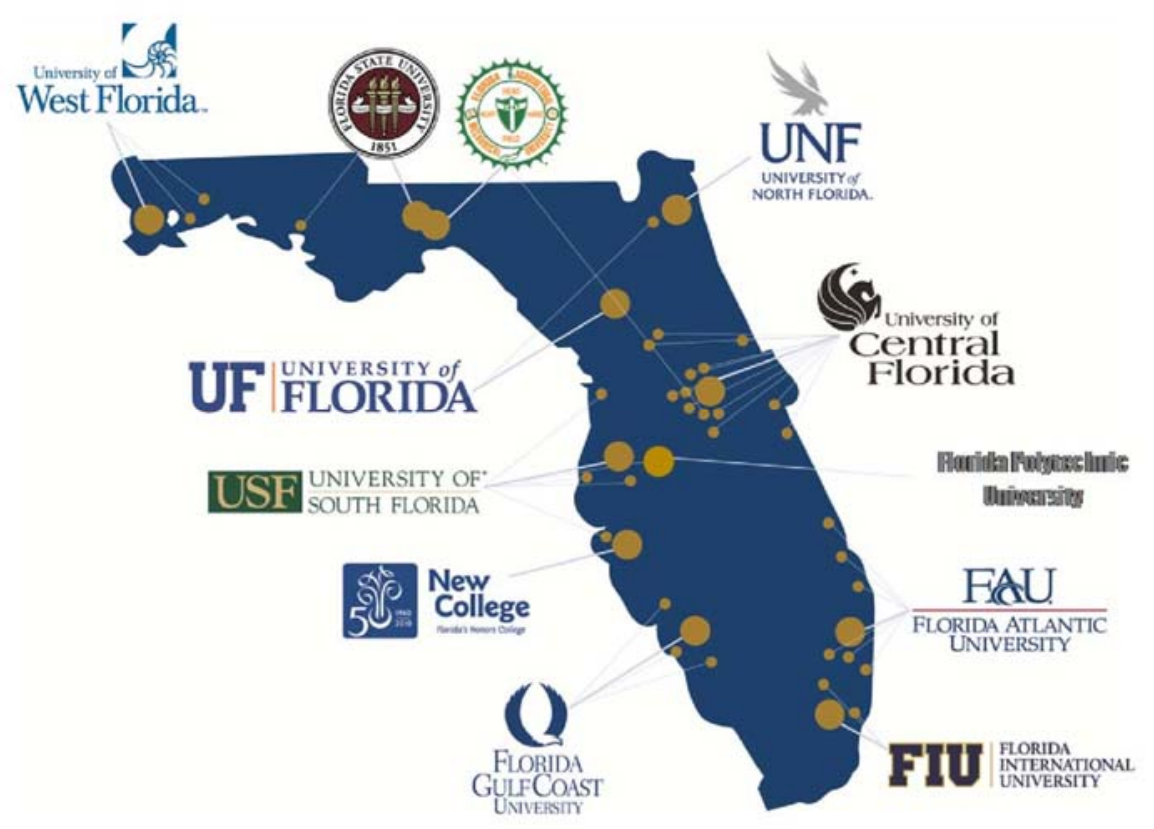

Figure 8. Map of the State University System of Florida.

Since only the SUS was selected for the study sample, it is important to clarify why not all universities in Florida were selected for the study. Because private institutions tend to have more academic homogeneity and are not always required to follow federal and state policies on safety and security (e.g., NIMS protocols, federal reporting, etc.), including them in the sample simply did not meet the study's scope and participant criterion.

The following list (in alphabetical order) summarizes each of the 12 SUS institutions who were asked to participate. All enrollment numbers listed were based on Fall 2013 data (which was the academic term used in the BOG's last published 
accountability reports) and rounded to the nearest 1,000. Cities and acreage were included for each university because of one of the sub-themes ("size and location”) that came out in the findings.

Florida Agricultural and Mechanical University (FAMU), with 420 acres of land, was founded in 1887 in Tallahassee. Their enrollment was 11,000. Their newest president, Elmira Mangum, was confirmed by the Florida Board of Governors in February 2014. Until then, Larry Robinson had served as interim president after a very public band-related hazing incident forced former president, James H. Ammons, to resign amidst the scandal in 2012. Going into data collection, I was cognizant that this interview would be difficult to obtain because of FAMU's cautiousness to discuss any matters related to the band. Proposed approaches on how this sensitive matter was handled is discussed further in the Research Design and Limitations sections.

Florida Atlantic University (FAU), with 850 acres, was founded in 1964 in Boca Raton. Their enrollment was 31,000. John W. Kelly was elected the university’s new president in January 2014. Their outgoing interim president, Dennis Crudele, who was the university’s Chief Financial Officer, took over after the university’s sixth president, Mary Jane Saunders, resigned amidst several controversies related to faculty, students and donors.

Florida Gulf Coast University (FGCU) was founded in 1991 in Fort Myers with 760 acres. Their enrollment was 14,000 . Wilson G. Bradshaw is their $10^{\text {th }}$ president, serving since 2007.

Florida International University (FIU) was founded in 1965 in Miami. With two main campuses, they lie on 573 acres. Their enrollment was 53,000, making them the 
fourth largest public university in the country and the second in the State of Florida. Mark B. Rosenberg is their fifth president, serving since 2009.

In 2012, the Florida State Legislature created Florida Polytechnic University (FPU), the SUS's $12^{\text {th }}$ institution, with 138 acres. This establishment, hence, dissolved the University of South Florida's polytechnic campus. Florida Polytechnic resides on a new campus in Lakeland and opened for classes on August 25, 2014. Randy K. Avent is FPU's founding president. Because they were still building their infrastructure, it was decided prior to data collection that no FPU crisis managers would be contacted for interviews.

Florida State University (FSU) was founded in 1851 in Tallahassee with 475 acres. It serves as one of the two flagship institutions for the State. Their enrollment was 41,000. Eric J. Barron was their $14^{\text {th }}$ president, serving since 2010. However, news shocked the SUS when he unexpectedly announced in February 2014 that he accepted a job offer from Penn State to become their president. FSU provost, Garnett Stokes, took over as interim in April 2014 and served until John E. Thrasher took office in November 2014. The timing of this transition, and the on-campus active shooter incident (both having occurred amidst this study's data collection), added some unique challenges to participation. Details are discussed later in this chapter.

New College of Florida (NCF), with 144 acres, was founded in 1960 in Sarasota. Their enrollment was just under 800 students. This low number is because they focus solely on undergraduate liberal arts degrees. Donal O'Shea is their fifth president, serving since 2012. 
University of Central Florida (UCF) was founded in 1963 in Orlando with 1,415 acres. Their enrollment was 60,000, making them the second largest public university in the country and the largest in the State of Florida. John C. Hitt is their fourth president, serving since 1992. UCF also boasts an Emergency Operations Center (EOC), a top model within the SUS.

Sitting on 2,000 acres (the most of the entire SUS), University of Florida (UF) was founded in 1853 in Gainesville. It serves as one of the other flagship institutions for the State. Their enrollment was 50,000. J. Bernard Machen was their $16^{\text {th }}$ president, serving from 2004 through 2014. On January 1, 2015, W. Kent Fuchs became UF’s new president. The timing of this change in leadership, similar to FSU, caused some scheduling challenges that are also addressed later on.

University of North Florida (UNF) was founded in 1972 in Jacksonville. Their enrollment was 16,000 with 1,300 acres. John A. Delaney is their fifth president, serving since 2003.

University of South Florida (USF) was founded in 1956 in Tampa. Their enrollment was 48,000, with 1,913 acres (the second most in the SUS). Judy L. Genshaft is their sixth president, serving since 2000.

Lastly is the University of West Florida (UWF). They were founded in 1963 in Pensacola. Their enrollment was 13,000 with 1,600 acres. Judith A. Bense is their fifth president, serving since 2008.

These SUS presidents comprised a potential sample of 12 participants. However, the sample also included each president's crisis managers. Some universities had a decentralized crisis management system where student incidents and disaster 
management (for example) were overseen by different administrators. Those more “technical experts” (Rubin \& Rubin, 2012, p. 176) offered the study a unique perspective into how, if at all, they believed presidents fit the role of a crisis leader and why and how those perceived roles played a part in creating the appropriate institutional culture of safety, security and preparedness.

In searching online, it was quickly evident that each institution defined the role of crisis manager differently. Therefore, it was difficult to locate the appropriate person(s) on each campus who had the most relevant oversight to crises as defined in this study. Not only did they all have different names (e.g., Safety Officer vs. Director of Emergency Management) and reported to different administrators (e.g., some police departments were under Student Affairs while others were under Finance), but each university divided their oversight for crisis management differently (e.g., Chief of Police for injuries, Director of Facilities Management for building incidents, Dean of Students for personal matters, etc.). In other words, each university potentially had more than one crisis manager (as defined in this study) available for interview. As to not miss any key participants or offend anyone by my assumptions that they would be suited for my study, I sought the assistance of two colleagues to participate in a pilot study: Cathy Akens (FIU Dean of Students) and Amy Aiken (FIU Director of the Emergency Operations Center). Details on their insight is described in the Data Collection section of this chapter.

Prior to the pilot study, there was an initial proposed sample of 23 participants (one president and at least one crisis manager for each university, except FPU whose president was the only one to be included). There was, of course, no guarantee that all proposed participants would be willing or available to meet. For example, it was posited 
that with so many presidents new to their posts, a request of this nature would be at the bottom of their priority list; and it was understood that the scope of the research could change dramatically if no president would agree to an interview. Therefore, extra effort was placed on confirming presidential participants.

\section{Data Collection}

The method for seeking interviews with the presidents and crisis managers was intentionally different given the idiosyncratic challenges in scheduling interviews with persons in their positions. University presidents, of course, are extremely busy and require special effort in getting past their "gatekeepers” (Seidman, 2013, p. 47). Crisis managers, on the other hand, could be difficult to locate given that each university classified their roles/titles differently.

\section{All Participants}

Each interview was what Rubin and Rubin (2012) called semistructured. In other words, there was a limited number of pre-determined questions while allowing the nature of the conversation to specify follow-up questions as necessary. An outline of these questions was generated from a pilot study, which was meant to help "refine [the] data collection plans with respect to both the content of the data and the procedures to be followed” (Yin, 2009, p. 92). FIU Dean of Students, Cathy Akens, and FIU Emergency Operations Center director, Amy Aiken, were selected as the participants in the pilot because of their expertise and my professional relationships with them. Though they were pilot participants, their interviews were included in the final findings described in the next chapter. 
The initial interview protocol (see Appendix A) included six joint questions (i.e., questions that would be asked of both the presidents and crisis managers). This list had three questions related to how each participant defined crisis, crisis management, and crisis leadership; and an additional three questions about their perceptions of what roles presidents and crisis managers play prior to, during and after a crisis. Participants from each group (i.e., presidents and crisis managers) then had one additional question posed to only them.

Akens and Aiken both offered detailed feedback to the proposed questions, especially in how best to reframe the questions. They also provided good insight as to being careful when choosing certain terminology with certain groups. For example, Akens proposed I change an initially planned use of the word “top management” to clearly stating “president” so as to not confuse the participant in thinking I was including university vice presidents into that group. Another example was when Aiken noted that reporting structures vary so much in her field that I needed to be sensitive to how I framed certain questions about leadership.

Once the pilot interviews were completed, there was a clearer direction for the proposed interview questions and edits to the interview protocol were made accordingly. Subquestions were also created to the initial six joint questions so that there was room for follow up questions depending on how participants responded. I also added two questions for each participant to answer. The first was asking them to describe their biggest challenges. The second was for them to list their "wish list" for their position, assuming there were no political or financial restrictions. At the end of each participant interview, at the recommendation of Akens, it was also decided to show them a copy of Zdziarski et 
al.'s (2007) “Crisis Matrix” (Figure 4). Showing this image allowed me to tie it back to the start of the interview (i.e., defining crisis) while also emphasizing the purpose of the study once more.

A few questions were also added specifically for each group. For crisis managers, questions about their reporting structure and duties as well as what trainings/certifications they and their teams received were included. For the presidents, three targeted questions were included. The first related to crisis managers, and who the presidents perceived to fit that role on their campus. This was a topic recommended by Aiken. The second question was linked to their accountability. After the incident at Penn State, university constituents (i.e., faculty, alumni, parents, etc.) began to place a greater burden on presidents to be aware of all potential risks for the university and address them immediately. The new question aimed at seeing how presidents felt about that perceived added role. And finally, I asked the presidents for their thoughts about an article from The Leadership Challenge that described the Five Practices of Exemplary Leadership. Each practice (Model the Way, Inspire a Shared Vision, Challenge the Process, Enable Others to Act, and Encourage the Heart) with a brief synopsis was read aloud to them one by one, and they were asked to respond to what extent they agreed or disagreed.

Once the interview protocol was finalized (see Appendix B), participants were contacted for an interview. This process is described in more detail in the next two segments. All participants were required to sign a written consent form (see Appendix C) prior to the interview. Each interview was voice-recorded. Field notes were taken to not only supplement the recordings, but also to keep track of new follow up interview questions. 


\section{Presidents}

A contact list for the 12 SUS presidents was pulled from the Florida Board of Governors. Each president and his/her scheduling assistant was initially contacted via email. All requests included an introduction of the researcher and study, a copy of the study's 5-page abbreviated proposal, and the requested parameters for the interview (i.e., length of interview and requested interview deadline). Five universities initially responded, all agreeing to participate in the study. After one month's time, a follow up email was sent to those who had not yet responded. Two more confirmed participation, but one subsequently cancelled because of the presidential transition that was occurring at his university.

Each president who agreed to an interview had the option to select a one-time, 2hour interview that would take place in-person, by video-conference or via phone interview. Having been a scheduler for two university presidents myself, this structure was set based on my own experiences responding to students asking my boss to participate in their research projects. Rarely were there times when meetings ran on schedule or as planned. Delays occurred, interruptions happened, meetings were shortened, and tangent conversations were commonplace. The person meeting with the president often left with only a fraction of his/her discussion items met. The scheduler would then then forced to find time to schedule yet another meeting in the president's already full calendar. Therefore, I had intentionally added 30 minutes to my proposed interview timeline so that there were minimal negative effects to the president's schedule and/or my interview goals. 
Though in-person interviews were the preferred method of data collection for this study, it was understood that the presidents’ schedules constantly fluctuated. Sometimes, conducting an interview while the president is being driven to his next meeting or while traveling - though not optimal for the interviewer - would be the only time they actually had to participate in an uninterrupted conversation. Therefore, limiting the interviews to only in-person could have reduced my sample size, simply out of the presidents' unavailability. This thought process was supported by Rubin and Rubin (2012) who noted that "elites may give you relatively short, one-time interviews" (p. 175), so it was imperative to take advantage of all possible options for data collection.

Luckily, all presidents who agreed to participate also agreed to meet in-person. This meant that I traveled to their respective universities for the interview (with the exception of one who asked to meet during a Board of Governors meeting). All travel costs associated with these interviews were incurred by me. One presidential interview was my home institution, so no costs were incurred for that meeting. Two more interviews were within driving distance, and the remaining three interviews required flights (with three of these five also requiring hotel stays).

At the start of each interview, the written consent form was presented. A summary of IRB regulations was reviewed. Of importance here was the promise of confidentiality and anonymity. "Maintaining confidentiality of information collected from research participants means that only the investigator(s) or individuals of the research team can identify the responses of individual subjects” (IRB Website). However, because this dissertation was a case study with university presidents, who are all considered public figures, it was impossible to guarantee confidentiality or anonymity. 
Though this study is considered to have minimal risk, the presidents were informed about this limitation up front. Participants were also informed that they could stop the interview at any time if they felt the line of questions made them uncomfortable and/or they needed to address a pressing matter for work.

All presidential participants committed to the full allotment of time, so the 30minute time buffer that was added to the interview request was not necessary. Each interview lasted around 70-90 minutes. After each visit, the signed consent form and field notes were securely stored in a locked filing cabinet. All corresponding voice recordings and other relevant electronic files were saved to a password-protected computer purchased solely for this study’s data, and also backed up on an external hard-drive that was kept in my campus office.

\section{Crisis Managers}

The interviews with the crisis managers were structured similar to that of the presidents: a one-time, voice-recorded, 2-hour interview. However, the method for scheduling differed from that of the presidents in two ways. The first was that the crisis managers were not offered a phone or video interview. The crisis managers were not contacted for interviews until after their respective president confirmed participation. Therefore, their emailed request listed the date that I would already be on campus. Using this method showed each prospective participant that the study was being taken seriously by the leadership, which assisted me greatly in confirming all of the participating presidents' crisis managers for an interview. The second difference was that some of the crisis manager participants were gathered through snowball sampling (Bogdan \& Biklen, 2007) instead of purposeful sampling as was done for the presidents. 
During the pilot study interview with Akens, she provided me a list of names and emails for all of her counterparts (i.e., Deans of Students) across the SUS. Aiken, on the other hand, advised that her counterparts would be more difficult to track down as titles in their field varied greatly. She thought it best for her to email her colleagues across the SUS to see who would first be willing to participate after reading a summary of the study. In this case, much like the schedulers to the presidents, Aiken served as a gatekeeper to the SUS crisis managers. She forwarded me all email acceptances to which I responded via email thanking them for their agreement to participate. In my email to them, I noted that I would follow up to schedule an interview as each of their university president agreed to participate.

After conducting the pilot study, the goal for crisis manager participants was to get two for each school, one from Student Affairs and one that dealt with Emergency Management. Given the inconsistent reporting structure for university personnel who deal with crises, it was important to collect data from crisis managers throughout the hierarchical spectrum. Based on this plan, and the total number of universities, there was an initial sample of 22 crisis managers (i.e., two per university, with the exception of FPU). It is important to note that no law enforcement or health personnel were included in the sample. This was intentional as the literature (and also confirmed during the pilot study) considered them more of crisis responders than managers.

Using the aforementioned tactic of contacting the crisis managers after their president had confirmed, all crisis managers who were contacted for an interview accepted to be participants. Therefore, based on the total number of presidents who 
agreed to participate (6), including the two pilot study participants who had already been interviewed, there was a total of 10 crisis manager participants.

At the start of each interview a synopsis of the confidentiality and anonymity issues was provided. Unlike the presidents, the public has little knowledge of who crisis managers are or what roles they play. However, given that all SUS institutions are subject to Florida's Sunshine Law, their information could be found with enough research. Hence, the crisis managers were also treated as public officials and were not offered confidentiality or anonymity.

\section{Data Analysis}

After each interview, the voice recordings were professionally transcribed by an online company called Rev. Since transcriptions are never 100\% accurate, all transcriptions were read through once with the sole purpose of correcting any typos made by the transcriber as well as any improper syntax or grammar used by the participants. These were manually corrected. Field notes were then added into the transcriptions, as needed.

Both a posteriori and a priori coding methods were used in developing initial categories (Bogdan \& Biklen, 2007). As each interview was analyzed, "certain words, phrases, patterns of behavior, subjects' ways of thinking, and events [were repeated and stood] out” (p. 173). For the presidential interviews, since each were asked for their thoughts on the Five Practices of Exemplary Leadership, these codes were created prior to transcription. Examples of some initial codes were "campus-specific highlights," “research verification,” and "leadership qualities.” Throughout analyses, these codes were listed throughout each interview, and subsequently grouped to form larger themes. 
These updated coding categories were bundled into an index at the end of each interview, and then compared to all other interviews conducted. As code comparisons and differences began to appear between interviews, the coding categories and themes were further refined. For example, “external partnerships,”, “cross-departmental meetings,” and "internal partnerships" were all bundled into a Teamwork and Collaboration category. This process continued until all scheduled interviews were conducted. Once the analysis for each participant was complete, the coding themes were cross-analyzed across each group and between participants once more. A total of 14 thematic categories were formed. After even more modifications, the themes were then richly described in order to answer the study's three research questions.

Though no confidentiality or anonymity was given to any study participant, each president and crisis manager was still assigned a pseudonym. Originally, each participant was a study code. This assignment was given based on their position and the order of when they were interviewed. For example, the first president interviewed was classified as President 1, or P-1, and the third crisis manager interviewed was Crisis Manager 3, or CM-3. After these were assigned, each study code was transferred into name (see Appendix D): CM-1 became Carlos, CM-2 became Amir, CM-3 became David, CM-4 became Toby, CM- 5 became Mitch, CM-6 became Rhashad, CM-7 became Bradley, CM- 8 became Pearce, CM-9 became Andrew, CM-10 became Jeremy, P-1 became Jose, P-2 became Ralph, P-3 became William, P-4 became Julian, P-5 became Martin, and P-6 became Josiah.

Additionally, since there were only three female presidents in the SUS and a handful of female crisis managers, there was a concern that use of the female pronoun 
would more easily identify those participants. Therefore, all participants were assigned a common pronoun - taking the one of the majority of the participants (i.e., masculine). Twelve of the 16 study participants were male, and hence any reference of "she" or "her" or were changed to "he" or "his."

Each university was also assigned a study code for the instances when institutionwide matters were addressed in the findings. Universities were labeled following a similar standard as with the participants (i.e., order of when university was visited). For example, U-5 was used for the fifth university where a participant interview from that institution took place.

The latter three points, though not necessary, were intentional. Each reduced the probability (of course, only to the extent possible) that readers would automatically connect responses to a specific participant or university. This helped avoid that the readers would develop their own assumptions about the participants' leadership style and culture of the participants’ universities. While not all participants minded having their names included in the study, it was decided to take an "all or nothing” stance. Since some participants did prefer the use of pseudonyms, then all participants were assigned one.

\section{Data Integrity}

Guba and Lincoln (1981) proposed four criteria for evaluating qualitative research and enhancing trustworthiness: credibility, transferability, dependability, and confirmability. Member checking occurred throughout the interview to ensure accuracy of the researcher's interpretation and understanding of the data. After an initial readthrough to correct any typos and redact sensitive or non-relevant conversations, all participants were provided a copy of their interview transcripts for further verification of 
the data. No participants provided any edits or feedback to their transcripts. As with all interview materials, the edited transcripts, codes and analyses were stored in a passwordprotected computer and also backed up in a secure portable external hard-drive.

As data collection and analyses progressed, the study's research design was improved in order to account for findings' conditions. After completion, drafts of this study were also shared prior to dissertation committee approval with colleagues who have experience with leadership and/or crisis management in higher education: Elizabeth Bejar (FIU Vice President of Academic Affairs), Cathy Akens (FIU Dean of Students and Associate Vice President of Student Affairs) and Nance Guilmartin (leadership consultant and international author). Their feedback on the overall structure and findings of the study contributed further to the study's trustworthiness.

\section{Limitations}

Rubin and Rubin (2012) discussed the difficulties of interviewing “elites”, or "those at the top of the social, political or economic hierarchy" (p. 175) - in this case, university presidents. They believed that this group may be too busy to take an interview or have no desire to agree to an interview. Outside of availability, there was also a concern about presidents participating openly during their interview (i.e., censor themselves). There were several methods implemented throughout the data collection process to avoid these pitfalls.

The first method was working through the presidential gatekeepers, or scheduling assistants, who were an important step towards the successful collection of data. The advantage in this scenario was that I used to be one of these gatekeepers. From 2008 to 2011, I served two university presidents as their scheduler. Also, though in a different 
capacity, I was still working for a university president throughout this study. Not only

was I sensitive to the challenges presidential assistants faced in trying to confirm meeting requests that were not relevant to university operations, but many of the schedulers that I used to work with were still in their positions.

Having those relationships in place, no doubt, enhanced the chance that their president reviewed my request. However, it did not guarantee it. Despite their best efforts, a couple of schedulers were just not able to make it work. One university president was amidst transitioning out, and had agreed to meet with me after the new president took office. Unfortunately, more pressing matters arose that forced multiple rescheduled meetings, which caused the interview to ultimately be cancelled altogether.

How universities, specifically presidents, dealt with crises on their campuses was another sensitive issue I had to address, especially given the scrutiny placed on leadership in recent years. Bogdan and Biklen (2007) made an important note on this matter:

When the trust level is low, when people are sensitive to particular topics, when there are strong barriers between insiders and outsiders, when the subjects feel they have a lot to gain or lose by what they say and with whom they speak, or when there are clearly delineated factions and subgroups, the researcher needs to tread with care. (p. 100)

For an institution like FAMU that had been severely guarded after the hazing-related death and the subsequent administrative resignations, it was integral for me to assure a safe environment for the interview. Therefore, the intended outreach strategy in requesting interviews was sensitive to those issues. Outside of the aforementioned items listed in the interview request correspondence, the interview requests included two key points: (a) no questions would be asked related to campus-specific incidents, unless the interviewee brought it up on their own and allowed for the topic to be included in the 
interview, and (b) if at any point, the interviewee felt uncomfortable with the line of questioning and/or direction of the conversation, he/she was free to ask for a topic change or stop the interview.

The combined issue of availability and timing came to light while I was trying to confirm the FSU president. Not only did their previous president abruptly depart, causing a lengthy presidential transition, they experienced an active shooter incident on campus during the data collection process. Between the scheduling demands of being a new president and the newness of the student injuries/death, it was evident that I would not get the interview.

Given these challenges with the presidents, in total, six presidents agreed to meet; two declined; and four did not respond.

In terms of researcher bias, a general concern of qualitative studies was what Guba and Lincoln (1981) referred to as "unusual problems of ethics." "An unethical case writer could so select from among available data that virtually anything he wished could be illustrated” (p. 378). One of the reasons that I assigned pseudonyms was so that I may use as much of the available data as possible without jeopardizing their jobs or relationships. Additionally, I did not believe that I had any biases that swayed the direction of the data analyses. Though I did realize that using my supervisor as part of my study could produce an uncomfortable scenario, we had spoken about my research enough that I believed the interview was taken seriously and handled professionally. Another potential bias related to the study's topic. Crisis management can, of course, be a difficult subject to discuss - especially when campus-specific examples are critiqued. The focus of the research was directed specifically to the definition of and roles 
in crisis leadership, not to analyze or judge a university's response to a previous incident. As such, I purposefully did not investigate any university incidents or the universities’ responses to them. Though slightly knowledgeable of some national or state incidents that were in the news, this unbiased perspective, I felt, offered me enough distance to not cloud the analysis of their responses.

The final limitation was the debate on the generalizability of case studies. According to Miles and Huberman (1994), a limitation of conducting case studies was that the results may not be commonly accepted for a larger population. Therefore, though results can be grouped into themes and a general understanding of the findings can be offered, they would argue that the findings of this study could not be generalized to all public university presidents and crisis managers across the nation. However, Flyvbjerg published an article in 2006 aimed at debunking this and four other "misunderstandings" about case studies. Specifically related to the generalizability of case studies, Flyvbjerg suggested the following:

One can often generalize on the basis of a single case, and the case study may be central to scientific development via generalization as supplement or alternative to other methods. But formal generalization is overvalued as a source of scientific development, whereas 'the force of example' is underestimated. (p. 12)

In other words, the supposed inability to generalize case studies to a larger population (in this case, generalize the SUS's findings to public universities across the nation) could be considered just a matter of semantics.

\section{Summary}

As far as the methodology is concerned, the study's theoretical framework was based on a basic interpretive approach, seeking how the participants made meaning of the 
crisis management phenomenon in higher education. The purpose of this dissertation was to better understand the phenomenon of crises on university campuses through the lens of crisis leadership. This study sought to learn how presidents and crisis managers defined “crisis” and "crisis management” on their campuses; how presidents and crisis managers used those definitions to structure their perceptions of crisis leaders, including themselves directly; and how those perceptions contributed to the campuses' creation and maintenance of a culture that supports crisis management systems.

Because of the scarce research available on crisis leadership in higher education, though, it was important to select university presidents and crisis managers as the sample for this study. Prior to outreach, an initial possible sample of 34 crisis leaders and crisis managers comprised this case study (i.e., 12 presidents plus 2 crisis managers per university with the exception of FPU). Given the sampling techniques and participants' willingness to participate, that total number was only an estimate. In the end, a total of 16 persons (6 presidents and 10 crisis managers) participated in the study. 


\section{CHAPTER IV}

FINDINGS

\section{Participants}

After contacting all university presidents, a total of six agreed to participate in this study. As noted earlier, one president declined outright, another president agreed but then regrettably declined after too many scheduling conflicts, and four did not respond to any interview requests. Of the university presidents who agreed to participate, two crisis managers from each of their universities, except for FPU, also agreed to participate. No crisis manager from FPU was interviewed because the university was still building their infrastructure and did not have anyone in the role of crisis manager (as defined in this study).

Of the two crisis managers from each university that were interviewed, one was from the field of student affairs and the other from either emergency management (EM) or environmental health and safety (EHS). Student affairs was selected for their direct involvement with "human” crises, specifically those involving students. As David put it, their job "is the people side." EM and EHS were selected because of their experience in managing campus emergencies and disasters. In the instances where both an EM and EHS department existed at a university, EM was chosen as the participant since they were more aligned with how crisis and crisis management were defined in this study. This brought the total number of study participants from all units to 16 (see Table 1). 
Table 1.

Study participants listed by title

\begin{tabular}{llllll}
\hline & President & $\begin{array}{l}\text { Vice Pres. of } \\
\text { Student Affairs }\end{array}$ & $\begin{array}{l}\text { Dean of } \\
\text { Students }\end{array}$ & $\begin{array}{l}\text { Director of } \\
\text { Emergency } \\
\text { Management }\end{array}$ & $\begin{array}{l}\text { Director of } \\
\text { Environmental } \\
\text { Health \& Safety }\end{array}$ \\
\hline $\begin{array}{l}\text { Total } \\
\text { interviewed }\end{array}$ & 6 & 1 & 4 & 3 & 2 \\
\hline
\end{tabular}

It is important to note the multiple titles for crisis manager participants. For the Deans of Students who were interviewed, three of the four held additional titles (e.g., Assistant Vice President, Associate Vice President, etc.). This was dependent on how the university’s reporting structure was framed, which is discussed later in this chapter. Some Directors of Emergency Management had variable titles (e.g., Director of Emergency Operations), and some Directors of Environmental Health and Safety held supplemental roles (e.g., University Safety Officer).

Crisis managers from schools that did not have presidents participating in the study were not contacted. This was because one of the study's goals was to gain insight on how presidents and crisis managers worked with each other. For comparative purposes (in the event that institutional idiosyncrasies were discussed during the interviews), it was important to have at least one participant from each group for each university.

As discussed in Chapter 3, each participant, though not promised anonymity or confidentiality, was assigned a pseudonym. These aliases were assigned in date and time order of each interviews and then by a person's name. Each participant was also assigned a common pronoun to avoid the reader from easily identifying the participants or universities who had female presidents and crisis managers. When university characteristics like size, location and reporting structures were discussed, a similar date 
order pattern was followed for each university. Therefore, university study codes ran from U-1 to U-6. Any ellipses found within participant quotations note removal of repeated or excess words, and any brackets found were used to fix tense issues or to replace proper nouns (i.e., names, university-specific programs, etc.) with generic pronouns and/or references.

\section{Findings}

This part of the chapter outlines the data results from the 16 interviews conducted with SUS presidents and crisis managers. Throughout coding and analysis, several categories emerged. Those categories were bundled into five themes: Definitional Morass; Culture; Roles, Responsibilities, and Accountability; Resources; and Variability of Crisis. All thematic categories were richly described using the literature review as well as the data collected in the interviews. The findings will be later used in Chapter 5 to answer the study’s research questions.

\section{Definitional Morass}

Chapter 2 thoroughly described the nuances in trying to define the word crisis. Though a standard definition of crisis in the field of student affairs exists (i.e., Crisis Matrix - Figure 4), this study aimed at finding a common definition of crisis, crisis management, and crisis leadership within the context of higher education from the perspective of university presidents and crisis managers. The first three interview questions for each participant revolved around how they defined these three terms within their roles.

Crisis. All crisis managers were relatively consistent in how they saw crisis. Student affairs professionals defined it mostly under the terms of students (e.g., crimes, 
student deaths, etc.); environmental health and safety employees saw crisis more as environmental or facilities-related (e.g., storms, chemical spills, etc.); while emergency management folks viewed crisis more holistically, or cross-departmentally (e.g., active shooter, hurricane, fire, etc.).

Presidents, on the other hand, defined crisis on a larger scale. Their point of view matched that of Pauchant and Mitroff (1992) and Mitroff and Anagnos (2001). William believed crisis is "something that's catastrophic that has brought impact on the university community.” This stance was reinforced by the last three presidents interviewed. Julian stated that crisis was “campus-wide;" that "there are problems, but a crisis affects everybody in the whole institution in general." Martin felt that crisis was a "major abrupt disruptive challenge, probably implying personal or institutional harm that could be potentially long lasting.” Similarly, Josiah thought that crisis meant: “A situation that calls for resources beyond the ordinary. It is in complexity, size or seriousness beyond the routine. It calls for a level of response that's going to go across boundaries probably, organizational boundaries.” Ralph offered an additional stipulation to these points: "Anything that's significantly newsworthy, not in a particularly good way. ... Things that you can't anticipate.” This issue of public criticism is addressed later in the chapter.

As discussed in the literature review, Zdziarski et al.'s (2007) Crisis Matrix, has three axes: type (i.e., environmental, facility or human), severity (i.e., critical incident, campus emergency, or disaster), and intentionality (i.e., intentional or unintentional). This matrix was shown to each participant (with the exception of Mitch and Bradley who answered the first interview question of defining crisis by using the terms in the matrix) at the end of each interview in order to tie it back to how they defined crisis. 
Andrew called it "a very comprehensive model that would touch on any other situations that a university could or would face.” Almost all others agreed with this sentiment. However, there were three participants who had some concerns or comments about the matrix. Martin had a concern about the intentionality axis: "When I talk to people about these kinds of issues, basically, what I say is expect the unexpected. ... I don't like dichotomies, so I'm not comfortable with intentional and unintentional. ... I'm not too sure it's black and white is what I'm saying." We discussed the example that an intentional campus emergency can have negative unintended consequences, and hence, Martin was hesitant to accept that intentionality was on one axis with an "either or" quality.

Ralph went on to suggest that another axis should be added to the matrix altogether - likelihood:

I'm an analytics guy. ... Likelihood's a big one and when you start looking at what types of crises you could have, one of the things that's important to keep in mind is which ones have the most likelihood. ... Generally what you would do is you would do plots of likelihood versus impact. ... Then plan for the ones that have the highest likelihood and the highest impact.

Given Ralph's academic and professional background, it was important for him to be able to prepare his university for crises around the most likely scenarios. This belief is an example of the impact on culture, the next theme that will be discussed.

The third comment was from Jeremy who argued against the entire matrix. For him, in the world of emergency management, "State Statute 252 will give you definitions of what you should be looking at when it comes down to that type of thing." After our interview, I researched the statute, as this was not something I had previously looked into. In the Florida Statutes, Title XVII (Military Affairs and Related Matters), Chapter 
252 (Emergency Management), Part 1 (General Provisions), Section 34 (Definitions), the following terms are defined: disaster, catastrophic disaster, major disaster, minor disaster, division, emergency, emergency management, local emergency management agency, manmade emergency, natural emergency, political subdivision, and technological emergency. Given these specific definitions, Jeremy noted:

A lot of people have a hard time with that. They think a disaster and an emergency is the same type of issue but they really are different definitions. That's what I was saying with the crisis, that's a little bit different too because they don't really define what crisis is in here as well. This is how we've been doing things and this is how all of our plans are represented with these type of definitions.

Jeremy's structured thought process about definitions was unique, as he was the only study participant under the emergency management or environmental health and safety that referred to this statute, let alone incorporated it into divisional safety plans. No doubt his professional experiences contributed to his informed position on the matter.

Of all the responses, though, the most unique and intriguing came from Jose and Andrew. Both of them defined crisis as an "opportunity.” Jose believed:

They've got an expression in politics which is, "Never waste a crisis." The thinking is, use a crisis as an opportunity to energize and maybe do something you couldn't get done otherwise but for the crisis. I guess, again, this is one of those things that comes down to definitions. I think you always want to end up better after. You want to end up better every day so if a crisis can somehow make you better, make your team be more bonded, morale improved, an opportunity for more money or funding, training. You don't want to waste a crisis. You want to see if you can get something good out of it.

His sentiment was supported by Andrew:

It's an opportunity for us to look at our policies and our protocols and ourselves from a critical lens, and to make sure that at a moment's notice that we are nurturing, that we are supportive, that we are on message, that we do put our students first, and whatever that crisis may be - it could be an active shooter, in 
could be a natural disaster, it could be a single student incident -...that's an opportunity for us really to make sure that our students are taken care of.

On the topic of opportunity, David noted that sometimes “it takes something bad happening to get folks' attention; even when it comes to safety in general.” This is supported by Lerbinger's (2012) belief that “shock learning” is one of the most common forms of crisis decision-making, as well as Pauchant and Mitroff's (1992) premise that crisis management is much like "crash management" when change only occurs when things go wrong. This impetus, though it contributes to a reactive culture, is sometimes needed in order for support to be gained and resources to be allocated (both topics that are discussed in later sections).

This generally positive twist on crisis, though, was the complete opposite opinion of Pearce and Julian who both defined crisis as simply "trouble.” The dichotomy of these points of views I think was due in great part by their own experiences dealing with crises, which leads into the differing definitions of crisis management and crisis leadership.

Crisis management vs. crisis leadership. When setting up the interview protocol, the intention was for each participant to offer a separate definition for crisis management and crisis leadership. However, in some of the interviews, participants defined leadership by defining management, or vice versa. Amir, who came from the emergency management side, had cautioned about the challenges in defining crisis management:

Crisis management has a very different connotation and it almost feels like it's dealing with the students.

Because of the very siloed effect of it ... Because there's a lot of people on campuses that are doing Crisis Management, but they're doing it within their context and within their world. 
In other words, how certain units define crisis informed how crisis managers define their own roles in managing those crises. As such, I joined the responses into one category so that the comparative and contrasting analyses could more easily be understood.

Crisis management. Most participants saw crisis managers as the on the ground, action-oriented teams. This is in line with Mitroff's (2004) point about crisis management being more reactive in nature. Rhashad defined crisis management as "the people who are in positions to deal with the crisis when they occur.” For participants like Bradley, the lines between management and leadership were clearly defined:

The president may give a directive and then my job is to execute and make sure that those things are done. At the same time as a manager, part of my job is to manage up and to make sure that my boss has the information that he needs. He can provide the president with timely accurate information so that [he] can make the best decision that [he] can with the information that [he] has at the time. They are hand in hand but there is definitely a difference between management and leadership, philosophically, to people.

Andrew agreed:

Crisis management is the actual process that we go through until our campus community is back to some sense of normal operation. It is not a one-hit operation. It is not simply talking points. It is making sure that from start to finish, we check all the boxes, and that we move our campus back to a place where they are whole after that crisis has taken place.

That to me is crisis management. It's not only managing the actual crisis in that moment, but subsequently everything that comes thereafter for our campus community.

And so did Julian: "The management team really does the implementation and makes sure that the right people are notified, properly notified. That's how I see them. [Leadership] decides what to do and [management] carries it out.” Jeremy, though, advised that he felt crisis management, while different than crisis leadership, was specific to his role in emergency management. For him, crisis management is described by the 
phases of the Crisis Management Cycle (Figure 5). To this point, Jeremy added that collaboration across crisis managers in a university is also important:

I have to be the jack of all trades, master of none; but I need to know who those masters are, who the subject masters are. I pull up into the right environment and then they help us with the response and we help manage that. We identify objectives, goals, responsibilities.

Along these lines, for some, the roles of crisis managers differed from that of crisis leaders.

Crisis leadership. Defining leadership in crisis was a little harder for participants to define. They all agreed that leadership was critical, but who served in that role varied from participant to participant. Mitch agreed that there had to be someone "above the fray" who can think more clearly about the overall picture, but noted that presidents serve that role whether anyone believes they are or not: "Well, I think the higher up you are, the farther you are away from serving. You're basically a leader by definition. You've been given a role as a leader.”

For the most part, though, participants commonly viewed crisis leadership the way Muffet-Willett (2010) described crisis leadership, as a broader term where the president is not necessarily the sole leader (i.e., inclusive of the executive leadership). Julian made the following point:

At the top, the top leader - the president or the vice presidents - they really decide the direction, the tone, the face, the level of how bad things are, and the direction. ... Management implements that tone; that face.

Similarly, Josiah stated:

I'll go back to the old Peter Drucker thing. Management is doing things well; leadership is being sure you're doing the right things. ... If it calls for leadership and many crises do, then you probably get up into the upper levels of the administration. 
Josiah’s reference to Peter Drucker was complemented by Ralph’s perspective:

I don't think [crisis management and crisis leadership] are exactly the same. I think crisis leadership is what you do after it happens. I think there used to be a saying: "Managers do things right, and leaders do the right thing." That's different. I think a leader is doing the right thing and setting an example of how you deal with a crisis. Managing the crisis is ... making sure that you're effectively executing. ... Crisis management also, I think, has a connotation of risk management, which is also anticipating what some potential crises could be and having things in place that might allow you to more effectively manage them once they happen.

For William, “leadership directs the management.” As Daniels and Daniels (2007) noted, leadership is more about integrated, strategic direction while management is more about centralized, efficient systems.

Additionally, and as mentioned in Chapter 2, Muffet-Willett (2010) discussed how this top management is needed in order to avoid certain pitfalls like "ego" and "turf wars.” Bradley believed that none of these should be present during a crisis:

There's no room for ego when managing a crisis. It's like some people would want to be out-front or out with the credit for solving this problem. It can't be about that. It has to be about helping those people that are going through the tough time or difficulty. If it's about showing how well you manage that or didn't, then you're in the wrong business - because you take pride in your work.

William took a similar stance, and shared how his leadership style has been imbedded into his decision-making process: "What we had developed with my VPs now over the years is when you come in this room, we all leave titles and egos outside. The only ego needed in this room is [the university's].” Regarding this sense of equality, Jose added: “We’ve got some clearly defined roles. We also have a lot of overlap where our vice presidents feel fairly comfortable in stepping in another person's turf.” What these participants were trying to address was the point that having the institution's best interest in mind, especially when safety is of concern, must be the number one priority in crisis 
leadership. As William stated: "the leadership in a crisis has to go beyond just effective actions.”

Overlap of management and leadership. A few participants, however, felt that crisis management and crisis leadership overlapped. Rhashad thought that "it’s probably a shared thing among a lot of people.” Martin also believed that there was a "shared responsibility for student safety.” Adding to this notion, Andrew noted:

They actually bleed over, because crisis leadership is critical in any crisis type situation. The actual leadership who's taken ownership of moving us through that crisis has to be, well, competent; have to be committed; have to be very decisive. It's important that the actual leadership empowers every corner of the university to be engaged in the overall crisis management issue. I'm seeing too many institutions have a core group of people trying to manage everything, while everyone else stayed on the fringes looking lost, confused, disconnected. That's not crisis leadership.

Crisis leadership is making sure that to the best of your ability that you have educated, you have trained every corner of the university to say, "Listen, in a crisis, we're all leaders not because you're the president, not because you're the dean of students.” ... That to me is where I think institutions should continue to move when we talk about crisis management. How do we empower? How do we equip every corner of the university to have leadership pop up, top-down, grassroots level, and so forth?

However, to this comment, Jose described "leading and management as picking among a set of options.” He shared a quote from a Russian author named Anton Chekhov: “Any idiot can face a crisis - it’s day to day living that wears you out.” As Bradley put it, “a leader can be a manager and a manager can be a leader.” In other words, there is no real difference between leadership and management, which is contrary to the ideas of Daniels and Daniels (2007). To these participants, either way, there is a collective responsibility needed from all involved for success to occur. 
Conversely, Martin, while he believed it could overlap, felt defining both terms

was issue-specific:

If it's an issue that has an urgency that transcends planning, then leadership and management may be one in the same. If there's a longer lead time, then leadership and management should be separated. ... I don't think there's a bright line. I think it's a question of the intersection between the leader's perception of the seriousness of the matter, the urgency with which it must be addressed, and the capabilities and perceptions of the team that is designated to address them.

I think it's very situational dependent. ... A lot of that depends upon what the leader's tolerance levels are on one end and his personal sense or her personal sense of responsibility for the health and well-being of those who he or she is responsible for.

Seeger et al. (2003) and Klann (2003) held this same belief; that the quality of leadership can decide and control the extent of and response to crises. Toby, agreed that response and action all depended on the matter at hand:

One size just doesn't fit all. ... It really is a matter of organizing all the information, evaluating all the information, taking what you have, looking at the resources with which you can tap into, and then develop and respond to the situation that fits that situation the best.

Again, it's crisis management if you want to call it. That isn't a science. It's an art. You need to be able to put those factors together.

The variability of how leaders respond to and act in crises is something addressed later in this chapter. In sum, in trying to define these three terms, Jose said it best: "I guess it's going to depend on either the speaker or the listener how you mean each of those words.”

\section{Culture}

Some literature has noted that the institutional culture (i.e., demographics, location, history, etc.) is key in building a safe community, while others have posited that leadership sets that tone through their personal values and direct emphasis placed on safety and preparedness. During their interviews, all participants were asked about the 
creation and maintenance of such organizational cultures at their universities. The following categories fell under this second theme: size and location; communication; presidential values; and institutional values.

Size and location. When I visited each campus, I drove around the campus perimeter at the start of the day (morning), I walked to all of my meetings, and I drove around campus once more at the end of day (evening). I took note of all major entrances and exits, emergency call boxes, lighting, distance between buildings, and other security features. This was done not to place judgement on what the university had or was lacking, but so that I could better understand what it was like to be a student, employee or visitor on their campus should an emergency arise. This also allowed me to tailor my questions and frame my analysis related to campus size and location to each participant's university.

Of the six universities interviewed, four had what I would define as isolated locations. They were built outside of the city center and core suburb area and/or were also surrounded by nature preserves or farmland. When asked if their unique locations aided in keeping their university safer, and therefore sustaining a cultural infrastructure, Rhashad noted that their isolation "is a drawback in some areas, but...not being in that urban environment helps a lot.”

As noted by Julian, one of the positives to being isolated is the ability to shut down the campus during an emergency:

I think it helps us, and the reason is - when I look at other universities - there are so many entrances and exit points, it's impossible to control. I shut those 2 gates; it's over. You've got to cross that swamp to get to campus. So I love it, with restricted exit and entry. I can really close off campus easily. 
However, Mitch offered a different view to the benefits isolation offers a campus:

Well, you could make an argument that it has [helped with safety], so far. If you really want to be cynical about it, you could say we're a prime target for somebody to come and really do some damage, because we're so isolated.

Pearce agreed that a minimum number of entrances to a campus is a benefit, as mentioned by Julian. But similar to Mitch’s opinion, Pearce thought it was just as important for all crisis managers and leaders to understand the potential contrasting dangers:

Now on the flipside - when you are trying to evacuate campus say for a bomb scare or if something happens that we shut the campus down. [Thousands of] employees and all the students trying to get off at one time...becomes an issue.

As Bradley noted in his interview, we must all think about how those unique campus characteristics fit into an EOP - both as an advantage and a hindrance to campus safety and security.

Of the two universities that were closer to their city center or core suburban areas, Martin expressed caution regarding the openness of his university: "It's wide open. We have to hope against hope that our capabilities are able to identify when there may be situations of challenge. That's a function of training, breadth, and luck.” This comment tied to the overarching issue of size and demographics, and the idiosyncrasies they posed (i.e., institution-specific characteristics that can affect how crises are seen and managed), which was also a topic raised by participants.

When asked whether incidents have occurred on campus due to the surrounding community (i.e., crimes/dangers by non-university members), all six presidents identified some sort of issue occurring during their tenure. However, as Jose stated in his interview: "You know, for some reason, the denser the population, the higher the crime rate." To 
this point, William shared that he believed his university's low crime rate "is in large part because of our location.” He then added:

When we have prospective students and their parents come on campus, we underscore that. [Our university] has to be a destination and you just don't wander in here. You have to be coming here [purposefully]. That is a good thing.

In other words, according to Jose, U-1 and U-6 would then naturally be placed at higher risk for incidents to occur on their campuses than the other four universities represented in this study because of their location.

An additional challenge for universities, as discussed by Jeremy, is growth. The more universities expand within and outside their main campuses, the more susceptible they will be to incidents if emergency operations plans are not quickly adjusted to the increased size and new locations. The issues related to growth are discussed further under the fourth theme, Resources.

Communication. Silva and McGann (1995); Mitroff and Anagnos (2001); Klann (2003); and Fearn-Banks (2011) all addressed communication as being a critical component of crisis leadership. Though questions on crisis communication were not part of the presidents' interview protocol, ease of communication as well as the respective gaps were brought up by all participants at least once. All agreed with the aforementioned authors that communication is key. David stated: "Obviously the number one issue is communication. Staying in communication and being informed. There's two sides of that, staying informed and then communicating what you know to the right folks.” Jose added that the timing and accuracy of communications are also of importance: "Communication is critical. It's [critical] to the various audiences that you need to communicate with. ... You've got to respond. You don’t want to over respond, but you've got to respond in the 
correct way.” Open messaging channels, transparency and timeliness of decisions are all part of crisis communications. How presidents deal with this is detailed more in the next thematic category of "presidential values."

A few participants touched upon the ease in which they communicate across campus. Mitch noted that their small size helps them communicate effectively and efficiently during crises:

Because of our size, we're able to...pick up the phone: "What are you going to do? You got this. You've got that." ... We're not that stratified, so I have access to the president. I have access to the provost. Any time I need to talk to them. We're also going to be a first-name-basis campus. I can pick up the phone with the chief of police. He could phone to me. We can talk. We don't have to go through protocols to get down to talk to somebody.... That works effectively, and we know each other, because we're still relatively small.

Bradley agreed with this sentiment: "If we hear about something or we see something percolating, we try to give each other a heads-up.” And Toby (who was from Student Affairs) shared that despite the separate supervisors, he is "on the phone with the [police] chief every day.” The ability to have open dialogue and allow information-sharing definitely contributes to a culture of safety.

Other participants, though, referred to the communication gaps they must deal with at their universities. Martin made a transparent statement about what he believed his university was lacking:

Our communication networks in a crisis are very weak. ... We are comfortable with what we do in the Emergency Operations Center, but to what extent are the unit managers, department heads knowledgeable on what they really need to do, what kind of telephone networks they need, and how they're going to put Humpty Dumpty back together again if we get hit by a dirty bomb or some kind of major wind event or water event? I'm uncomfortable about what happens below. 
By "below", Martin meant those employees outside of the EOC participation list (i.e., administration, support staff and faculty). Interestingly, Martin was the only president who addressed real communication issues that needed to be fixed. This self-awareness likely comes from personal values and direct involvement in crisis management systems, which are both addressed in the next segment.

For the interviews with crisis managers, they were asked how communication worked during crises, especially when reporting out issues that may need the president's attention. Rhashad advised that he continuously reported things up to his supervisor, not just during incidents. His boss, in turn, would decide what raised to the level to the president: "I keep trying to push information up so they're aware of things that are going on. Because I think a lot of times, they are so insulated that they don't really know what's going on.” Bradley expanded on this issue of reporting up information. He believed that continuous information to top management can better prepare them for when an issue does have to go to the president:

Humans are humans and we naturally are filtering things. What one person may see as important, [another] may not think that that's important enough to make [it up the] chain, which could leave out a big chunk of information. Sharing information and talking about this emergency response team we're trying to build - that's the place where I think it can cut down on communication errors. It also enables the vice presidents and I to get so deep down into the weeds where they can make decisions at a larger 50,000 feet area of management that can inform [the president].... As the president, there's just so much going on. I do a lot of briefings for [the VP] and he'll give them to [the president], or I'll give [the president] assessments or numbers or trends or issues. I make sure that the appropriate people that interface with [the president] have that information so that it's ready for when [the president] needs them.

Therefore, as reinforced by Skinner and Mersham (2002), these crisis managers held that over-communication (i.e., sharing constant informing, not just when it involves bad 
news) is better for the safety and well-being of the university community than under-

communication.

Toby followed the same standard of informing his supervisors, but more so

because of the potential escalation of an incident:

I wouldn't say I elevate [matters], necessarily. I would say I inform. The reason I inform is whenever there's a possibility even of an incident on campus that might be newsworthy, [the VP] needs to know. The President needs to know. The Vice President for Public Relations needs to know. Because I don't want them to be caught in the sense, as I say, with their pants down. It's important that they know what's going on.

Specifically related to an issue that is "newsworthy", Bradley and Andrew, respectively, articulated how to handle those situations best:

Yeah, we have our internal operating protocol on how I'm filtering at the AVP level before they get to [the VP]. The directors are filtering things, but if it's going to make front-page above the fold of the paper, that's something that's going to go all the way up to [the president]. If it's going to be on the page six... [the president] is pretty good about hiring good people and trusting them to do good work too. This is a sign of leadership. You got to empower and trust the people. You got to train them and you got to trust the work that they're doing and that they're giving you good information.

You have to tread very, very lightly. ... [Police are] going to be very limited in what they can share and what they're going to share in the midst of an ongoing investigation. That's a part of crisis management. Then, as information is critical and sensitively handled, then you also have to be prepared to deal with the media. That's another piece of crisis management. When you talk about your actual leadership team, a part of that should always be ...your actual news team. They need to know what you know, and the university needs to be talking from the same script. That is important.

Bradley highlighted the importance of the leadership's ability to be accountable, while at the same time letting their crisis management teams do the work they were hired to do; and Andrew discussed the significance of all university officials speaking with one voice, 
while protecting the sensitive matters at hand. Both perspectives are valid points to consider in crisis communication.

For the interview with presidents, they were asked how they preferred to receive information. Jose shared the communication strategy he has with his direct reports:

I meet with our Vice Presidents. We schedule them three times a week: Monday, Wednesday, and Friday mornings. Usually one gets cancelled because I'm out of town or whatever. A required topic is if we have a violent crime, a sexual misconduct allegation, or hazing. We discuss every single one of those and what we're going to do and what needs to happen and the process. Then we've got a continuing schedule to go back over them. ... You get the various perspectives to make sure we're not dropping the ball on something.

Jose later noted, though, that he sometimes takes a middle ground when receiving information. He likes to be quickly informed of important issues, but only in true emergencies when a decision from him is required:

All of the VPs are direct reports. The Police Chief is not a direct report, but the Police Chief would also contact me [directly in an incident]. You know, you don't have to call between 9 PM and 7 AM unless you think there's something [I] really need to know or that it couldn't wait until the next day. Email is a wonderful thing too. You wake up and they've given a report. ... If there's something, "Hey, I need you to decide this" or "should we notify the board?" That's another little test to do a notice. You don't want your board to read it in the newspaper or see it on the news that night without you telling them first.

William advised that he prefers to be informed expeditiously. There was no concern from him on how or from who he gets information; as long as he gets it: “All of my reports about incidents that might rise to the level of crises or even tragedies, I get that information. I get it directly. I get it quickly.” Julian acknowledged that though he likes to remain informed and has no problems with being contacted by non-direct reports, it usually does not happen that way:

The first person to know is the person who can do something right now. ... Then I'm the second to know, either just to inform me that this is what happened and 
this is what they're doing, or we've got a stop-gap measure of "What should we do next?” But I'm usually not the first to know.

Josiah, on the other hand, prefers that his team handle the initial action steps and/or analyses before information gets to him. He prefers to have as many of the facts vetted by his team as possible before he needs to make a decision or offer a response:

I want to know from them, from the VPs or someone who knows from them, what they're best assessment is. We'll talk about it is; what we know now. I try to emphasize it. We need to be very mindful of what we know and what we're supposing.

From these interviews, it was evident that communication styles of presidents was all a matter of personal preference that has been formulated by their professional, academic and personal experiences.

Presidential values. Seeger et al. (2003) discussed four factors of crisis leadership (detailed in Chapter 2) and how those characteristics could affect decisionmaking. A president's character, or personal traits, has a lot to do with how he responds to crises. How much a president is involved or not involved in decisions, crisis response, or support can also contribute to the university's culture; specifically, how much importance is placed on these matters. All participants were asked how involved presidents are and should be during these events at their universities. The findings showed that presidential involvement in crises greatly depended on their own personal beliefs, values and experiences, which then framed their perspective on how to deal with crises.

Personal beliefs. Prior to the interview with the first presidential participant, I was exploring to see if there were any recent publications that I could use to further enhance my interview questions. I found a website called LeadershipChallenge.Com, 
which aims to "liberate the leader in everyone.” They teach people how to lead using their Five Practices of Exemplary Leadership: Model the Way, Inspire a Shared Vision, Challenge the Process, Enable Others to Act, and Encourage the Heart. Two of these practices coincided with two of Klann's (2003) three components to effective leaderships: clarity of vision and caring relationships. Gordon Meriwether, a retired Navy Captain and the Founder of The Uriah Group, a crisis leadership consultancy, wrote an article on the website titled "Leadership in Crisis" and how crisis leaders could incorporate these five practices. Towards the end of each interview (prior to showing them the Crisis Matrix), I asked all six presidential participants about their take on these leadership methods.

Modeling the way, or showcasing balanced leadership, was the practice that most resonated with the president participants. Jose offered his experiences with "inept" leaders:

We've all seen people that have lost it and they're sharp-tongued and quick deciding. That's why in a strange way, a crisis almost calms me down because I'm going, "Okay. I've got this much time frame to make a call. Let me make the best call I can." That means I need to make sure people are comfortable giving me input and I'm not being rash.

Ralph added that it was important to instill assurance of presidents’ leadership capabilities in others:

People have to have confidence in you, especially during a crisis. During a crisis the people you're leading have to be confident that you know exactly what you are doing - you know - how you are going to get them through.

William, Julian and Martin, respectively, all agreed that an appropriate level of calmness in crises was also very important: 
I think you need to be appropriately calm, cool, and collected. Sometimes a crisis requires not yelling or losing it, but to bring a different balance, if you will, to it. A right to, in my opinion, display a sense of urgency or a sense of urgency, as needed. ... I think that the way I would say is having the appropriate emotional equilibrium. Some of that might be exhibiting heightened emotion. I don't think the whole approach should be characterized by that, but the emotions should be appropriate.

I do think that it's important for me to remain calm. Never let them see you sweat; never let them see you cry. That doesn't mean you don't do it. Don't ever let them see you do it.

I think the most important quality as a leader is to remain calm. That being calm implies confidence, implies purposeful behavior, implies solution-centered decision making, and it also implies working with a sense of urgency. But not urgency that is unexamined. It's examined urgency.

While Josiah agreed with the latter three presidents' opinion on keeping stable emotions, he did add in an extra point about empathy: "People sometimes want to see some emotion, but they don't want to see you being ruled by your emotions. ... They don't want you to seem you've lost control.” For this first practice, it was clear that emotional self-awareness was an important characteristic for crisis leaders to have.

The second practice, inspiring a shared vision was about goals. Crisis leaders should always implement common objectives. Jose shared thoughts on this as part of his definition for crisis (i.e., early communication) in the previous section. For William, goals were something that should be shared prior to any crisis occurring:

I think that that shared vision should be clear before the crisis happens. ... We need to understand, going in, the factors that contribute to the decisions that you make. You don't start visioning in a crisis. You don't start assessing whether or not you all have this shared vision in a crisis. That should be done before. It should be actualized in a crisis. It shouldn’t be developed.

Julian believed the concrete reason behind a needed response was more important than an overall vision: "I think we need to keep our larger and practical, not vision, but purpose 
in front of our mind and not let people get distracted, because crises distract people.”

Martin and Josiah, on the other hand, felt inspiring a vision was the responsibility that each president has to keep the university safe:

I think that leadership has the obligation to define the situation to set the targets and to help with or guide the execution. ... People want to know, I think, that the leaders understand the situation. They understand how it impacts on the university's people.

Based on their responses, it was apparent that presidents preferred a more realistic, tangible approach to leadership as opposed to thinking in abstract plans. This, though, was contrary to Mitroff (2004) and Fearn-Banks (2011) who described that approach to be more in line with crisis management, not crisis leadership.

The third practice, challenging the process, was the ability for a leader in crisis to be flexible and adapt to the changing circumstances, which are also points made in Dressel's (1982) seven dimensions for decision-making. Martin’s point of view matched the perspective taken by other participants when defining crisis management and leadership; that there was a sense of shared responsibility:

I think there's [three] qualities. One, great listening skills and two is really good questions, being willing to ask good questions. Then to take corrective action if necessary. Great listening skills, one. Two, great questions. Three, willingness to take corrective, make mid-course corrections.

It's a shared responsibility asking great questions, but in the first instance, the principal has to have a commitment to, not just talking, but also listening and challenging and posting up good questions, so that those who are direct reports and others in the room also understand they have that same ... that it's a shared responsibility down the line, down the chain of command.

Josiah also expressed that adjusting the leader's course of action as more information comes to light was also important: 
You can't let process rule. It's a guide and if it breaks down and isn't functioning then you got to be able to step in and lead the formation of a better, another process.

You need to understand, if your preconception of the situation doesn't match the reality then you're going to have to alter your assumptions to match the living understood reality.

More insight on this practice is discussed in the upcoming segment of decision-making, as well as under the Variability of Crisis theme.

Enabling others to act is about effective partnerships and was the fourth practice. Responses to this are described in more detail under the "teamwork and collaboration" sub-section of the Roles, Responsibilities, and Accountability theme.

The last practice, encouraging the heart, touched upon the importance for leaders to take care of their own. Crises can take a toll on first responders and crisis managers, and that must not be lost on presidents. Jose shared a quote that one of his consultant friends shared with him once:

He said, "This is a time when the president almost needs to be pastoral to the employees in the workforce.” That you almost need to become a comforter and a shepherd. You need to help lift their spirits up.

Martin agreed with the unique role he has played in supporting those affected by crisis incidents:

You got to be in touch. You got to be in tune. That also means that you got to be in touch and in tune with yourself and I feel that your empathy is critical here and that empathy is probably the major factor in being able to understand your team where they're at and also to stay calm to ask good questions.

By empathy, that obviously implies that they're going to have really good listening skills. I think that's very important. The leader has to be able to maintain himself or herself in a really good frame of mind, alert, and not unintentionally send off contradictory non-verbal communications in particular. 
More on this topic is detailed in the support category of this section. The five practices, though not universal, are a good measure for crisis leaders. Each presidents' individual perspectives can tie into how they make decisions, offer a response and show support in crises.

Crisis decision-making. There are countless decisions made prior to, during, and after crises occur. Some may seem insignificant and happen almost instinctively, while others can be so major that they require group consensus. How much a president is directly involved in that decision-making process is what is discussed in this segment.

Josiah felt that it is not necessary for him to be involved in all decisions or response scenarios. His comment tied back to earlier comments made about communications and trusting your teams to act:

We've got two natural spokespeople for us there who are also very good at thinking through what needs to happen. They will typically involve me as little as possible. That is probably a pretty good rule.

If you think about how the public is going to respond especially if you - this is often the case - don't really have a full understanding of the facts. It's probably better that the president not be the one who speak because you're going to be held to your account for whatever gets said. I don't mean that I'm reluctant to take responsibility ... It's not that at all. We're just trying to think: "we're going to get through this as an organization.” If there's a chance that inaccuracies creep in, it may be better that the president not be the one who speak. However, if it's a really serious enough problem, inevitably the president is going to get involved.

For Josiah, there were clear levels of separation between him and some decisions. But to the point of an organization riding out the storm as a community, William believed that joint decision-making was also critical:

When we walk out of here, it's the cabinet that has decided to go this way. That's why I tell my VPs: "Leave it all here. Say what you have to say.” Once I've decided, you don't go out and say, "I didn't agree with that but he did it anyway." That doesn't help anything. 
Expanding on the notion of collaborative decision-making, Ralph added:

When my direct reports say "yes" too much I get upset at them.

[I] tell them that they have to start pushing back on some things. It's encouraged, and I think that it's the only way you really do leadership right. Not everybody knows everything, so I encourage it. I tell everyone, every organization I've been at, is that my goal is to never hire anyone that's dumber than me and therefore I expect everybody to be smarter than me and then to push back when they don't agree.

I certainly instigated a culture where pushing back and question[ing] things is appreciated. ... I think that being adaptable and being able to listen to other people's views on in it, but there is a point where, at some point, you have to make a decision.

Ralph worked best under teamwork and open communication channels, but also understood that group consensus was not always feasible when safety was on the line. William, like Ralph, also felt that his team should challenge decisions: "If you talk to members of my team they know that I strongly encourage that because I think that's how we get the most out of what we're doing."

Adding further to, and summing up well, the responsibilities each president has for making decisions, Jose shared:

In a crisis, usually you've got a time crunch. I don't mind them because what I'm doing is trying to assemble decisions, getting as many options as I can get picking. Because you don't have time to reflect and you don't have time to second guess and to research and to contact other people and get advice, you're just doing the best you can.

You've got to be willing to kind of challenge the convention. The more good options you can have developed or that you can develop, the better off you are. That means that you've got to keep making sure each step of the way that you're doing ... You're making the best decision or the best choice.

Jose’s point of view was in line with Silva and McGann’s (1995) opinion that an important piece of crises was the ability for the leader to respond and act quickly. In the 
end, when a person's or the university's safety and well-being are on the line, regardless of who makes the decision - whether it is the president directly or the president empowering his team to make the calls - a decision must be made.

Crisis managers were asked similar questions, but flipped on its side; in other words, how they viewed their president's involvement in making decisions. From a crisis manager's perspective, David understood that a crisis manager and a president play different roles in crisis leadership:

The way it works is the president, obviously, has the ultimate decision making authority but he doesn't play an active role on our team, incident command team or staff. He is advised on situations by the command staff, incident commander and or the chief of staff for his office. Then he ultimately makes the final decision like we're going to close the campus or cancel classes or whatever it might be. He's involved in those decisions. We're kind of the feet on the ground, the day to day operations and then we advise up through the command staff as to decision making.

Jeremy took a similar stance:

At the end of the day, the buck stops at the president. As [emergency manager], I have to make sure that we're making the right decisions on [the leadership's] behalf. Not just for them but for the university overall. Because if anybody at any level of that crisis leadership makes a bad decision, it's going to be somebody he's going to answer to, because eventually we all work for [the president].

... When it comes down to leadership, I understand my role and I also understand that at the end of the day, [the president] is going to make the final decision. What [the president] needs in order to make that final decision is going to be information, and it's my job to make sure that he gets the information he needs to make the final decision.

Decisions during crises come quickly. In order to make the best decisions possible, information from experts (i.e., crisis managers) is utterly important. The roles played by presidents and the university in crisis leadership are discussed in greater detail under the third theme. 
Crisis response. Crisis managers, by their job descriptions, are built to respond.

They are trained and paid to take immediate action and follow through post-crisis.

However, crisis leaders (i.e., university presidents) vary in their need to respond to a

crisis. Almost always they will be quoted in a press release or university message

(normally drafted by their media relations team), but rarely do they get in front of a

camera or physically visit those affected by the crisis. Contrary to this stance, Mitch

described his president as extremely involved with campus crises:

He’s very involved. He's a very sensitive person. He’s a very caring person. It's a small campus, still. He believes he should have a role in these things, and he's very good at it. He gets personally involved with the families. He goes and talks to them. He speaks to student groups.

Julian and Martin followed this same position during crises when it has affected student lives:

Almost always, I'll try to get to the hospital and offer some words of, if you can, comfort to the parents - to let them know we are concerned. ... It's genuine. It's not reflexive.

My preference would be to have contact. ... It is situational, but my preference is to give contact as I think that's the human thing to do; and to be aloof and to be distant is ... It's easier, but it's not the right thing to do.

Later in the interview, Martin elaborated on a specific incident that occurred at his university a few years earlier, and how he responded to the victims' family and the community:

I thought it was the right thing to do. Not to hide, be very direct. Be reassuring, because that was part of the purpose of the message to say, "This is a safe campus.” To express profound regret, dismay, but at the same time, be calm and provide reassurance that we were going to find that perpetrator on one hand, and also that the university would be okay.

There were people out there who second guessed - for about two years - my direct hands-on approach to some things. ... It's easier not to descend out of the bunker. It's easier not to show emotion. It's easier to be concerned, but only moderately 
engaged. It's a lot easier. You let somebody else carry that load. It's not the right thing to do, particularly if the buck stops with me, but there was a lot of second guessing. I think, in most instances, there would be under any circumstance, but you do what you think is right and you got to live with it.

Jose added that presidents have a lot of responsibilities on their plate, but agreed that they must never lose touch with the emotional aspect of the crisis: "You've got a million things you're thinking of. You're thinking of more than just someone that's hurt, but you need to always try to convey sensitivity.” From their perspective, presidents will be criticized regardless of what they do or don't do, how much or how little they respond. Bradley shared his opinion on the importance of leadership in crisis response:

Being someone that is engaged when we have those type of emergencies, that's the leadership, it gives you like I know “I'm here.” It's not just to check off a bunch of checks that I've done these things in an action.

Since there is no perfect way to respond, as with communication, how presidents directly respond to crises is a matter of their personality. In other words, if they value empathy, they will likely be more involved with their university’s crisis management system and response efforts.

Support. The fourth aspect of presidential values in crises is the support they show to their crisis managers. For crisis managers, only two participants felt they received the necessary support from the university’s leadership. The first, was Amir, who felt that not only his president's words, but also actions, spoke loudly:

The fact that we bring what we call the top 40 [university leaders], ...that it's mandated by the president, that's it's not [emergency management] sending out the email, it's the president wants this to happen, so people respond - it makes all the difference in the world. 
Outside of tangible support like training and funding, Bradley elaborated on when he believed the president would be involved at his university and how his president shows support in those instances:

There are levels of critical incidents, crises or emergencies. I think probably disasters and emergencies, those are going to involve our president because they are affecting the broader campus. If there is a student that has indicated suicide or ideations, but no threat of harm to others, that may be a crisis that I'm navigating as Dean of Students. [The president] may not necessarily need every minute by minute update of what is going on. That might stop at either me or the Vice President for Student Affairs or the [campus response group], which is our incident response team.... Where the leadership comes into play is say [the president] giving support and talking about the [campus response group].... Still, though [he] may not have [his] hands on every single critical incident, that leadership behind it saying "yes, I trust my staff, I empower them, I am briefed and updated as needed." Not micromanaging if there is a smaller issue on campus.

For him, presidents can also show symbolic support (as mentioned by Seeger et al., 2003)

to their crisis managers by enabling them to act.

From a wider perspective, Amir discussed the current subculture within

emergency management and how he viewed the relationship dynamics of support:

I don't feel that same commitment across the SUS. I think you're going to find out when you speak to the emergency managers. I'm thinking they're basically going to speak badly of their administration because - it's not like there's bad relationships by any means. I don't think the sense of priority is there than the way it is here, because they are university presidents or dealing with so many other things that at our level we're not even aware of and things that until you work in administration, you don't understand what the administration's going through.

He added:

[Presidents are] all going to "talk the talk", because they have to and because on some level they do understand it. Let me not, short change them. They do understand it, but that actual commitment, isn't there the way it is at all places. Let's just put it that way. It's not across the board. 
I think you're going to find that. And I think that's going to come out. You're going to hear that from some of the Emergency Managers.

There may be some - I don't want to use “bitter”, I think that's too strong of a word.

But there may be some frustration there. And, unless you have somebody fighting for your cause to the administration, somebody at a higher level, it's a tough fight. It's a tough, tough fight and you're just sort of going and going and going.

I think that's key and I think that, in terms of the micro-managing, ... I think it's about knowing the priorities of the institution and knowing some of the things that you don't necessarily want to make a priority, but you're forced to. And that happens when there's an incident.

In other words, Amir was implying that true support is only shown when an incident is occurring or has occurred because presidents then have no other recourse but to be involved. From Amir’s perspective, and as supported by Mitroff and Anagnos (2001), unless a crisis manager (and their department) has a champion within the leadership, it will greatly affect their department's worth amongst the university's priorities.

Institutional values. Outside the values held by presidents, there is also a sense that each university has its own set of beliefs and values regarding safety, security and preparedness. Sometimes this culture is created because of what the president values himself, other times via the community in which the university was established. Tying into the earlier sub-section on communication, Jose shared his opinion on creating a sense of open communication amongst his team:

One of the things I had the hardest time getting when I first got here was you want your vice presidents to feel comfortable in disagreeing with you and with each other and to not feel that if the President disagrees with them, or another VP disagrees with them, that they're belittled or shamed or they're in trouble. Or they may be getting demoted or they may be getting fired. You've got to create a culture of openness in there where people are not afraid to bring forth bad news. Where they're not afraid to say, “Hey, I know you're doing this. I think you're 
making a mistake.” Once you get that, when people feel that they're comfortable with that, you're miles ahead.

The notion of empowerment was described by Mitroff and Anagnos (2001) in the literature review, and is an example of a president's values being indoctrinated into the university's modus operandi. On the other hand, William underscored the value his university places on safety, which he noted in the interview was a value that was imbedded in the university prior to his arrival:

We pride ourselves on our low crime rate. ... Our philosophy is, and we tell this to parents, a safe campus depends on all of us. We do what we can, but everyone has to be responsible for the overall safety of the campus. They all need to understand that. Your own behavior, the behavior of others that you observe that is disruptive for the campus, all of us participate. That's easy to say but that's our philosophy about safety.

These institutional values, as touched upon by William, must be supported by the employee base and student body. Toby believed:

There has always been ... a pervasive sense [that you are a] member of the [university] community and you watch out for each other, and you respect each other, and you're civil towards each other, and all of those other things. ... I know when I do my crisis management workshop for new faculty and staff, I get in my soap box for a little while and say, "Here's how we keep the campus safe. We care about each other. We respond to each other.” ... There is a kind of pervasive "take care of each other" message on campus. ... I think that's why I have students calling me up and [expressing] concern about [other] students.

Martin felt the same way regarding Toby's opinion as to why students are open about their concerns:

I think you have to have a community that is certainly...caring and that can have essentially early warnings in terms of students at stress, as well as visitors who may be out of place. That's the second thing. I think as well, you have to have the confidence that if there are those issues that we got the skills to respond and to keep people safe. I think it's a combination of things.

Additionally, Andrew had the following take about his student body: 
I think overall, I'm very confident that our students are very cognizant of trying to be as safe as possible. ... I think for the most part that they make some very good decisions. ... I think that is also challenged by what I call the superman mentality, and that all of us have. That mentality is "Not me. It won't happen to me. I can take care of myself.” That sometimes positions us to let our guard down in situations where we normally wouldn't. ... We don't see danger in things the same way at 18 and 17 that we may at 22, 23, and 24. All of those things are a significant factor.

Josiah agreed with Andrew's perspective on the effectiveness of systems because of the current societal culture: “The other thing is now the kids don’t want email. You have a great system but if they ignore it or block it. They all feel invincible, immortal.” This awareness of strengths and weaknesses of their own communities is critical to building an institutional culture where everyone’s safety and well-being comes first.

Connected to the universities' values on safety, I received thoughts from both presidents and crisis managers on how they perceived the importance of preparedness. Outside of personal crisis response, one president (Ralph) expressed his stance on creating a culture of safety at his university and also discussed his plans to personally improve preparedness at this university:

I think there's certainly a difference between creating a culture versus preparedness. Although part of preparing is contributing to the culture - that we do that up-front. I'd say that they were related: create a culture of safety plus preparing for it. I think that maybe if you do the preparations, and you spend a lot of time on that, then that starts instituting a culture.

I think it's Peter Drucker that said that "culture eats strategy for breakfast every day." That's one of the really difficult things in higher ed or at companies or anywhere else: is that you can come up with a strategy, and it's the best strategy in the world, but if the culture of the organization doesn't support it you'll never implement it. That's one big advantage we have.

One of the things that we have on the list to do is a whole enterprise risk management study. ... We're putting a team together to go do at least some beginning risk management, crisis management, types of planning. ... It'll be driven by me, I think. We're small enough. The other thing is I'm hands-on 
enough. I'm an analytical person, so I like doing studies and things like that, so generally what's happened in these things is I'll just appoint a team and say "let's do a study." Then I'll work with them fairly closely.

The latter part of Ralph’s comments on preparedness tie back to his earlier suggestion of adding likelihood to the Crisis Matrix. It was clear that running assessments and being vigilant of risks is an important part of his leadership style. Complementing Ralph's point of view, Amir also talked about preparedness as well as the importance of that culture:

We want to create a culture of preparedness, meaning that whatever comes our way, we're going to be ready to respond to it. Whether it's a police incident, whether it's a weather incident, whether it's something happening with our students, our faculty, our staff, there's something going on here every day. If it starts to become bigger and badder, we have the overall culture university-wide to be able to deal with it.

We all create our little worlds and our little safety systems and our little people that are go-to people, we need something we can call, we all have that, but is there an overall university wide culture of preparedness that if I know in my little world that it's hitting the fan, who can I talk to? Who can come in and step in and help me? Who can do that? Is that there?

Whereas the safety, they're all going to tell you, "Yeah, of course. It's my responsibility to ensure a safe and secure campus for my students, faculty, and staff.” Nobody's going to say that they don't have that because they're just not, because they do take steps. ... There's a distinction there. I don't know if you understand that.

...That to me, that is a culture of preparedness and that doesn't happen overnight. That happens with commitment. It's not always a commitment of resources. It's commitment of time and holding to your word and walking the walk and being the example and showing up at the exercises and being the one that says, "No, we're going to do this. I don't care whether you like it or not. This is what we're going to do.” That makes all the difference in the world.

Preparedness also means being proactive, which most crisis management systems are not:

You're always reactive. You can’t possibly be ready. ... We're not going to put metal detectors all over campus. We're not going to have passes; everybody has to wear a necklace with your picture ID on it. ... We don't want a college campus to be that way. 
A culture of preparedness, hence, equates to strategy creation, training implementation and steadfast, long-term commitment.

A few crisis managers added some other key points that their presidents did not mention in their interviews. Toby admitted that they need to improve certain aspects of their crisis management system:

When it comes to students, we're not as good, quite honestly. Typically, I will meet with all the new resident assistants every year to train them. I go to all the orientations and talk to them about [our safety program]. That's in 10 minutes. Then we give a full-blown overview [in the program]. Really, that's about it.

It was also noted that program implementation takes time, but it will eventually have an effect on institutional culture. Jeremy noted:

Back when I first started it was like pulling teeth to get people to write safety plans and emergency plans for the buildings, now everybody wants one. The mindsets [have] changed, which is great for us but it's a lot of work for us.

Support by presidents and investment by the top management no doubt helps support a culture of safety and preparedness.

Expanding on the earlier section of "size and location," the type of universities we have within the SUS (i.e., public, open-access) also matters in building and sustaining this culture. Ralph discussed how his university recently looked at safety measures:

There is a fence that goes around the campus, and there was discussions about whether we do a gated campus. We did study that and look at that and came to the conclusion that it wasn't worth it to do.

For Ralph’s university, physical barriers of protection did not remove the potential risks of crises still occurring. Andrew supported this sentiment of the need for protection:

As you indicated, because we are a public, open institution, and there [are] no gates, like you have around some private institutions or much smaller institutions, our campus can be easily accessed by any and every one. That has its advantages and disadvantages. I think that our students are very cognizant of that. 
William also added to this perspective as it related public universities across the nation:

We're very open. This is not a gated community. None of our universities are. That's just the nature of our public universities and not just in Florida. It's anywhere, all over this country. I just assume I can walk on a public university campus and just walk in.

All university constituents need to be aware that issues like location and lack of physical barriers make the SUS unique, and this uniqueness can bring with it some limitations to safety. This transcends, though, the issue of fencing. Upcoming issues like allowing guns on campus (SB 176 was approved in March 2015 by the Senate Higher Education Committee of in the Florida Legislature, which could have allowed anyone to bring a registered, concealed gun onto campus, but eventually died in judiciary) can also help or hinder this culture. As Martin expressed:

The common denominator is students and student safety and each of them has unique circumstances that we have to be very attentive to. ... No two campuses are alike. They'll each have the opportunities for extreme risk and damage and danger.

This also means that universities cannot simply implement other processes and operations simply because it worked elsewhere. As William noted: “what works at an urban institution is not necessary; in fact, could be counterproductive at [our university].” Crisis managers and crisis leaders alike have to take a close look at the distinctive features of their size, demographics and missions in order to create and sustain a culture that best suits their university.

\section{Roles, Responsibilities and Accountability}

Presidents and crisis managers each have unique roles and responsibilities that can sometimes be affected by institutional culture, which was the third theme found within the collected data. These roles are inclusive of how reporting structures are 
created, the need and support for collaboration, as well as accountability measures that crisis managers and crisis leaders believe they must adhere to. Their interactions with one another can vary greatly.

Reporting structures. This study brought to light the inconsistent reporting structures for crisis managers within the SUS. Each university's organizational charts were recreated below, but only illustrating the hierarchy for the units being analyzed in the study (i.e., the 16 participants listed in Table 1).

Given that each university had slightly different titles for their executives, though their roles were relatively the same, the following generic titles were given to these employees for the sake of remaining consistent through each description: (a) the Chief Academic Officer was called "Provost”, (b) the head of Finance and/or Administration was titled "CFO", and (c) the leader of Student Affairs was noted as "VPSA." Though police were not included in the study as participants, they were included in the following organizational charts given their important role in many crisis response situations as well as their close operational ties to the crisis managers in the study. The titles and departments within each chart that are in bold are those shown in Table 1 and the generic titles just mentioned. For comparative purposes, the titles in parentheses show each position’s actual human resources title at their respective university.

At U-1, the Department of Emergency Management, which was also inclusive of Environmental Health and Safety (EHS) and the Police, reported to the CFO. The CFO, in turn, reported to the president. The Dean of Students, on the other hand, reported to the VPSA. The VPSA reported to the Provost who then reported to the President. 


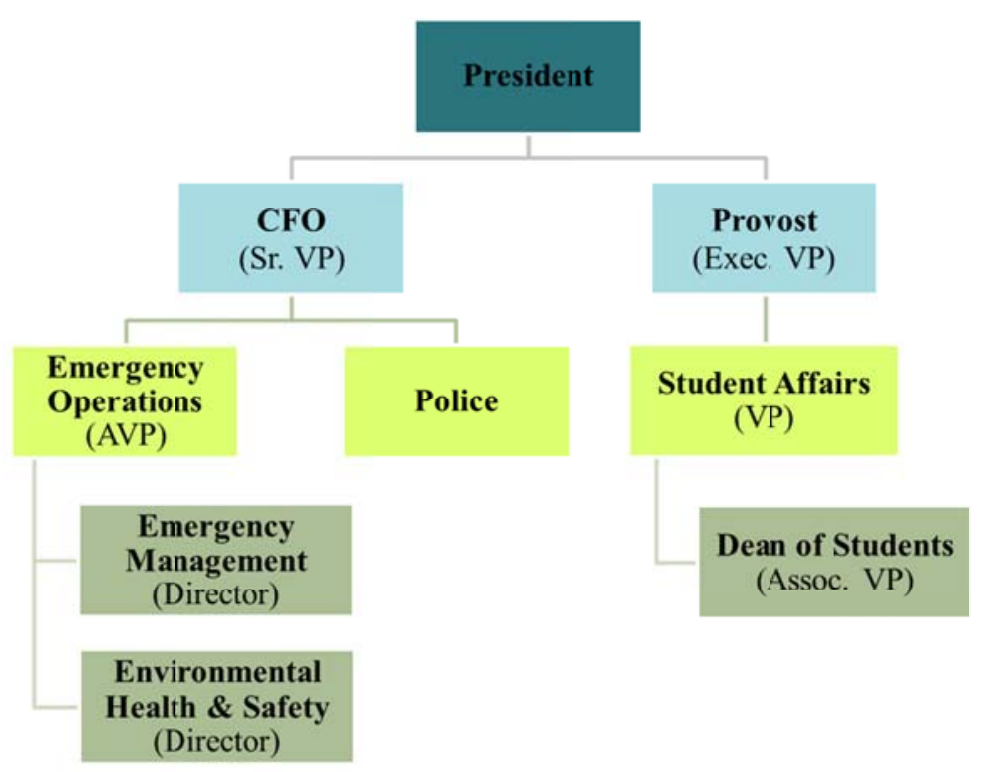

Figure 9. Organizational structure of University 1.

The Dean of Students and Director of EHS at U-2 reported to separate units:

Student Affairs and Finance \& Administration, respectively. The Dean of Students at this school held this title alone, reporting to an Associate Vice President who reported to the VPSA. However, the police chief was a direct report to that VPSA (not the AVP, like other directors in their organizational structure). On the other side, the Director of EHS also reported to an Associate Vice President who reported to the CFO. Both vice presidents (i.e., VPSA and CFO) reported to the president. David advised that "several years back, we were moved to student affairs. I used to report to the administration, but they wanted to sort of change the focus.” At this university, no emergency management department existed. 


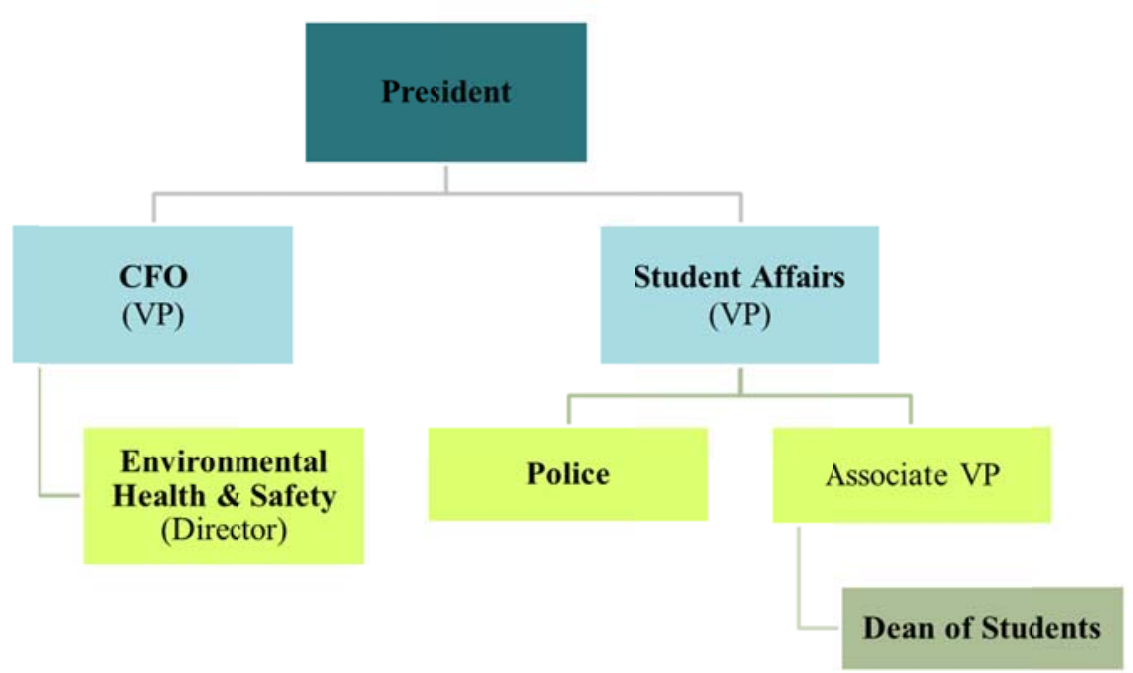

Figure 10. Organizational structure of University 2.

The EHS Director at U-3, also reported to the CFO. There was no Dean of Students or VPSA by title at this university, but there was by function. This position reported directly to the university's Provost. Both of these vice presidents reported to the president. The police, uniquely, also reported directly to the President. Similar to U-2, there was no emergency management department at this university.

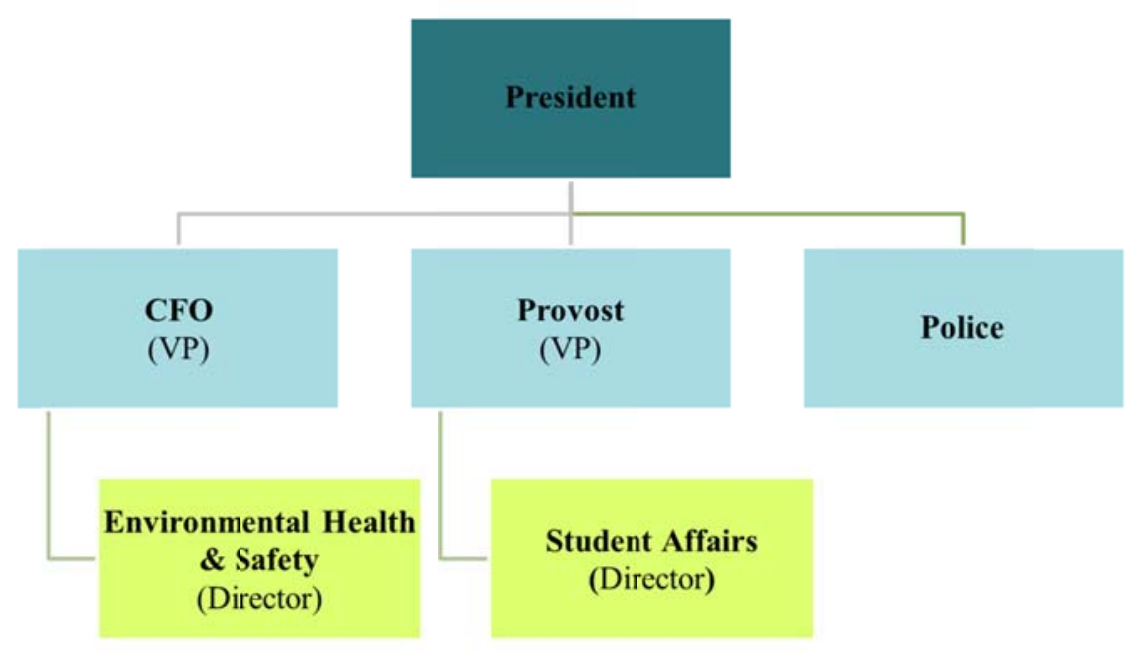

Figure 11. Organizational structure of University 3. 
At U-4, the Dean of Students reported to the VPSA while EHS and Police reported to the CFO. Both vice presidents reported to the president. Here, you will note that the Dean of Students, like at U-2, held no additional title. Also, as with U-2 and U-3, no emergency management department existed.

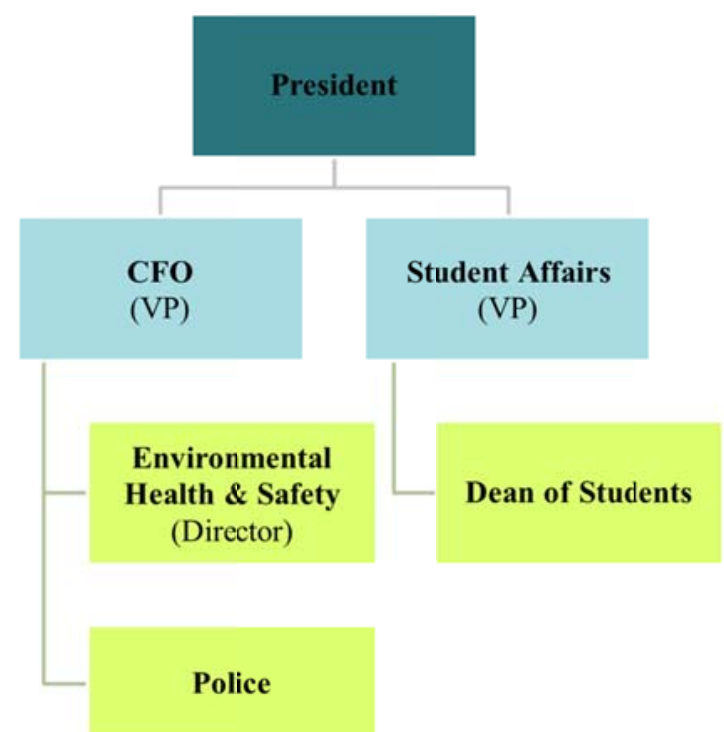

Figure 12. Organizational structure of University 4.

U-5 had a distinctive hierarchy where all vice presidents reported to an Executive Vice President who then reported to the president. At this university, the Dean of Students reported to the VPSA. EHS reported to the Police Chief who then reported to the VPSA. Per Bradley “that happened probably a year ago.” Pearce advised that their department had moved a lot in recent years:

We were under administrative affairs. Then the vice president who was over administrative affairs ... made some major changes in the structure. We ... were a separate department, an individual department under an AVP. Then [the vice president] ... separated EHS and emergency management. Then [the vice president] brought EHS emergency management back together and put it under the police. 
... so that was the structure for a while and then when [the vice president] left, the president and one of the other vice presidents brought all the administrative affairs directors in to talk. [The President] was asking what we thought as far as structure and that sort of thing. The police moved under student affairs. We were part of the police so we just went us a packaged deal.

Pearce closed by stating:

So, that's the dynamic now. I will say, though, as far as EHS here - 20 years ago when I started here - EHS was under the police. It's kind of historical.

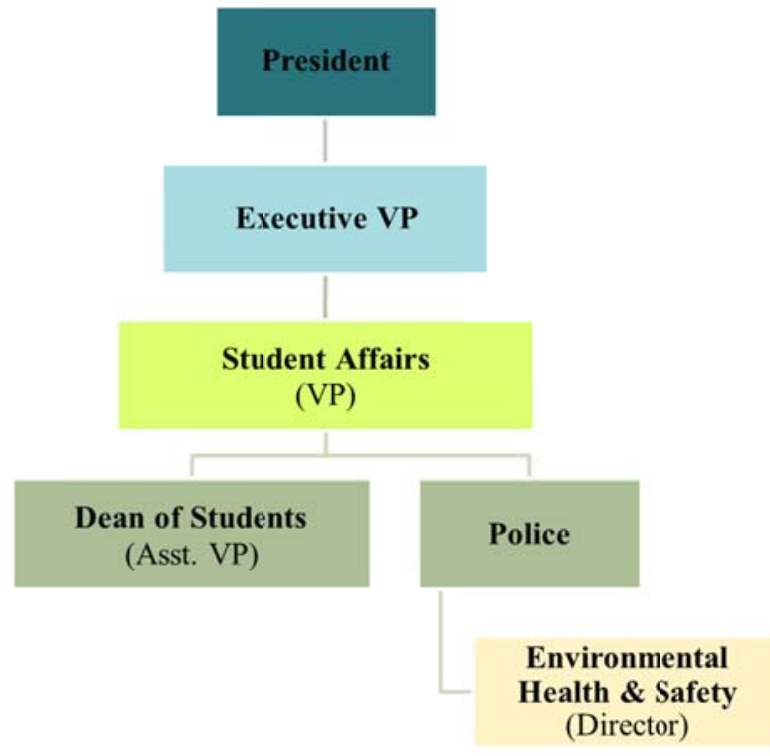

Figure 13. Organizational structure of University 5.

Lastly, at U-6, the Dean of Students also held the title of Senior Associate Vice President who then reported to the VPSA. EM and Police reported to an Associate Vice President, while EHS reported to separate Associate Vice President. Both of the AVPs reported to the CFO who reported to the president. Initially, EM, EHS and Police were all under one division. Jeremy advised:

After [the incident a few years ago] happened, the [CFO] made the decision to pull the Chief and Emergency Management separate and let [Associate Vice President 1] keep EHS. In my opinion, EHS should have come with [Police and DEM] but [the leadership] probably didn't want to pull too much away from 
[Associate Vice President 1]. EHS stayed with Facilities and Safety. The chief and myself separated and now we report directly to [Associate Vice President 2].

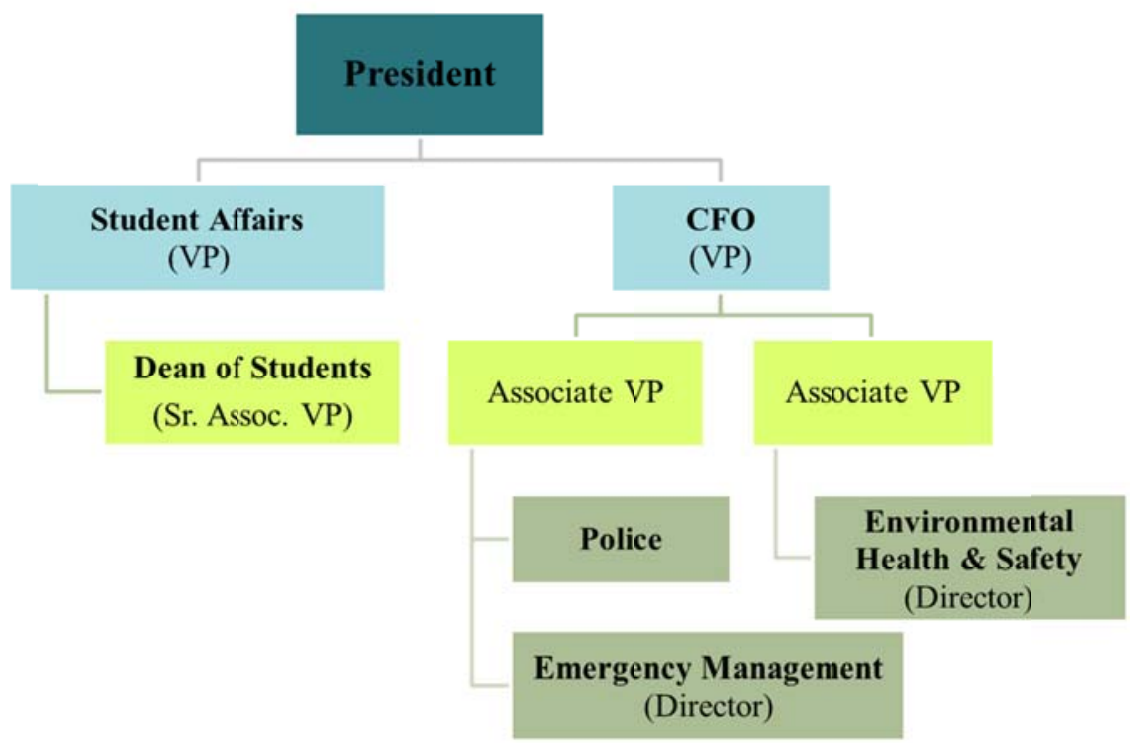

Figure 14. Organizational structure of University 6.

It was evident by these participant institutions that there is little uniformity in the organizational structure of not just departments, but the university as a whole. Amir's thoughts on this organizational standardization were:

There's a lot of movement of emergency managers within higher ed. You will find them in facilities. You will find them under police. You will find them in environmental health and safety. Rarely, you will find them in student affairs.

This rarity is shown in U-5's organizational chart, which was the only university interviewed that had such a structure. Amir also added:

Very rarely do you find a stand-alone department; that's where we're unique. We have one of the shortest lines to the president as far as reporting and that's the way it should be. Emergency management needs to be reporting, not necessarily directly to the president, but maybe one step below. Because when it's hitting the fan, you need to be able to get to your decision makers.

Amir's sentiment about the proximity to leadership was supported by Jeremy: 
About two years or about a year and a half ago, [the Chief of Police] and I reported to another AVP but after [the incident], they recognized that we need to be closer to our president so we actually moved up into the current chain of command.

As noted, visibility and proximity can be tied to accountability (discussed in greater detail later in this section). When asked about a multi-layered reporting structure, Martin advised that it could be both a positive and a negative.

It gives people the opportunity to take responsibility and to take action independent of the chief executive officer's involvement.... That's a good thing because you want people to take action. It potentially is a bad thing depending upon the level of risk, but what is important is good communication and trust ... good communication and trust between the executive and his or her direct reports. ... I think in the main though, it does increase the likelihood that responses will be made earlier, not later, and I like that.”

Mitch stated that reporting to the president is "not as critical as long as you're on the cabinet.” He added:

If you've been pushed out of visibility of their biggest leadership level of campus, then you got more issues. Then there's other people out there making decisions who have no concept of what you're doing, and that can become a problem.

In the interview with Jeremy, it was noted that "everybody's doing it differently, so there's no standard; that's across the country, not just the State.” When asked why that was, Jeremy posited that not just personalities, but professional experiences mattered: “Some people want [these departments]. Some people don't because they don't understand it.”

When probed about their thoughts on reporting structures, the remaining crisis managers had interesting opinions. When asked about the instances of multiple restructuring, Pearce noted:

That shows the level of - how am I going to put it? - importance that they put on the departments. When you start kicking around departments like EHS - we've 
moved, God I don’t how many times, physically and struck organizationally - it shows you the kind of importance they put on it.

Pearce added that current events had also contributed to the changes in structure at his university:

Look at emergency management and EHS [historically]. Emergency management was always under EHS in most places. Well, now with all that has been going, the spotlight is on emergency management. EHS is starting to recede into the background.

What Pearce was referring to were the recent incidents like Virginia Tech and Florida State shootings, which have forced universities to reconsider their processes and systems; presidents have been forced to act (as noted in earlier sections). Given size and location, this may be why some of the smaller schools have not yet created emergency management departments at their universities.

Roles. Universities’ core missions are all academic in nature, but their main responsibility is to offer their constituents a safe environment. As Julian articulated: "the purpose of a university is to hold classes and to get students educated and to facilitate their earning of a degree", but later noted that "the whole issue is safety first.” The rest of this section is divided into the perceived roles crisis managers, presidents, and the universities as a whole each play in crisis leadership.

Universities. To the point about safety being the most important aspect of a university’s responsibility, William expressed:

What you see here on this campus is a campus that's very intentional about a lot of things because we can afford to be. One of those things is safety. ... That's what I think about as safe campus. It's all of our responsibility. ... I know what the expectations are.... We have a responsibility to provide safe environments as much as possible both on and off campus.

Martin also spoke to this issue: 
I see the university as a sanctuary; it's a privileged place. It's high neutral ground. It ought to be characterized by serenity and order and peacefulness. For the most part, most universities are that, but it's an artificial environment and so you have to be prepared for anything and you hope nothing happens. I think it's our responsibility to keep it the way it is, but it's [also] our responsibility to hope for the best and prepare for the worst.

David, however, had a totally different opinion on what a university actually is:

People have a real misunderstanding of college university campuses, anyway. They see them as this little, protected enclave - a Disneyland, almost - and it's just not. It never was. It clearly isn't today. When something bad happens, it really throws people.

It's still pretty safe, very safe, as a matter of fact, but it's just, when it happens, of course, it's a shock, because you expect it to be safe.

Andrew also believed that universities have an inimitable role to play in student safety:

We want you to know that in loco parentis, it's still something that many of us believe in. When your son or daughter comes here, we take on that responsibility of looking after them, and helping them grow as we would our own children.

Ralph, though, noted that this responsibility for student safety is dual-pronged. The

leadership and students have to work hand-in-hand to create such a culture:

I think [students] have responsibility as well. Too often these days in society we don't hold people accountable for their own actions. We want to blame them on someone else, and so I think the kids have to be accountable, but we have to also make sure that we're protecting them. That we're doing everything that we can to minimize any of those things. We're taking a dual-hatted role to that, I would say.

In sum, and as Maslow's (1943) theory posited, the basic need for safety and security must be a university's primary goal.

Presidents. Drilling down a level, presidents believed they played their own unique roles. Martin brought up the importance of defining crisis, which could affect how roles are perceived:

Values are critical. Everybody is going to have a different bottom line. Everybody has going to have a different bright line. Everybody is going to have a different 
risk perception. Ultimately, the president is the one who gets paid to make the right call, but everybody will be different in terms of how they perceive the situation. One person's pending calamity is another person's slow motion flood that is business as usual.

Jose added: "You're the public face of the place. You get paid a lot of money. It's your job to try to keep things running smoothly and the students safe.” William also commented on the ultimate responsibility that presidents have:

At the very top, the president's role doesn't change. He or she is the icon of the university. The expectation of the university community and the external community is that the president is in charge and leading whatever efforts there are going on to address that crisis.

One crisis manager saw presidents' roles, noted in an earlier section, as dependent on the president's personality. Specifically on the topic of newsworthy crises, Mitch noted: "Presidents, depending on the campus, have different roles and different visions of what they're supposed to do and some are just much more comfortable in front of the camera.” Another crisis manager, Amir, also mentioned this external role: "This is just my opinion, but I think one of the biggest crises a University President may face is protecting the brand.” These perspectives are all supplemental to the earlier theme of Culture, specifically "presidential values.”

The most eloquently stated opinion on the president's role in crisis management and crisis leadership, and how the two intersect, came from William:

I think in my mind, leadership directs the management. A true crisis, what I might see as a crisis, it's important for me as a president to make sure my management team understands that we're in crisis mode. We know what we do in crisis mode. It's important that people know their roles. They don't change a lot at the very top. My role is going to be the same whether that crisis was in student affairs or academic affairs or you mentioned environmental health and safety.

I think it's the president - the leader of the organization - [who] really sets the foundational approach to crises. Everyone needs to be on that same foundation. 
In sum, as Julian noted, "[presidents are] responsible at the end of the day.”

Crisis managers. Moving further down the organizational chart are crisis managers who have their own responsibilities in building a safe environment at their universities. David and Jeremy, respectively, shared:

Our role is trying to basically keep the university out of trouble and keep folks from getting hurt.

We're the doom and gloom folks and thinking about the worst case scenarios, but that's what we get paid to do and have a solution for those worst case scenarios.

Crisis managers can also have a supporting role in crisis leadership, as Amir and Jeremy advised:

If you have an administration or university president that knows what systems are in place, they need not know the particular details and it's not their job to know all of the details. That's why I'm here.

When it comes down to crisis management, the way I view it as my job and my role at this university, is to identify who has what specific roles here...to help us respond to any particular crisis because they're all going to be different.

Within crisis management, there are also unique roles played within the departments involved. Specifically for student affairs, David advised that in his world, they are "always thinking about 'what impact does it has on the people of this campus?'” For police, Andrew stated that in a real crisis "university police is the ultimate authority, not the president.” All of these roles collectively, though differing and university-specific at times, support a healthy and safe environment.

Teamwork and collaboration. Working in cooperation with other units, internal to your department and the university, as well as externally, is crucially important for the success of crisis management and crisis leadership. Jose shared his thoughts on teamwork: "We want to be in this together. If you can kind of get it to where people are 
all pulling the same way and understanding why they're pulling, that's great.” Martin expressed his expectations for his crisis managers: "I do expect teamwork. I do expect collaboration and really good communication.” When asked if he felt his emergency management team had enough staffing, he stated: "I think that's about right as long as they are continued to be collaborative with and embedded in the university.”

All participating universities advised that they had partnerships with local police, fire, and emergency operations agencies. This was in line with the literature on FEMA and how institutions receiving federal support can more easily receive mutual aid funding during and post crises. These interactions are critical to the success of any crisis management system, especially in a university-wide incident. Amir and Toby shared their perspectives on this:

We've broken down some of those high-lows and I think that's huge anywhere and anything and you know that relationships make everything. No matter what you're trying to do, it's all about the relationships. When something happens, that's not the time to develop those relationships. You're too late, you're already behind the eight ball.

Developing that network and developing the relationships, so that you can collaborate seamlessly is really important.... The other part of it is, again, we operate as a team. Not only that - many hands make light work. When you're trying to figure out what's going on, if you're looking for someone or whatever, it just helps to have more eyes.

Another crisis manager (David) recognized, though, that they could give more focus to nurturing those types of relationships:

Interacting with all the agencies - we don't have anybody that's really actively reaching out to all the appropriate agencies, to stay in communications, to stay in the know, to develop those relationships as a resource if we ever need it. 
In addition to these structured partnerships, two participants mentioned how their universities have created inter-departmental projects to aid in being a university with a more proactive culture. Jeremy noted:

We're working on that as a collaborate project right now with a lot of our team folks and a lot of our other folks. We didn't do a good job drawing up, implementing those processes early on but we now we recognize it's a gap and we're working on fixing it.

And Josiah shared:

We've also got, in addition to the crisis management group, we've got another group that meets periodically that just tracks issues. Their charge is to think about the things that may impinge on us. In other words, if you had been really listening to some of the dialogue about sexual assault for instance, you might... have gotten your campus a month's head start ...

What are the issues that are floating around out there that are just pretty clearly going to get to campus one way or another?

This awareness of and sense of ownership for the existing gaps within the safety, security, and preparedness realm of the university is definitely a plus in terms of crisis leadership. It also leads into the next responsibility that universities and their leadership have: staying accountable for the roles they play and the actions they take.

Accountability. As with roles, the level of accountability for crisis managers, presidents and universities vary. However, no greater pressure of responsibility is placed than on presidents. Adding to this, there is also a sense of accountability placed on the SUS to also serve as a cultural ambassador of sorts to all 12 universities for safety and security.

Presidents. Presidents were each asked how accountable they believed they were if a national issue like at Penn State occurred at their university. Each had their own special take on the matter. Jose noted: 
The problem - and you've been in a President's office - it's 90 miles an hour. Sometimes people are intentionally not flagging things and you just think, "Oh, it's no big deal. No big deal. No big deal." You've got to kind of always be sensitive that this may be a bomb. This may be a ticking bomb. This may be a time bomb that will blow up later. This may really be a problem. I need to make sure that we batten down those hatches.

Ralph's thoughts on this matter (i.e., dual-pronged responsibility) were mentioned

previously in the "roles" section of this theme. Similar to Jose's thoughts on the amount

of information presidents receive, William offered this response:

I think that of course presidents can't know everything. That's why the upper administration needs to reflect the values that the president holds dear and adheres to.

You can have a lot of debate about that of what's that's about really is that one of the values of the organization. People have to understand that. One value is not to cover up transparency, honesty, integrity. You apply that to everything.

The folks you put in leadership positions in the various divisions in the university need to understand that, need to reflect that. When that's not happening, hopefully then [it won't] reveal itself in a crisis. I think you've heard the saying, "Character is not developed in a crisis, it's revealed in a crisis."

Julian also shared:

I think that Penn State showed us that, when in doubt, report it, whatever it is, to the police.

At the level of a Penn State, at a University of Florida, you can't own all of them. I mean, there's no way to do it. You have to assume that the chain of command is making sure that you're finding out the ones that are really, really important and the ones that you really need to be involved in. My Board Chair...He says when you're the CEO, you can't be into all the details but you need to be in some of the details. You've got to be able to discern when you're meddling and micromanaging and when you're being responsible for really getting down to understanding what has gone on.

Partially contrary to Julian, Martin believed:

I prefer sins of commission or I think people need to take action. That's what they get paid to do. I have a lot of curiosity and I don't apologize for that and I want to know. Then I have to rely on my gut instincts to determine whether what I'm 
hearing squares [with] what I'm saying, and whether what I'm hearing and seeing square with what I feel in terms of my values and the concerns that I have. I think that there's no single fixed response to that.

Josiah also had a slightly differing perspective:

When it involves something that either by board of governor's rule or by statute, the president has to do then I'm going to do it. If it's something that can legitimately be delegated, I may well do that. We jokingly sit around here - but only joking in part - that the first law of academic administration is if it's worth doing, it's worth delegating.

If you have good people and you trust them, it is generally a good thing to delegate, not always, but generally. You need to know when to step in and say this isn't the usual. If you got good people, they certainly know more about their area than I will and by and large, we're better served by letting him make the call at the senior level for sure. I know them. I may not know some of the people down the line.

Josiah later added:

I think one of the things we need to do in a situation like that is without seeming to try to duck responsibility, point out that we are in the early stages of something. Here's what we think we know but we're not often in cases like this. New information emerges or details are discovered that are misinterpreted and whatnot. Try to manage expectations somewhat. There are situations where that's simply, you're going to be overwhelmed.

To the extent you can, try to help people understand that while, yes, you do have a lot of people working for you, reporting to you, it is the nature of a lot of these situations that full knowledge of the facts emerges over time, if ever. There are things you know and things you don't know. There are things you don't know you don't know. .... Often, it's true, it's what you think you know that aren't, so that really gets you.

The important takeaway here, as discussed in the "communication" segment of the

Culture theme, and noted by Amir, is that "no reaction will sink an institution.”

Regardless of who responds, a response must occur.

State University System. Outside of the accountability placed on each university and its president, there is also a sense of accountability for safety as an entire system. 
Along the lines of leadership support, several participants were questioned about a request from the State University Systems' Chancellor that asked for all universities to be on an urgent call to discuss safety and preparedness across the SUS. On September 18, 2014, the following email was sent out to all presidents and their assistants:

At our Board meeting this week, the Board discussed the topic of campus security. Our Board members believe it is important to provide a safe learning environment for our students. During the meeting Chair Hosseini asked the universities to work together to determine what additional measures can be taken to enhance the safety and security of our campuses for our students.

With that said, I would like to schedule a conference call on Friday, September 26 at 10:00 a.m. (EST). During the conference call we will be discussing how we can make our campuses safer and to ensure that we are doing all that we can to prevent sexual assaults on our campuses. We will work together over the next few months and will report back to the Academic and Student Affairs Committee. I would ask that either you or a designee be part of this discussion.

Given the topic of the call correlated with my dissertation topic, I joined the call (no permission was needed given that the BOG is governed by Sunshine Law and all calls/meetings must be open to the public). I was eager to learn about the BOG's plans, but was let down when the call only lasted 10 minutes. Only a brief summary of the UCF Workshop held a couple years back and notice that a follow up gathering should occur was discussed.

When probed about his thoughts of the call, Mitch believed, though short, there was good intent behind the call:

I think [the BOG is] beginning to realize - not beginning to - they realized that this is a very, very dangerous flashpoint for them; that they really [have to] do what they can do to control it. ... [The Chancellor] understands that ... the college campus today is very, very much more volatile than it was 20 years, 30 years ago, and so I think they're realizing that the mental health concerns with campus and the ability to respond to crises is a much more fluid situation than it used to be. 
William agreed with this thought: "There needs to be some type of system

acknowledgement that this is something that could happen anywhere and we need to be prepared." Conversely, Jose noted that the shortened call was likely due to the sensitive nature of the topic:

What I think they really concluded was, you don't have a public conference call for a university to say, "Here's three things I'm worried about. I don't have enough counselors. I don't have enough cops. I don't have a bomb dog. I don't have a this. I don't have a that.”... You invite opportunists. There's healthier ways to convey that. That's why I think he shortened it.

I don't know if it should be a university system issue or not, or should that just be...[dependent on] each school. Each institution's dealing with it's ... You know, you've got your own geography, your student mix, and your location.

Though understanding their perspective, sometimes words and the attention given to a topic matter. Nonetheless, words must be turned into actions.

The accountability measures placed on presidents and the SUS tie into the next

theme: Resources. How, when and if resources are allocated are always a criticism shared post-crises by constituents and the media, which ties into the earlier comments made on trying to change the culture from a reactive to a proactive state.

\section{Resources}

The fourth theme deals with the availability, or lack thereof, of safety and preparedness resources provided to institutions. These resources are inclusive of budgets, personnel, space, training, and institutional support.

Available resources. As noted earlier, universities play a distinctive role in safety and preparedness. Given that safety must be their number one priority, David believed: “That’s...I think where university probably can excel, because it has resources. It’s just a matter of figuring out how to use those resources most effectively.” The one university 
that has used their resources best has been the University of Central Florida, who was hailed by all participants as the best emergency management system in the State. Many of the following points are related to how their operation runs, as well as a workshop that UCF held after a March 2013 active shooter incident in their Tower 1 residence hall.

Of the six universities that participated, U-1 and U-6 had stand-alone Emergency Operations Centers where training and live incident management occurs. Both of those universities also have mobile command units that can be used on the actual site of a campus incident. U-6's student affairs program had the greatest multitude of resources for student health and safety. Two examples provided in the interview were free taxi vouchers for students who are too intoxicated to drive home or back to campus, and a mobile water station that roams campus on Friday and Saturday nights. It was evident that these robust programs were due, in part, to the universities' more urban locations and larger populations.

These resources often yield robust crisis management systems. Success of these systems, though, takes time and money. As Amir noted,

When you think of all the range of specializations and the talent that we've cobbled together here at [U-1], it's a work of years; it's a work of decades. You can't do it overnight. So if you lose a whole cadres of specialists, you've really hurt your institutions and set it back.

Amir also felt, though, that it is sometimes difficult to justify institutional support of such an intensive program:

It's hard to see the payoff of the investment. It really is. Ideally, we'll never see the payoff. That is my goal. Ideally, we use this room to train, to exercise, and never actually have to use it. That's ultimately the goal. That's a hard thing to quantify. You're spending a lot of money on what-if scenarios. 
Outside of financial support, it also takes a strong commitment from the leadership.

Something that both Amir and Jeremy discussed during their interviews. For Amir:

I have, here, the best "buy-in” from an administration. I can tell you that without a doubt. One of the factors that makes my job easy is that the administration gets it, and they buy into it. They have an understanding of Emergency Management. They know that it's important. They know that sometimes you've got to spend money - up front.

To invest the time, the commitment, the money. Coming here every semester I can guarantee you that there is not another University President that has done as many tabletop exercises as ours has. That, to me, is crucial, because if you don't have that "buy-in," it's very difficult to get any traction.

For Jeremy, direct commitment from the administration was also critical. It was because of his former supervisor that he obtained all of the space and funding to build his program. This departmental champion, as noted earlier under the topic of presidential support, is truly key to a program's success.

Needed resources. During the interviews, each participant was asked for their wish list of sorts - putting aside any financial or political restrictions their universities are currently under. The recurring theme from crisis managers was that, as Rhashad so pointedly stated, "basically, all of this comes down to money." This lack of funding creates a deficiency in effective operations. It can sometimes be like a system of bandages that is holding the entire system together. As Pearce noted: "You do what you can; you do everything you can and you hit the highlights; hit the high points and the things that will get you in trouble.” In order of the frequency stated amongst participants, the list of needed resources breaks out into money for personnel, physical resources, training, and space. 
Personnel. For staffing, Jeremy noted that potential future growth would change

his desire for more employees:

I feel pretty comfortable with saying I think from the emergency manager perspective, as far as staffing goes, I got what we need. I mean, the next university closest to us has two people. I mean, we got five. We're in good shape in my opinion. Now, if we keep building more and more campuses that might change. ... We might need more staff to support the rest of the regional campuses.

Other crisis managers pointed to current key deficiencies they would like to immediately address. For David:

Number one would be an emergency manager, a dedicated person to fill that role. I think that we're large enough. As well intentioned as our folks are and as highly trained as we've become and practiced as we've become, we're still missing out on that expertise.

[Also], I think it would be helpful to have more resources for mental health. [Student affairs professionals] basically were generalists. We've become very, very specialized and people are not comfortable dealing with the crises for mentally ill people or mentally unstable people, and even our own student affairs people don't know what to do, because they've been trained as administrative roles, not counseling roles.

For Mitch and Bradley, as shared also by David, that personnel gap fell within health services:

I think it would be helpful to have more resources for mental health. ... We need, almost, a crisis responder group in the Dean of Students office or in the division that deals with people over the short run ... like crisis case managers.

I would like to have another case manager with this as mental health issues have grown over the last few years with the advance in psych or pharmaceutical drugs. ... As we've grown as an institution over the last few years, more students are just needing more people [to help them].

And for Rhashad, it was about her own personal well-being: "If I had about five more positions, I could rest.” Undoubtedly, crisis managers are unable to focus on moving their 
university towards a more proactive culture when they are always focusing their attention on putting out fires (and for some that would be literally and figuratively).

Physical resources. In terms of physical resources, crisis managers mentioned items such as equipment and programming. Jeremy had the most specific request:

One thing on the emergency management side of the house - I think that we need some kind of an emergency management software to help manage an eTeam or WebEOC. ... That software alone, to buy into it, ranges between $\$ 100,000$ and $\$ 150,000$ the first time and then after that it's usually between $\$ 15,000$ to $\$ 20,000$ annually. How often do you use it? That's the thing. If a hurricane comes through, that's one thing. You got to train people. ... On emergency management side of the house, that's probably the biggest gap, is that type of capability. Now, that also helps you with what you call a virtual EOC.

Andrew, on the other hand, is "looking to create what I call Community Development Assistance (CDAs) that serve really as off campus RAs in our apartment complexes” (this would be for student housing around outside of campus that is not directly managed by the university). Additionally, Andrew noted that his university "could always use more funding in the area of education and preventive type of education.” For Pearce, the need lies in “money for certifications...instrumentation and instruments,” and “additional money for like indoor air quality testing.” And for Toby, “the biggest gap is really training.”

Interestingly, only one president made mention of specific resources needed for his university. Josiah noted that he would "love to have a really good modern replacement for the old key system, whether it’s a badge or a reader.” Josiah, along with other presidents, simply asked for more of the obvious resources. For example, Josiah felt that "it's as simple as having another half dozen police officers" and Jose mentioned that 
they "could always argue for a couple more cameras.” For the most part, all presidents "felt pretty good" as to where they stood on resources.

Training. The ability to train and be trained was one that some crisis managers discussed at length during their interviews. For crisis managers themselves, all advised that they do their best to participate in conferences and keep up with the latest literature, but "limits of our budget," as expressed by Toby, cause some roadblocks. To combat this constraint, Mitch advised they "study very carefully what happens at other campuses." This gives them a direct, yet inexpensive, method to educate themselves on best practices and lessons learned from other universities. For example, Mitch mentioned that his university was looking closely to how FSU was responding to the active shooter incident. Conversely, though, William felt that there was only so much training you can do without wasting resources: “You won’t find anything that’s really innovative. We all probably watch the same thing."

In terms of training for the leadership and university as a whole, participants were asked for their point of view on what is called "tabletop exercises" (i.e., live simulations of potential university crises like floods, fires, chemical spills, tornadoes, etc.). They all discussed doing some sort of activity at their university, but responses varied regarding who was actually involved. Some universities advised that they partner with their local emergency management agencies to host a community-wide review. Others focused only on internal operations. Jeremy shared his take on how they manage their tabletops:

Majority of our exercises so far had been mostly on AVPs and below but we've had discussions with the vice-presidents and the president. 
Do I think that we need to do exercises a little more with the vice-presidents and our president? Yes and they agree also. They know the importance of doing it but we just got to get a time.

This response, that no top management participates in tabletop exercises, was consistent with all interviewees, except Amir. He shared, as stated earlier in this section, that his president and all top management attended almost all of his scheduled simulations. Direct involvement from crisis leaders is critical if universities are to move away from "shock learning” and towards “innovative learning” as described by Warren Bennis in Lerbinger’s (2012) book.

Mitch and Bradley had very positive comments about what the exercises provide their universities:

What those do, the positive part of those, it gets the people in the room who will have to deal with it when it happens.

We learn from it and the whole thing is a learning experience what are we doing right, what are we not doing that sort of thing.

Amir recognized that the annual exercises they do can sometimes be excessive, but necessary if you want the top management to be reminded of its importance: "I hate those hurricane exercises every year because like how many times can you just get a hurricane, but when we stop doing it, that's when we start to lose it. We get complacent, we lose the commitment." David felt that his university was "well trained and well exercised, but we've been very fortunate that we haven't really had it tested.”

Two presidents offered their take on these gatherings. Martin felt strongly that his university needed more of them, but at “all levels.” Currently, his university only has them for the top management, yet he believed, as noted earlier in the "communication" 
section of the Culture theme, that across-the-board implementation is necessary.

Conversely, though, William believed that these exercises were not important:

I don't feel that you need to simulate that on campus because the simulations can go on in places where this training happens for law enforcement professionals, but we have not felt the need to simulate that on campus and have fire drill kind of thing.

His point of view touches upon a point alluded to earlier that sometimes practicing scenarios and investing money can be more of a self-fulfilling prophecy where “you're always seeing everything as a crisis” (as stated by David and Mitch).

Space. When asked about a common space for all crisis management units, responses from each university were mixed. Mitch thought it would be a waste of space and money given their size:

It wouldn't hurt to have something kind of smaller scale the police could use for weather stuff or just if they need some space - it would be convertible for them but they surely couldn't use what Central Florida has.

Toby and Rhashad both thought it would be very beneficial to them, specifically to improve communications:

We could have like a behavioral intervention team building where we could all live together under the same roof, so that if I needed to talk to university police I just walk down the hall. If I needed to go to the counseling center I could walk down the hall.

I think it would help. It would make communications easier. If I could just walk across the hall and talk to the director of the physical plant.

Additionally, Rhashad expressed that "PECO money from the state would also help." (PECO, Public Education Capital Outlay, is the State fund that provides money to each university for buildings, which has been dramatically cut in recent years). 
System-wide, Amir noted the following after attending the UCF workshop held after their active shooter incident:

One of the takeaways was that they wanted funding to do [something similar to] a call center - like if we could get a contract - so that all the [SUS schools] could tap into a call center because they were obviously fielding a ton of calls with this incident.

However, something like this would require a significant amount of funding. And with dwindling budgets to each university, it is doubtful to ever occur - especially when state employees are now more often expected to "do more with less,” which goes back to issues of accountability for the SUS.

Summary. What is clear is that universities need to be more proactive with crisis management, especially resource allocation. As Amir noted in his interview: "we are very reactive as a whole society and we tend to throw money after the fact and we throw commitment and resources and attention after the fact.” Following up on the earlier comment noted by Pearce, the sense of importance placed on a program matters greatly. To this point, Amir shared the following about his university: “They're committing dollars, they're committing. There's a sense of importance and understanding the priorities of it.” Notably, more students equals more risk. Consideration should be given by both the universities and the SUS to better service these programs and departments as the total enrollment for each university increases and their campus reach grows, so that their students can be in a safe and low risk environment as possible.

\section{Variability of Crisis}

In 2007, Nassim Nicholas Taleb wrote a book called The Black Swan: The Impact

of the Highly Improbable. Black swan events were introduced by Taleb in his 2001 book 
Fooled By Randomness, and described as an event, positive or negative, that is deemed improbable yet causes massive consequences. Ralph brought up this book during his interview and summarized it as follows: "What he essentially says is that those rare things really are things that you can't plan for - you can't prepare for - and those are the things that really matter.” To this point, David added: "What [crises] point out more than anything is that people like us or you have no ability to really respond quickly.” This variability of crisis was the last theme pulled from the data. Many of the participants felt that defining terms and roles were incident-specific and required adaptability on everyone's part. This last section discusses how universities, crisis managers and leaders make decisions in a world of uncertainties.

On the topic of establishing an Emergency Operations Center at his university, David did not believe it was worth the investment:

How we could sustain it? It would be ... we don't have crises like that on this campus. It would almost have to be us constantly training; make ourselves have crisis - imaginary crisis - all the time just by using it.

While he agreed that UCF's model was a well-structured one that made sense for their institutional culture, David believed that it could change the lens through which universities define crises:

They're really prepared for a major urban environment, and I think it's a good idea for them, but at the same point, if you operate that way, if you have that kind of facility and you staff it and you pay for it, you're always seeing everything as a crisis.

Along the lines of general training and an overall culture of preparedness, other participants shared their perspectives. William believed that regardless of how much you plan, it would be impossible to think of every single scenario that a university can 
experience: “I can conjure up a lot of things; you just can’t simulate it, you can’t

anticipate it.” Similarly, David expressed how difficult planning is because of the innumerable variables involved in any given crisis:

It's hard to answer those questions because it really depends on how a scenario, any scenario plays out. I mean, that's why it's hard to do, have written plans. We all have plans but they're generic because each scenario is different.

However, David did believe that planning around current events like Ebola does have it benefits: "Had it not been for that, we might not have ever developed a sort of a response for that.”

As noted earlier under the "presidential values" section of the Culture theme, the role of crisis leadership in unpredictable situations is the ability to adapt. As Julian stated, "usually all the real rules go out the window during a crisis." As such, crisis leaders and managers must both analyze the facts in front of them and make, as Jose mentioned earlier, the best decision possible: “There’s not just a standard tool kit. You've got to be able to adapt and be creative on those.” David and Bradley, respectively, had similar perspectives:

For the most part, it's really...a gut feeling, just from experience and sort of common sense thinking, which...sometimes isn't very common but we have to. I think to be a good safety officer, certainly, you have to have good common sense.

When you get into an emergency, you don't want to pull out like some 300 page document like okay, how do we fix this? A lot of it is with experience you learn in these situations. What's one, common sense? Who are the players that need to be involved in making this decision? Understanding that no matter how many situations we have in a book, real life always has curveballs. How do you have a group of smart, trained, adaptive people with broad skillsets that can respond to the curveballs?

To the point about experience, Bradley added: 
I think we have to gather the information as best as we can, act responsibly with the information that we have. Do our diligence in addressing the issue and make sure that we're trained and using active exercises to be prepared. At the end of the day, there's a reason they call them emergencies or disasters as there's going to be some unknowns and some curveballs. I think having people who [are] going to adapt and are flexible and are nimble enough to navigate those with confidence is important. It goes back to your statement earlier about leadership and tenacity.

However, how, why, and what decisions are made are also critically important, as Toby

noted: “Depending upon your response, it can either be resolved or get worse.” Toby also felt that “you can’t always anticipate everybody's behavior all the time.” For this reason, Josiah believed that if something bad is going to happen at your university, it's going to happen regardless of how well you plan:

Guess what? It's 2015 and we get all those issues just as you do. You have your police force, you do your best. But if there's an issue out there, it’s going to find its way on our campuses one way or another.

This unexpectedness, which can create an inability to fully prepare, was discussed throughout the corporate definitions and typologies of crisis in the first chapter. Overall, how one views, prepares, and responds to crises is all based on subjective perspectives. In other words, each university has to make decisions on preparation and leadership based on their own unique culture.

\section{Summary}

The 16 study participants (6 presidents and 10 crisis managers) offered a great deal of insight on how they defined crisis leadership and its respective roles pre-, during and post-crises. They felt that the differing definitions of crisis; the university's culture towards crisis management; the roles played by the university, presidents and crisis managers; resources (current and needed); as well as the inevitable variability of crises, 
all played a critical role in leadership. Their perspectives helped to answer all three research questions, which are discussed in greater detail in the next chapter. 


\section{CHAPTER V}

\section{DISCUSSION AND CONCLUSIONS}

\section{Summary of Study}

Issues of safety and security within higher education have evolved over the last five decades. Universities have had to learn how to deal with protests, shootings, natural disasters, health epidemics, terrorism, among others. Historically, the responsibility for safety has shifted throughout the university from professors to police officers, deans of students to presidents. Accountability on university presidents to be omniscient leaders and keep all constituents safe has been a growing phenomenon, especially from concerned parents and community members.

This study was initiated to better understand crisis leadership in higher education through the lens of the university president and his/her crisis managers. Of the 34 potential interviewees with the SUS (12 university presidents plus 2 crisis managers per university, with the exception of FPU), 16 agreed to participate in 2-hour qualitative interviews. Their interviews aimed to answer the study's three research questions: how they each defined crisis, crisis management and crisis leadership; how those definitions contributed to the roles they each played as well as the roles they perceived the others played; and how those roles supported and maintained an institutional culture of safety and preparedness.

In a society where incidents, emergencies, and disasters on university campuses have increased in frequency, presidents and crisis managers have had to place greater emphasis on their crisis management systems. Their dedication, or lack thereof, to these systems, as noted by the interviews, has been attributed to their personal values and 
professional experiences. Their beliefs, decisions, response and support can all contribute to the university's overall culture of safety, security and preparedness.

\section{Findings and Interpretations}

Chapter 4 offered a richly described overview of the study's findings, which were described in five themes: Definitional Morass; Culture; Roles, Responsibilities and Accountability; Resources; and Variability of Crisis. All themes helped to answer the study's three research questions, described in further detail in this section.

\section{Research Question 1}

The first research question was: "In the State University System of Florida, how does each president and crisis manager define 'crisis', 'crisis management' and 'crisis leadership' on their campuses?” These definitions were all addressed within the first theme described in Chapter 4, Definitional Morass.

As discussed in the literature review by Mitroff et al. (1996), the term crisis has multiple, subjective meanings. However, it was also posited that Zdziarski (2006) offered the best definition of crisis within the context of higher education. His description was the comparative point to which responses to the first part of this research question were analyzed. For Zdziarski, crises affect the university's normal operations and were likely unexpected. To some degree all participants agreed on this, but what "normal operations" meant to them greatly differed. For some participants, a closure of a building or road was a disruption to university operations; whereas, others saw that merely as an inconvenience. For the latter participants, interference with normal operations meant the event had a significant university-wide effect (e.g., tornado, active shooter, etc.). 
Similarly, and for the most part, all participants agreed on how Zdziarski et al. (2007) defined crisis in their Crisis Matrix. However, seeing the division of "severity" of crises within the matrix (i.e., critical incident, campus emergency, and disaster) did affect how participants viewed their involvement. While all study participants agreed that there was a certain urgency to crises, how each of them defined a crisis was strongly related on their roles. For example, crisis managers varied on whether they saw a campus shooting versus a chemical spill as a crisis based on whether they worked in student affairs, emergency management, or environmental health and safety. A campus shooting may not directly impact operations for EHS departments, and therefore, they may have considered it a crisis for the university but not necessarily one that required their attention.

Presidents, on the other hand, almost all saw crises as something disastrous that affected the university as a whole; and therefore, involving them only during those events.

How participants defined the differences between crisis management and crisis leadership was even more personal than how they defined crisis. A handful of participants viewed management and leadership in the traditional sense: leadership directs management, and hence presidents guide the course for crisis managers' response and systems. These participants took Peter Drucker’s perspective that “management is doing things right; leadership is doing the right things.” This was also the stance taken by Daniels and Daniels (2007).

For leaders to do the right thing and also be successful and effective, they must hold specific skills, which, as described by Silva and McGann (1995), include insight, decision-making, communication and focus. Those who took this perspective believed, then, that crisis management was a system that followed rules and reacted to needed 
action; whereas, crisis leadership used a more strategic, holistic and moral approach to response and decision-making.

Conversely, there were participants - both presidents and crisis managers - who believed management and leadership overlapped; that at times, managers must be leaders and leaders must be managers. These participants felt that there was a sense of shared responsibility to keep their universities and its constituents safe; egos and titles are thrown out during crises. For them, and as with Lerbinger’s (2012) support of Warren Bennis’s “innovative learning” method, leaders and managers alike should learn new skills and share their knowledge so that the entire crisis management team can succeed.

This study sought to get a clear, concise definition of crisis, crisis management, and crisis leadership. As mentioned in Chapter 1, it also assumed that Zdziarski et al.'s (2007) definition of crisis could be a standard definition to be used by all universities. However, the study's findings only provided evidence that, though there are accepted descriptions of these terms, there are no collective, mutually-agreed upon meanings. Every participant in a presidential or crisis manager position created their own definitions based on their titles, job descriptions, academic credentials, professional experiences and/or personal beliefs and values.

For those who fill president and crisis manager positions within the SUS, it will be important to get a firm understanding of which point of view their departments, supervisors and presidents take when it comes to defining crisis as this could greatly affect their roles and responsibilities in crises. These perspectives can help solidify and/or improve communication, collaboration, and response strategies. 


\section{Research Question 2}

Per the aforementioned definitions, the second research question was also threepronged: "What roles do crisis managers and crisis leaders see themselves playing in crisis management and crisis leadership, respectively? What roles do the crisis managers see the presidents playing in crisis management, if any? And, what roles do the presidents see crisis managers playing in crisis leadership, if any?” These questions were answered by the third theme discussed in Chapter 4: Roles, Responsibilities, and Accountability.

How each university organized their crisis management departments was not only a testament to the importance placed on these units, but also an expression of the president's leadership style. The lack of consistency in reporting structures throughout the SUS supports this statement. Of the six universities interviewed, no two had the same organizational structure for their crisis management units. Not even the Dean of Students was consistently under Student Affairs. As noted by one of the participants, there are no standard organizational models in existence. Every structure is highly dependent on the university's culture and the leadership’s priorities. This can make it difficult for crisis managers to argue for improved operations.

There was also a noted frequency of changes to the organizational structure at some universities. The shifting of reporting over the university's history was in large part to how the president set up his direct reports, and what those direct reports felt their primary responsibilities should cover. For example, if a CFO felt that his/her main focus should be the finance side of job, areas like EHS and EM could be placed under an Assistant Vice President. The next CFO at that university may not feel that way, and thus might restructure to better suit his own beliefs and/or priorities. For those crisis managers 
who have been with their departments for several years, this can be extremely frustrating and disenchanting. The feeling that their unit is not an institutional priority can greatly affect morale and their support of leadership, as noted throughout the interviews.

Admittedly though, if a division has a true champion for safety and security, reporting structures become less important. Positive change occurs when these supporters exist, as noted by Mitroff and Anagnos (2011) and a couple of study participants. For example, EHS may report to an Assistant Vice President, but if their CFO still offers needed resources and support to keep the EHS department running efficiently and effective, a multi-tiered organizational chart between crisis managers and their presidents is inconsequential.

In addition to the organizational chart for each institution, the roles played and perceived to be played by the university, presidents, and crisis managers were also specifically addressed by the participants. These roles could either hinder or aid teamwork and collaboration. As noted throughout the findings, internal communication, external partnerships and cross-training were all dependent on what presidents and crisis managers mutually felt was imperative.

This most certainly supported the added accountability measures now placed on presidents and the SUS to keep university students, employees and visitors safe. Through the 1960s, universities were seen as safe havens. As societal issues such as mass-campus violence and protests infiltrated campuses across the nation, universities were no longer shielded from community dangers. University administrators had to become more vigilant. And as crises diversified, police, student conduct, mental health services and emergency management departments were established and/or expanded. 
Universities across the nation looked at incidents like Virginia Tech as a learning exercise, forcing them to re-examine their own policies, communication systems, and allocate resources. Similarly, presidents looked at the Penn State scandal to better understand the pitfalls of filtered communication and being too trusting of top management. Though educating students is their ultimate goal, universities must also understand that the second phase of Maslow's (1943) hierarchy of needs is just as critical to their mission and necessary to establish an institutional culture of safety and wellbeing. Whether they like it or not, as posited by Ferraro and McHugh (2010), universities, including its leaders, have a public expectation to keep their constituents safe.

\section{Research Question 3}

The last research question was: "How do those definitions and perceptions create a culture of preparedness towards and support of crisis management systems at their universities?” The second and fourth themes in the findings of Culture and Resources helped to answer this question.

The university's size and location; how presidents and crisis managers communicate; the president's personal and professional values, specifically related to crisis decision-making, response and support; and also the institution's values (which relates also to the aforementioned roles the university plays) all contributed to an overarching culture of safety and preparedness at each university. Resources, both available and needed, also added to how efficiently and effectively each university ran their crisis management systems.

How large a university's enrollment was and where they were located affected institutional culture in terms of demographics, probability of risks, and proximity to 
resources. A university in a secluded part of rural Florida is not going to have to deal with the same probabilities that a university in a metropolitan city would. Similarly, a university with 10,000 students versus one with 40,000 students, or one with 500 acres versus 1,200 acres, has different orders of magnitude to consider. This “ecology” and “milieu”, as described by Tagiuri (1968), all contribute to the creation of a university’s foundational culture. While anything can happen anywhere at any time, universities must of course appreciate these variables when considering where potential threats lie and how much institutional support to give any department in the university.

Adding to this physical environment are the president's own values - the importance they place on safety and how that stance matches with their words and actions. In and out of crises, all leaders inevitably have their own ways of communicating; and specifically in crisis, a unique way of making decisions, showing support, and responding. These personal philosophies can sometimes be learned through books, articles, trainings and seminars, but for the most part are innate characteristics formed over time through the president's own academic, professional and personal experiences.

An institution’s organizational climate (i.e., politics, budgetary and infrastructural environments), which can rarely be changed, along with the values setting created by its president (an inconstant variable), undeniably creates an institution's overarching ethos. It is the spirit and tenets that crisis managers and their teams follow. It is the base on which crisis management systems are formulated. These, in turn, further perpetuate a university-wide culture that is passed through each employee, visitor and supporter throughout the years. Therefore, when things are not working, leaders must take a close 
look at themselves; what have they been doing or not doing, saying or not saying, that must be changed in order to sustain a more effective culture.

Supporting this culture are the available and needed resources to flourish such an environment. There were a couple of schools that had top-notch resources, including an Emergency Operations Center. However, all six universities interviewed offered some sort of list of needed resources for them to be better equipped to respond to and recover from crises. They each expressed a necessity for more personnel, physical resources, training, and/or space - all of which comes down to the need for added funding. While some universities have key administrative supporters who help crisis managers and their departments thrive, the uniqueness of the SUS provided specific challenges in meeting these financial demands.

The State of Florida has cut its funding for higher education 22\% between FY 2007 and FY 2012 (Quintero \& Orozco, 2012). With university enrollments increasing across the SUS, universities are becoming more state-assisted instead of state-funded. This means that universities have to use diminishing state and private funds more wisely; in other words, use funds to cover critical operational costs like academic programs, employee salaries, and building utilities. All non-critical items like units that have a low return on investment (i.e., large financial output and little input) are then put at risk of being cut or forced to do more with less.

Tied to budgetary decisions is the demand to meet ethical, accountability measures. When an EHS budget, for example, remains the same, yet enrollment has grown by $20 \%$ and 10 new buildings have opened in the last five years, a university is intentionally (though albeit, indirectly) putting themselves in jeopardy of being ill- 
prepared and ill-equipped to respond to crises. As noted in the Findings, universities and their leaders are being held more accountable for these types of decisions. If a bad incident were to ever occur, and it was learned that the appropriate resources were not in place because of a deliberate decision to not do so, university presidents will quickly be blamed and targeted as the responsible party (or at least one of). While they may try to redirect blame, the responsibility will still be seen are theirs.

These doom-and-gloom scenarios are also what continues to propagate a highly reactive culture of crisis management (i.e., only when things go wrong should universities act). This mentality must change if universities are to support Mitroff's (2004) claim that crisis leaders must be proactive. Through across-the-board training, yearly examination of budgetary needs, and strategic analysis of future areas of concern, university presidents, as posited by Klann (2003), can become not just successful leaders but effective ones.

\section{Summary}

The last theme described in Chapter 4, Variability of Crisis, does not directly answer any of the research questions, but it does touch upon all of them and helps synthesize the answers well. As it relates to definitions, all participants at one point during their interviews described the "case-by-case" or "it depends" nature of crisis leadership. Adding in presidential values, some universities had clear-cut opinions that the crisis leader is the president, others take Muffet-Willet's stance of "top management" being named the leaders (i.e., the executive officers of the university), and yet others believe that anyone in a position to respond to crises (i.e., deans, directors, etc.) could be classified as crisis leaders. Additionally, the findings found that many participants felt 
that a culture of safety was naturally imbedded into the university's mission and did not need specific attention, or that a culture of preparation was not sustainable or necessary in their environment.

While feasible to train for certain scenarios, it is impossible for universities to plan for all potential crises; every incident will bring with it its own idiosyncrasies that can affect decision-making and response. Similarly, a culture of over-preparation can become counterproductive to the goals of effective crisis leadership. Because of the unpredictability of crises, crisis leaders and managers alike, must pay close attention to the facts, the university's environment, and institutional resources. These, although can change over time, are, for the most part, concrete attributes during a crisis. Institutional and personal values as well as a sense of moral or ethical responsibility are two things that are more adaptable. Tied with the foundational culture, it all can certainly make or break how effective crisis leaders and managers can actually be.

\section{Limitations}

The first limitation to this study was the decision for it to be a qualitative study, specifically the potential for research bias in setting interview protocols and analyzing the data. Prior to the interviews commencing, there was concern about how much participants would actually share (especially as it related to their personal thoughts on leadership or their institution’s pitfalls). I never felt that any participant was hiding anything or avoiding a response. Though some were guarded at the beginning of the interviews, all participants seemed very transparent by the end. As evident by the findings, the data analysis was very comprehensive and illustrated diverse points of views 
throughout each theme. This openness, depth, and detail are some of the key advantages of qualitative research.

The lack of anonymity and confidentiality for participants was another limitation. Given each participant took part in a face-to-face interview and all were state employees, it was impossible to offer either option. However, with a concern that directly tying their names to their comments in the latter chapter could cause them to censor themselves, an intentional decision was made to assign each participant a pseudonym. Though yes, someone with enough time could probably "figure it out," the level of protection and comfort it offered the participants far outweighed that risk.

The total number of participants was a third limitation. Not all 12 universities within the SUS participated in the study. Specifically, only about half of the intended sample (16 of the 34) participated. Given this was a case study of the entire State University System of Florida, an argument can be made that this study was left incomplete. Unfortunately, the timing of this study was poor with so many new university presidents starting their posts. This caused challenges in achieving a higher participant rate. However, those who did participate still came from universities with differing locations, enrollments, demographics, and academic missions. Therefore, the findings still provided a unique perspective to crisis leadership and management within the SUS and fully addressed the study's three research questions.

A fourth limitation, and as noted in the Methodology section, was the debate on whether qualitative case studies are generalizable or not. Depending on the reader's opinion regarding this academic standing, this study could be viewed as simply a summary of perspectives. For these readers, this study was able to provide richly detailed 
findings and conclusions regarding crisis leadership within the SUS. However, it was not necessarily a predictor of how all public university presidents and their crisis managers across the nation define the meaning of and roles in crisis leadership, or how those definitions contribute to an institutional culture of safety. Conversely, though, this case study did address the phenomenon that is crisis leadership, specifically the relationship between university presidents and crisis management.

The last limitation to the study could be its lack of theoretical testing, with a focus on summarizing the study’s findings. Flyvbjerg (2006) also had a stance on this matter:

The opposite of summing up and "closing" a case study is to keep it open. Here I have found the following two strategies to work particularly well in ensuring such openness. First, when writing up a case study, I demur from the role of omniscient narrator and summarizer. Instead, I tell the story in its diversity, allowing the story to unfold from the many-sided, complex, and sometimes conflicting stories that the actors in the case have told me. Second, I avoid linking the case with the theories of any one academic specialization. Instead I relate the case to broader philosophical positions that cut across specializations. In this way I try to leave scope for readers of different backgrounds to make different interpretations and draw diverse conclusions regarding the question of what the case is a case of. The goal is not to make the case study be all things to all people. The goal is to allow the study to be different things to different people. (p. 22-23)

This study offered a descriptive narrative of the multifaceted points of view on the definitions and roles of crisis leaders. The findings all supported and/or opposed previous literature on the effectiveness and pitfalls of crisis leadership and management without the creation of a new theory. In sum, and in response to the perceived and subjective limitations, this case study was intended to be both generalizable to other university presidents and crisis mangers, and its findings left open for interpretation by the reader. 


\section{Implications for Practice}

The results of this study indicated three important factors for higher education administrators to consider. The first is that university support, especially from university presidents, is critical to the success of both crisis managers and crisis management systems. However, with inconsistencies in reporting structures and resources offered, universities will only be left at risk and open for widespread criticism if something serious were to occur.

It was evident throughout many of the crisis manager interviews, especially those in the EHS and EM departments, that there was deep frustration on the lack of moral and financial support they receive from their universities (i.e., direct supervisors, division leaders, and/or presidents). These units are critically important to the safety and wellbeing of all constituents. If they do not feel appreciated and included in institutional priorities, employees suffer. These sentiments can easily lead to morale issues, which in turn can lead to indifference. Apathy, as I was told once by a mentor, is a lurking murderer knocking on your door; you have to kill it before it kills you. The only way to do so is by crisis leaders showing crisis managers how important they really are, and how much they are truly needed (in both tangible and intangible ways).

Outside of leadership support was the issue of how crisis management departments are organized at their universities. Reporting structures varied university to university, and were mostly a function of presidential preference. Deans of Students should, of course, remain under the division of student affairs. Police, emergency management and environmental health and safety could all collectively report to the same 
division. Based on the units' functionalities and overlapping responsibilities discussed during the interviews, this alignment seems to be the most logical.

This structure would not only increase communication and allow for quicker decisions to be made, but will also allow for more efficient use of resources (e.g., space, budgets, etc.). However, given the varying cultures of universities (i.e., size, constituent groups, etc.), standardization for crisis management units could be difficult to manage as a system-wide initiative. This proposal for merged resources, though, should not replace the current and future needs for personnel, equipment, space, and trainings. How to solidify these funds is a key issue for presidents and crisis managers alike.

In today’s political climate, Florida's public universities are moving away from being fully state-funded. As state budgets dwindle and as universities' use of budgets become restricted, little funding remains available for long-term investments. Especially for universities without emergency management departments (regardless of the breadth) and for those institutions that are growing at an exponential rate each year, the state must begin to invest direct funding into crisis management programs. Though a concern has been expressed by SUS leaders, words should be turned into deeds.

A comprehensive state-wide strategic plan should be created and implemented regarding these issues, which should also include details on funding shared and also university-specific areas. Shared communication strategies (like the call center idea described by Amir) could be one example of creating more efficient operations while at the same time showcasing that campus safety is a priority for our state leaders. Funding based on the universities' current resources and their projected growth could be another area described in the plan. Even though investments will never fully protect a university 
or its constituents from total harm, if properly implemented, dedicated funds will significantly reduce universities’ risks for and probabilities of crises from occurring.

At a more macro level, there could also be federal implications. Incidents like the one at Lehigh University can lead to statutory policies and regulations. The Clery Act not only affected almost every college and university in the nation, but also affected governmental reporting and accountability measures with these institutions. However, governmental agencies (state and federal) see crises more in terms of disaster and risk management. The conversation on the idiosyncrasies of crises for higher education institutions needs to become a national topic. The growing number of mental health cases and issues related to fraternities and sororities are only two examples of rampant crisisrelated areas that can greatly change (negatively) the landscape of higher education if a system-wide, state-wide, and/or nation-wide approach is not taken soon.

\section{Recommendations for Future Research}

Given the lack of empirical research on crisis leadership in the field of higher education, it is important that this study be expanded and that further research be conducted. There may be a possibility of conducting a national survey to all public university presidents and their crisis managers in order to expand this study's sample and help contribute to the study's generalizability. The survey would include closed-ended and open-ended questions so that a thorough analysis could occur. However, there would be two challenges with a study of this nature.

The first would be time and costs given the sheer number of public university presidents there are in the United States. Obtaining a list of all public universities would not be very difficult. Even getting mailing addresses for those presidents would be more 
of a mundane process than overwhelming. The difficult part would be trying to locate the crisis managers at those institutions. Given the inconsistencies in titles and organizational structures, it would be unmanageable to aggregate all that information without having someone from each university assisting the researcher in locating the appropriate persons. Adding to that, the funding necessary to print the surveys and create mailers would be a big challenge for most researchers. Of course there is the option to create an online survey, but costs associated with dissemination and data analysis software could still exist.

The second issue would be that presidents don’t always personally fill out these national surveys. Though most surveys nowadays include a section in the survey on who actually filled it out, it would be impossible to know if the responses were that of the president or the person filling it out. The reliability of the study could then come into question. This would be especially true if the survey was heavy on closed-ended questions, which can lower validity rates.

Another possibility would be to conduct another case study, but expand the types of institutions and/or number of participants. Though this case study intentionally left out private universities in Florida because of their less strict requirements on crisis management systems and policies, there would still be value in interviewing them. It would be interesting to learn if and how the less stringent processes for private universities hinders, supports or has no effect on the relationship between crisis leaders and crisis managers. Similarly, how, if at all, roles between crisis leaders and crisis managers change depending on the type/size of the university, or if it is still dependent on the leader's own values, as found in this study. 
In analyzing the transcripts of the 10 crisis managers, I assessed that other executive-level leaders should have been included in the study. The one Vice President who participated in the studied offered a very unique perspective on how he perceived the president's role in crisis leadership. Because the other crisis managers interviewed were three or more notches below the president (only two having frequent, direct contact with their president), I felt there were more negative undertones regarding their opinions of top management and their president than there was from the VPSA that was interviewed. Including the vice presidents that oversee these crisis management departments (i.e., Provost, CFO and/or VPSA), may offer greater insight into the opportunities and challenges presidents face in crises that crisis managers may not know, understand and/or appreciate.

Additionally, a study including first responders (e.g., housing staff, psychological counselors, police, medical professionals, etc.) may be useful. Similar to the perspective of how the intermediary touch point between crisis managers and presidents is an executive leader like a Vice President, crisis responders are the connections between the victims and the crisis managers. Understanding their ground level perspective, could contribute further in understanding - in a more holistic way - the continuum from crisis management to crisis leadership.

This bridging of information could provide further findings in how the relationships between presidents and crisis managers could be improved or inhibited. This direction, though, was the one taken by Muffet-Willett (2010). Therefore, a merger of the two studies, or a meta-analysis of all available literature of crisis leadership in higher education, may also be an area for further research. 


\section{Summary}

As noted in the Introduction, crises have simply become imbedded into our society (Mitroff \& Anagnos, 2001). They are unavoidable and are things that all leaders must now prepare for. When the study of crisis management emerged in the 1960s, Hermann (1972) created three limitations to the field. His first two were that, up to that point, crises had only been analyzed on an incident-by-incident basis because of the unique idiosyncrasies each case posed. To an extent, that is what the higher education literature of crisis management and crisis leadership still entails; it lacks empirical research. Hermann's third limitation was that the term crisis had too many meanings (as supported by my literature review). This study aimed at addressing those boundaries Therefore, this dissertation was unique and was intended to be an empirical study on crisis leadership as well as crisis management in the field of higher education.

At the onset of this study, it was posited that Zdziarski’s (2006) definition of crisis could be a widely accepted description for university presidents and crisis managers because of its foundations in student affairs. While it was a relatively agreed-upon synthesis, it was found that the meaning and classification of crisis was very idiosyncratic. University presidents each interpreted them based on their leadership styles (a function of personal beliefs and professional experiences), and crisis managers saw them solely within the context of their specific departments. This, therefore, also affected how the study participants defined crisis management and crisis leadership.

Prior to conducting interviews, there was also a stance that crisis management and crisis leadership were vastly different and that the findings would support this belief. Many participants did take Drucker's philosophy as well as the perspectives of Mitroff 
and Anagnos’s (2001) and Daniels and Daniels’s (2007) that the roles for each were unique. Though there was a noted distinction between manager and leader by all participants, the level of division between the two was less clear. For some participants, there could be crises where the lines between roles would be blurred, and rightfully so. This, in part, was based on how managers and leaders defined a crisis. A crisis to an EHS director, may not be one to a president, and hence would affect if a president would be involved. Similarly, a president could see something as a crisis that an EM director believes is his responsibility and does not need the president to be making decisions.

These perceived roles, in turn, affected a university's culture towards and maintenance of safety and preparedness. A strong crisis management system, as noted by Fink (1986), should help to reduce "risk and uncertainty" that can allow an organization to be better prepared. They should help guide the university to define terms and roles. A leader, though, must consider a university’s specific culture (i.e., size, location, values, etc.) to ensure that those systems are implemented around the university's needs - not just national best practices that may not be a good fit for that university. The conscious decision for presidents to place crisis management as a university priority, though not true for all participants, in and of itself, defines crisis leadership. This also supported Dressel's (1982) belief that enforcement is key to success. Given these differentiations, I stand behind my initial position that there is a strong difference between a crisis manager and crisis leader.

That being said, what is to be supposed about the collective role that university presidents and crisis managers play in higher education towards the study of crisis leadership? In Cowan’s (2014) book, he brought up the two distinct kinds of leadership: 
direct and indirect. Those in positions of authority (i.e., presidents) use direct leadership. Crisis managers, on the other hand, use indirect leadership by "assum[ing] a take charge role and change things". While the latter is in line with how a crisis manager was defined in this study (Daniels and Daniels, 2007), despite the difference in approach, both can still be considered leaders - albeit, on different scales.

In analyzing the findings, I must support Muffet-Willett's position that crisis leadership is fundamentally connected to the relationship between presidents and crisis managers. Both must offer support, tangibly and intangibly, to one another so that others across the university see the importance being placed on crisis management (i.e., resources, decisions, etc.). To do so, they must also work collaboratively if they are to create an institutional culture that not only has resources to keep constituents safe, but also sustain a deeply imbedded culture of safety and preparedness that transcends all current and future institutional processes.

Overall, engaged crisis managers and crisis leaders are needed to provide optimal success. However, the more important of the two is an engaged president. When they place emphasis on campus safety and set crisis management as an institutional priority, this vale trickles down to other executives and crisis managers. It will help ensure that the university creates and sustain an overarching culture of preparedness and responsiveness.

In sum, yes, the assumptions made by student affairs authors that presidents are critical to crisis management are fully supported by the findings of this study. However, it was also found that crisis managers are just as important to crisis leadership as university presidents. The relationship between both groups should be a symbiotic one, where cooperation benefits both groups and their respective constituents. 


\section{REFERENCES}

Bland, M. (1998). Communicating out of a crisis. London, England: Macmillan.

Bogdan, R. C. \& Biklen, S. K. (2007). Qualitative research for education: An introduction to theories and methods ( $5^{\text {th }}$ ed.). New York, NY: Pearson Education.

Burrell, S. M. (2009). An examination of crisis preparedness at Christian-affiliated institutions of higher education. (Doctoral dissertation, Mississippi State University). Retrieved from ProQuest Dissertations and Theses. (UMI 3386308)

Clery Center for Security on Campus (n.d.). Retrieved from http://www.securityoncampus.org/summary-jeanne-clery-act

Cole, V., Henry, B., Tyson, D., Fitzgerald, R., \& Hopkins, R. (2009). In the face of danger: Comprehensive emergency preparedness and response for schools. Urban Education Journal, 5(2), 1-15. Retrieved from http://www.urbanedjournal.org/archive/volume-5-issue-2-spring-2008/facedanger-comprehensive-emergency-preparedness-and-response-s

Collison, M. (1990, September 12). Students at U. of Fla. struggle to cope with grisly murders. Chronicle of Higher Education. Retrieved from http://chronicle.com/article/Students-at-U-of-Fla/88350/

Coombs, W. T. (1999). Ongoing crisis communication: Planning, managing, and responding. Thousand Oaks, CA: Sage.

Cowan, S. (2014). The inevitable city: The resurgence of New Orleans and the future of Urban America. New York, NY: Palgrave Macmillan.

Daniels, A. C., \& Daniels, J. E. (2007). Measure of a leader. New York, NY: McGrawHill.

Dressel, P. L. (1981). Administrative leadership. San Francisco, CA: Jossey-Bass.

Dunkel, N. W., \& Stump, L. J. (2007). Working with emergency personnel and outside agencies. In E.L. Zdziarski, N.W. Dunkel, J.M. Rollo, \& Associates (Eds), Campus crisis management: A comprehensive guide to planning, prevention, response, and recovery (pp. 121-143). San Francisco, CA: Jossey-Bass.

Fearn-Banks, K. (2011). Crisis communications (4 ${ }^{\text {th }}$ ed.). New York, NY: Routledge. 
FEMA Incident Management Institute (n.d.). IS-100.HE: Introduction to the Incident Command System for Higher Education. Retrieved from http://training.fema.gov/EMIWeb/IS/courseOverview.aspx?code=is-100.he

FEMA Incident Management Institute (n.d.). IS-700.A: National Incident Management System (NIMS) An Introduction. Retrieved from http://training.fema.gov/EMIWeb/IS/courseOverview.aspx?code=IS-700.a

Ferraro, R. J., \& McHugh, B. (2010). Violence in the shadow of the ivory tower. In B.O. Hemphill, \& B.H. LaBanc (Eds.), Enough is enough: A student affairs perspective on preparedness and response to a campus shooting (pp. 1-38). Sterling, VA: Stylus.

Fink, S. (1986). Crisis management: Planning for the inevitable. New York, NY: Amacom.

Florida Board of Governors. (2015). 2013-2014 Annual Accountability Report. Retrieved from http://www.flbog.edu/about/_doc/budget/ar_201314/2013_14_System_Accountability_Report_Summary_REVISED_FINAL.pdf

Florida Legislature (n.d.). Florida Statute 252: Emergency Management. Retrieved from http://www.leg.state.fl.us/Statutes/index.cfm?App_mode=Display_Statute\&Searc h_String=\&URL=0200-0299/0252/Sections/0252.34.html

Flyvbjerg, B. (2011). Case study. In N.K. Denzin, \& Y.S. Lincoln (Eds.), The SAGE handbook of qualitative research ( $4^{\text {th }}$ ed., pp. 301-316). Thousand Oaks, CA: Sage.

Flyvbjerg, B. (2006). Five misunderstandings about case-study research. Qualitative Inquiry, 12(2), 219-245. Retrieved from http://qix.sagepub.com/content/12/2/219.short?rss=1\&ssource=mfr

Gross, K., \& Fine, A. (1990, February). After their daughter is murdered at college, her grieving parents mount a crusade for campus safety. People Magazine, 33(7), 113. Retrieved from http://www.people.com/people/archive/article/0,,20116872,00.html

Guba, E. G., \& Lincoln, Y. S. (1981). Effective evaluation: Improving the usefulness of evaluation results through responsive and naturalistic approaches. San Francisco, CA: Jossey-Bass.

Hauser, C., \& O’Connor, A. (2007, April 16). Virginia Tech shooting leaves 33 dead. The New York Times. Retrieved from http://www.nytimes.com/2007/04/16/us/16cndshooting.html?pagewanted=all\&_r=0 
Hermann, C. F. (1963). Some consequences of crisis which limit the viability of organizations. Administrative Science Quarterly, 8(1), 61-82. Retrieved from http://www.voxprof.com/cfh/hermann-publications.html

Hermann, C. F. (1972). Some issues in the study of international crisis. In C.F. Hermann (Ed.), International crises: Insights from behavioral research (pp. 3-17). New York, NY: Free Press.

Klann, G. (2003). Crisis leadership: Using military lessons, organizational experiences, and the power of influence to lessen the impact of chaos on the people you lead. Greensboro, NC: CCL Press.

LaBanc, B. H., Krepel, T. L., Johnson, B. J., \& Herrmann, L. V. (2006). Managing the whirlwind: Planning for and responding to a campus in crisis. In B.O. Hemphill, \& B. H. LaBanc (Eds.), Enough is enough: A student affairs perspective on preparedness and response to a campus shooting (pp. 53-81). Sterling, VA: Stylus.

Lerbinger, O. (2012). The crisis manager: Facing disasters, conflicts, and failures $\left(2^{\text {nd }}\right.$ ed.). New York, NY: Routledge.

Lewis, J. M., \& Hensley, T. R. (n.d.). The May 4 shootings at Kent State University: The search for historical accuracy. Kent State Department of Sociology. Retrieved from http://dept.kent.edu/sociology/lewis/lewihen.htm

Lindahl, R. (2006, March 2). The role of organizational climate and culture in the school improvement process: A review of the knowledge base. Connexions. Retrieved from http://cnx.org/content/m13465/1.1/

Maslow, A. H. (1943). A theory of human motivation. Psychological Review, 50, 370396. Retrieved from http://psychclassics.yorku.ca/Maslow/motivation.htm

McKinney, M. (2008, February). Miles’ Law and Six Other Maxims of Management. Leading Blog. Retrieved from http://www.leadershipnow.com/leadingblog/2008/02/miles_law_and_six_other_m axims.html

Meriwether, G. (n.d.). Leadership in crisis. The Leadership Challenge. Retrieved from http://www.leadershipchallenge.com/resource/leadership-in-crisis.aspx

Merriam, S. B. (2002). Qualitative research in practice: Examples for discussion and analysis. San Francisco, CA: Jossey-Bass.

Miles, M. B., \& Huberman, M. A. (1994). Qualitative data analysis. Thousand Oaks, CA: Sage Publications. 
Mitroff, I. I. (2004). Crisis leadership: Planning for the unthinkable. Hoboken, NJ: Wiley.

Mitroff, I. I. (2005). Why some companies emerge stronger and better from a crisis: 7 essential lessons for surviving disaster. New York, NY: Amacom.

Mitroff, I. I., \& Anagnos, G. (2001). Managing crises before they happen. New York, NY: Amacom.

Mitroff, I. I., \& Pearson, C.M. (1993). Crisis management: A diagnostic guide for improving your organization's crisis-preparedness. New York, NY: Jossey-Bass.

Mitroff, I. I., Pearson, C. M., \& Harrington, L. K. (1996). The essential guide to managing corporate crises: A step-by-step handbook for surviving major catastrophes. New York, NY: Oxford University Press.

Muffet-Willett, S. L. (2010). Waiting for a crisis: Case studies of crisis leaders in higher education. (Doctoral dissertation, University of Akron). Retrieved from ProQuest Dissertations and Theses. (UMI 3437839)

Muffet-Willett, S. L., \& Kruse, S. D. (2008). Crisis leadership: Past research and future directions. Journal of Business Continuity \& Emergency Planning, 3(3), 248-258.

Newlands, M. (2014, August). 5 thing successful leaders to in a crisis. Inc. Retrieved from http://www.inc.com/murray-newlands/5-things-successful-leaders-do-in-acrisis.html

Nickerson, A. B., Brock, S. E., \& Reeves, M. A. (2006). School crisis teams within an Incident Command System. The California School Psychologist, 11, 63-72. Retrieved from http://www.eric.ed.gov/PDFS/EJ902519.pdf

Pauchant, T. C., \& Mitroff, I. I. (1992). Transforming the crisis-prone organization: Preventing individual, organizational, and environmental tragedies. San Francisco, CA: Jossey-Bass.

Pestello, F. P. (2015, February) Core values should guide a university's crisis response. Trusteeship, 23(1), 40. Retrieved from http://agb.org/trusteeship/2015/januaryfebruary/core-values-should-guide-auniversitys-crisis-response

Pinto, B. (2005, December 9). Katrina wallops Tulane University. Retrieved from http://abcnews.go.com/US/HurricaneKatrina/story?id=1390382\&page=1 
Quintero, J. \& Orozco, V. (2012, April 3). The Great Cost Shift: How Higher Education Cuts Undermine The Future Middle Class. Demos. Retrieved from http://www.demos.org/sites/default/files/publications/Florida_HigherEd_StateCut s_Factsheet.pdf

Rehak, J. (2002, March 23). Tylenol made a hero of Johnson \& Johnson: The recall that started it all. The New York Times. Retrieved from http://www.nytimes.com/2002/03/23/your-money/23iht-mjj_ed3_.html

Rollo, J. M., \& Zdziarski, E. L. (2007). The impact of crisis. In E.L. Zdziarski, N.W. Dunkel, J.M. Rollo, \& Associates (Eds.), Campus crisis management: A comprehensive guide to planning, prevention, response, and recovery (pp. 3-33). San Francisco, CA: Jossey-Bass.

Rubin, H. J., \& Rubin, I. S. (2012). Qualitative interviewing: The art of hearing data (3 ${ }^{\text {rd }}$ ed.). Thousand Oaks, CA: Sage.

Seeger, M. W., Sellnow, T. L., \& Ulmer, R. R. (2003). Communication and organization crisis. Westport, CT: Praeger.

Seidman, I. (2013). Interviewing as qualitative research: A guide for researchers in education and the social sciences ( $4^{\text {th }}$ ed.). New York, NY: Teachers College Press.

Seymour, M., \& Moore, S. (2000). Effective crisis management: Worldwide principles and practices. London, England: Cassell.

Sherwood, G. P., \& McKelfresh, D. (2007). Crisis management teams. In E.L. Zdziarski, N.W. Dunkel, J.M. Rollo, \& Associates (Eds.), Campus crisis management: A comprehensive guide to planning, prevention, response, and recovery (pp. 55-71). San Francisco, CA: Jossey-Bass.

Silva, M., \& McGann, T. (1995). Overdrive: Managing in crisis-filled times. New York: NY, John Wiley \& Sons.

Skinner, S., \& Mersham, G. (2002). Disaster management: A guide to issues, management and crisis communication. Cape Town, South Africa: Oxford University Press.

Snow, R. L. (1996). SWAT teams: Explosive face-offs with America's deadliest criminals. New York: Plenum Press.

Stake, R. E. (2000). Qualitative case studies. In N.K. Denzin, \& Y.S. Lincoln (Eds.), The Sage handbook of qualitative research ( $3^{\text {rd }}$ ed., pp. 443-466). Thousand Oaks, CA: Sage. 
Syracuse University PanAm Flight 103 Lockerbie Air Disaster Archives (n.d.). Retrieved from http://archives.syr.edu/panam/

Taleb, N.N. (2007). The black swan: The impact of the highly improbable. New York: NY, Random House.

Trombley, L. S. (2007). The care and feeding of presidents. Change, 4, 14-17. Retrieved from http://www.changemag.org/Archives/Back\%20Issues/JulyAugust\%202007/full-care-and-feeding.html

Yin, R. K. (2009). Case study research: Design and methods ( $4^{\text {th }}$ ed.). Thousand Oaks, CA: Sage.

Zdziarski, E. L. (2001). Institutional preparedness to respond to campus crises as perceived by student affairs administrators in selected NASPA member institutions. (Doctoral dissertation, Texas A\&M University). Retrieved from ProQuest Dissertations and Theses. (UMI 3033906)

Zdziarski, E. L. (2006). Crisis in the context of higher education. In K.S. Harper, B.G. Paterson, \& E.L. Zdziarski (Eds.), Crisis management: Responding from the heart (pp. 3-24). Washington, DC: NASPA.

Zdziarski, E. L., Rollo, J. M., \& Dunkel, N. W. (2007). The crisis matrix. In E.L. Zdziarski, Dunkel, N.W., Rollo, J.M., \& Associates (Eds.), Campus crisis management: A comprehensive guide to planning, prevention, response, and recovery (pp. 35-51). San Francisco, CA: Jossey-Bass. 


\section{APPENDICES}

Appendix A: Interview protocol (pre-pilot study)

Appendix B: Interview protocol (post-pilot study)

Appendix C: Participant consent form

Appendix D: Participant codes 
Appendix A: Interview protocol (pre-pilot study)

\section{$\underline{\text { Joint Questions }}$}

1) How do you define “crisis”?

2) How do you define “crisis management”?

3) How do you define "crisis leadership"?

4) What differences, if any, do you see between crisis managers and crisis leaders?

5) Do you believe top management plays a distinctive role prior to, during and after a crisis? Why or why not?

6) What role do you believe crisis leaders play in creating the direction towards and support of crisis management systems on their campuses?

\section{Presidents Only}

- Per the previous definitions (i.e., joint questions 1-4), how do you see crisis managers playing a role in crisis leadership, if any? (or vice versa, depending on their definitions)

\section{Crisis Managers Only}

- Per those definitions (i.e., joint questions 1-4), how do you see presidents playing a role in crisis management, if any? (or vice versa, depending on their definitions)

\footnotetext{
* Formulation of all questions are pending the proposed pilot study.
} 
Appendix B: Interview protocol (post-pilot study)

\section{$\underline{\text { Joint Questions }}$}

1) How do you define "crisis"? - OR - What types of crises do you deal with?
a. Human / Environmental / Facility
b. Unintentional / Intentional
c. Critical Incident / Campus Emergency / Disaster

2) How do you define "crisis management”?

3) How do you define "crisis leadership”?

4) What differences, if any, do you see between crisis managers and crisis leaders?

a. At what point does crisis management elevate to crisis leadership, if ever?

5) Depending on response to above ...

a. Do you believe presidents play a unique role prior to, during, and after a crisis? Why or why not?

b. What role do you believe crisis leaders play in creating a culture of preparedness towards and support of crisis management systems on their campuses?

6) Do you see a distinction between safety and preparedness?

7) What are your biggest challenges?

8) In a perfect world without budget/political constraints, what would be on your wish list for your crisis management program

9) ** Refer to group-specific questions **

10) ${ }^{* *}$ To close interview, show Crisis Matrix ** 


\section{Crisis Managers Only}

1) Describe your duties.

2) Describe your reporting structure.

a. How does your EM / EOC operate?

b. Are you familiar with ICS?

c. What trainings / certifications have you had for CM?

3) How does your definition / types differ from that of other campus crisis managers (ie. a Dean of Students)?

4) Per the previous definitions, how do you see presidents playing a role in crisis management, if any?

a. Is there a difference between Emergency managers vs. Crisis managers? (human vs. facility vs. environmental issues)

\section{Presidents Only}

1) Who do you perceive as your crisis manager on campus?

a. Who has overall responsibility for safety preparedness? Response?

2) Per the previous definitions, how do you see crisis managers playing a role in crisis leadership, if any?

3) More and more, presidents are being held responsible for campus safety. How do you feel that plays out for our university, the SUS, and/or your colleagues? (ex. Penn State)

4) ** Prior to showing Crisis Matrix, discuss 5 crisis leadership points (next page) 


\section{http://www.leadershipchallenge.com/resource/leadership-in-crisis.aspx}

"As a brief demonstration of the application of the Five Practices of Exemplary

Leadership to crisis leadership, I offer the following:

- Model the Way: In my experience as a leader in business and the military, the quickest way to lose your leadership credentials is to not demonstrate balance in a crisis. Instead of calmly addressing a crisis at hand, the inept crisis leader will lose control of his/her actions, temper, emotions, or awareness. In the Navy we call it "losing the bubble"; not being aware of the tactical situation at sea can cost lives. Demonstrate balanced leadership.

- Inspire a Shared Vision: It is critical in a crisis that we all share the same goal. We may have different reasons for the goal but we have the goal in common. For example, the obvious goal is to return to normalcy. To employees this means ensuring that their job survives, while an executive worries about stopping the revenue loss. Return to normalcy.

- Challenge the Process: The organizational processes are stressed in any crisis and may become dysfunctional. A leader in crisis must have the flexibility to adapt to the situation, regardless of the inherent processes of the organization. Flexibility to adapt.

- Enable Others to Act: In a crisis, much more than in normal operations, effective partnerships are critical to the success. Simply put, partnerships save lives.

- Encourage the Heart: Taking care of the response staff is not much different in a crisis as in normal operating situations. What is different is the stress the team is under and how fast this can change. A leader in crisis needs to be more aware of 
the physical, psychological, and mental condition of the team. ... The leader must be aware and respond.” 
Appendix C: Participant consent form

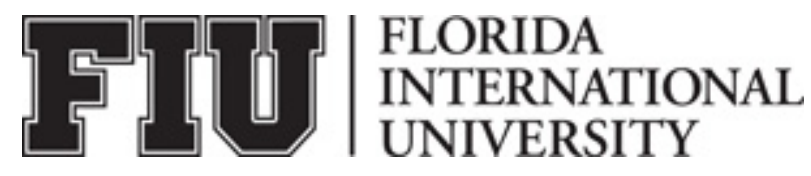

\author{
ADULT CONSENT TO PARTICIPATE IN A RESEARCH STUDY \\ Crisis Leadership: The Role University Presidents and Crisis Managers Play in Higher \\ Education - A Case Study of the State University System of Florida
}

\title{
PURPOSE OF THE STUDY
}

You are being asked to be in a research study as part of a doctoral dissertation. The purpose of this dissertation is to better understand the phenomenon of crisis leadership in higher education. Specifically, I have chosen to conduct a case study of the State University System (SUS) of Florida, interviewing all available university presidents and crisis managers. Through the study, I hope to find commonalities and analyze key differences amongst the presidents and crisis managers related to their definitions of and roles in crisis leadership that can contribute to the higher education literature.

\section{NUMBER OF STUDY PARTICIPANTS}

If you decide to be in this study, you will be one of roughly 24 people in this research study.

\section{DURATION OF THE STUDY}

Your participation will require a one-time, 2-hour (max) interview session. Post interview, you may be contacted and asked to clarify responses via email or phone.

\section{PROCEDURES}

If you agree to be in the study, we will ask you to do the following things:

1. Schedule and participate in a 2-hour interview. In-person interviews will be requested, but phone or Skype interviews will be offered to the university presidents if scheduling conflicts become an obstacle.

2. Allow for the interview to be voice recorded. This will assist in minimizing any follow up meetings or clarification calls post-interview.

\section{RISKS AND/OR DISCOMFORTS}

There are no known physical, psychological, societal or economical risks associated with your participation in this study. Though the interview questions will not deal with any specific on-campus incidents (e.g., crises that have been in the news and/or tied to legal matters), if the flow of conversation leads us down that path, it is important that you make me aware of any discomfort so that the interview can stop or be redirected. 


\section{BENEFITS}

There are no direct benefits associated with your participation in this study. However, your interview responses will offer a great deal of insight into crisis leadership and therefore could help change the landscape of crisis management at universities across the nation.

\section{ALTERNATIVES}

There are no known alternatives available to you other than not taking part in this study. However, any significant new findings developed during the course of the research which may relate to your willingness to continue participation will be provided to you.

\section{ANONYMITY AND CONFIDENTIALITY}

The records of this study will be kept private and will be protected to the fullest extent provided by law. In any sort of report we might publish, we will not include any information that will make it possible to identify a subject. Research records will be stored securely and only the researcher team will have access to the records. However, your records may be reviewed for audit purposes by authorized University or other agents who will be bound by the same provisions of confidentiality.

Because this dissertation is a case study with university presidents, who are all considered public figures, it is impossible to guarantee confidentiality or anonymity. As such, you and your institution will be identified by name with regard to your responses. If, however, you wish to remain anonymous, please let me know and a pseudonym will be provided for you in the analysis and results sections.

Crisis managers, however, may or may not be considered public officials. Though the public often has little knowledge of who you are or what roles you play, but given that all SUS institutions are subject to Florida's Sunshine Law, this information can be found with enough research. Because crisis managers may be asked about presidential leadership, they may feel more comfortable with a pseudonym, so one will be provided for them.

Each crisis manager (and president, upon request) will be still assigned a letter and number, respectively. The assignment will be given based on the order of interviews. For example, the first crisis manager will be referred to as Crisis Manager 1, or CM-1, the second as Crisis Manager 2 or Amir, etc. This will not only reduce the probability (to the extent possible) that the reader will not automatically connect responses to a specific manager but also offer the reader an easier way of distinguishing among respondents. The presidents who request anonymity will be similarly given such letters and numbers depending on the order in which they are interviewed. Others will be identified by name.

\section{COMPENSATION \& COSTS}

You will receive no payment or reimbursement for your participation. You will not be responsible for any costs to participate in this study. 


\section{RIGHT TO DECLINE OR WITHDRAW}

Your participation in this study is voluntary. You are free to participate in the study or withdraw your consent at any time during the study. Your withdrawal or lack of participation will not affect any benefits to which you are otherwise entitled. The investigator reserves the right to remove you without your consent at such time that they feel it is in the best interest.

\section{RESEARCHER CONTACT INFORMATION}

If you have any questions about the purpose, procedures, or any other issues relating to this research study you may contact Breny DaParre Garcia at FIU - 11200 SW 8 St., Miami FL 33199.

\section{IRB CONTACT INFORMATION}

If you would like to talk with someone about your rights of being a subject in this research study or about ethical issues with this research study, you may contact the FIU Office of Research Integrity by phone at 305-348-2494 or by email at ori@fiu.edu.

\section{PARTICIPANT AGREEMENT}

I have read the information in this consent form and agree to participate in this study. I have had a chance to ask any questions I have about this study, and they have been answered for me. I understand that I will be given copy of this form for my records.

Signature of Participant

Date

Printed Name of Participant

Signature of Person Obtaining Consent

Date 
Appendix D: Participant codes

(assigned in chronological order of each interview)

$\begin{array}{lll}\text { Date } & \text { Code } & \text { Pseudonym } \\ \text { (Pilot) } & \text { CM-1 } & \text { Carlos } \\ \text { (Pilot) } & \text { CM-2 } & \text { Amir } \\ \text { Oct. 27, 2014 } & \text { CM-3 } & \text { David } \\ \text { Oct. 27, 2014 } & \text { CM-4 } & \text { Toby } \\ \text { Oct. 27, 2014 } & \text { P-1 } & \text { Jose } \\ \text { Nov. 6, 2014 } & \text { P-2 } & \text { Ralph } \\ \text { Nov. 21, 2014 } & \text { CM-5 } & \text { Mitch } \\ \text { Nov. 21, 2014 } & \text { CM-6 } & \text { Rhashad } \\ \text { Nov. 21, 2014 } & \text { P-3 } & \text { William } \\ \text { Dec. 17, 2014 } & \text { CM-7 } & \text { Bradley } \\ \text { Dec. 17, 2014 } & \text { CM-8 } & \text { Pearce } \\ \text { Dec. 17, 2014 } & \text { P-4 } & \text { Julian } \\ \text { Jan. 26, 2014 } & \text { P-5 } & \text { Martin } \\ \text { Feb. 6, 2015 } & \text { CM-9 } & \text { Andrew } \\ \text { Feb. 6, 2015 } & \text { P-6 } & \text { Josiah } \\ \text { Feb. 6, 2015 } & \text { CM-10 } & \text { Jeremy }\end{array}$


VITA

BRENEZZA DAPARRE GARCIA

2013

2012

2011

2010-present

2010

2007-2010

2007-2008

2006-2007

2001-2005
Protocol Officer Training School

Protocol School of Washington

Incident Command System for Higher Education Training National Incident Management System Training

Federal Emergency Management Agency

Record Management Training

State of Florida

Maximizing Your Leadership Potential

Center for Creative Leadership

Active Shooter Training

Federal Emergency Management Agency

Deputy Chief of Staff

Office of the President, Florida International University

Notary Public

State of Florida

Executive Assistant

Office of the President, Florida International University

Assistant Director of Operations

Office of the President, Florida International University

M.S., Higher Education Administration

Florida International University

Budget Coordinator

Office of the President, Florida International University

Program Assistant

Office of the President, Florida International University

B.A., Political Science (and Honors College)

Florida International University 